\title{
ALKALINE ASSISTED THERMAL OIL RECOVERY: KINETIC AND DISPLACEMENT STUDIES
}

Topical Report

By

Shahrouzeh Saneie

Yanis C. Yortsos

June 1993

Work Performed Under Contract No. DE-FG22-90BC14600

\author{
Prepared for \\ U.S. Department of Energy \\ Assistant Secretary for Fossil Energy
}

Thomas B. Reid, Project Manager

Bartlesville Project Office

P.O. Box 1398

Bartlesville, OK 74005

Prepared by

University of Southern California

Petroleum Engineering Program

Department of Chemical Engineering

Los Angeles, CA 90089-1211 


\section{CONTENTS}

1 INTRODUCTION

1.1 Organization $\quad 5$

2 Fundamentals of Alkaline Flooding $\quad 7$

2.1 Alkaline Chemical 7

2.2 Alkali-Oil Reaction 9

2.3 Oil Recovery Mechanism 10

2.4 Alkali-Rock Reaction 10

2.5 Review of Silica Chemistry 14

2.5.1 Composition 14

2.5.2 Structure 14

2.6 Silica-Water System 17

2.6.1 Silica-Water Interface 20

2.6.2 Solubility of Quartz 23

2.6.3 Solubility of Amorphous Silica 26

2.6.4 Effect of $\mathrm{pH} \quad 26$

2.6.5 Effect of Salinity 30

2.6.6 Rate of Dissolution 30

3 Mechanistic Model of Silica Dissolution 37

3.1 Quantitative Model 38

3.2 Formulation 40

3.2.1 Dissolution in Alkaline Media 41

3.3 Theoretical Predictions 47

3.3.1 Effect of the Number of Ionization Reactions 47

3.3.2 Effect of $\mathrm{pH} \quad 47$

3.3.3 Effect of Specific Area 53

3.4 Silica Dissolution In The Presence of Ion Exchange 60

3.4.1 Model Development and Formulation 60

3.4 .2 Results 65

4 Silica Dissolution Under Dynamic Flow Conditions 71

4.1 Mathematical Development 71

4.1 .1 Conservation Equations $\quad 72$

4.1 .2 Conservation of Silicic Species 73

4.1.3 Numerical Solution 76

4.2 Model Predictions 76

4.2.1 Effect of Ion Exchange Rate 78

4.2.2 Effect of Damkohler Number 78

4.2.3 Effect of Adsorption Exchange Capacity 78

4.2.4 Effect of Salinity 83

4.3 Hot Alkaline Flooding 83 
5 Displacement of a Viscous Oil hy the Combined Injection of Hot Water and Chemical Additive

5.1 Introduction

5.2 Mathematical Formulation

5.3 Method of Solution

5.3.1 Path Topology

5.4 Results

5.4.1 Continuous Injection

5.4.2 Chemical Slug Injection

5.5 Conclusions

6 Conclusions and Suggested Future Work

6.1 Conclusions

6.2 Suggested Future Work

Nomenclature 


\section{List of Figures}

2.1 Interfacial activities of original and extracted crude oil and $\operatorname{extracts}^{16} \ldots \ldots \quad \mathbf{8}$

2.2 Silicon-oxygen tetrahedron (schematic). The oxygen atom on top has been drawn as a cross-hatched sphere to show the location of the silicon atom located in the cavity formed by the four oxygens ${ }^{58} \ldots \ldots \ldots \ldots$

2.3 Network structure of a symmetric silicon-oxygen tetrahedron sheet (schematic). The dark spots represent silicon, the white circles oxygen or hydroxyl groups ${ }^{58}$. 16

2.4 Schematic illustration of a silica surface in a perfect vacuum (a) and in water vapor at low pressure $(b)^{104} \ldots \ldots \ldots \ldots \ldots$

2.5 Possible arrangements of the $\mathrm{OH}^{-}$groups on the silica surface ${ }^{163} \ldots \ldots 19$

2.6 Approach to the solubility equilibrium from both $\operatorname{sides}^{83} \ldots \ldots \ldots 21$

2.7 Schematic illustration of a silica surface in an electrolyte ${ }^{104} \ldots \ldots \ldots 22$

2.8 Basic and Acidic dissociation of hydroxide groups on the silica surface ${ }^{103}$. . 24

2.9 Solubility of quartz and amorphous silica at different temperatures ${ }^{74} \ldots \ldots 25$

2.10 Effect of $\mathrm{pH}$ on solubility of amorphous silica at different temperatures ${ }^{75}$. . 28

2.11 Relative concentration of different silicate species caused by solubility of amorphous silica versus $\mathrm{pH}$ at $25^{\circ} \mathrm{C}^{78} \ldots \ldots \ldots \ldots$

2.12 Rate of dissolution of silica powder in $0.1 \mathrm{~N}$-sodium hydroxide solution ${ }^{85}$. . 32

2.13 Dissolution obtained with quartz samples of different specific surface area. Total surface area Suspended in $500 \mathrm{ml}$. of solvent is 10 sq. meters ${ }^{92} \ldots \ldots 34$

3.1 Schematic of the dissolution mechanism. . . . . . . . . . . . . 39

3.2 Effect of the initial $\mathrm{pH}$ on the time required to reach equiliurium $\mathrm{pH}$ and the total dissolved silica at $T=24^{\circ} \mathrm{C} \ldots \ldots \ldots \ldots \ldots \ldots \ldots$ 
3.3 Effect of the initial $\mathrm{pH}$ on the time required to reach equilibrium at $T=24^{\circ} \mathrm{C} . \quad 50$

3.4 Equilibrium values of $\mathrm{PH}$ versus different values of initial $\mathrm{pH}$ at room temperature. ........................... 51

3.5 Total dissolved silica versus different values of initial $\mathrm{pH}$ at room temperature. $\mathbf{5 2}$

3.6 Effect of area/volume ratio on the time required for equilibrium. . . . . . . . 54

3.7 Hydroxyl ion consumption with crushed fired brea sandstone ${ }^{50} \ldots \ldots$

3.8 Effect of temperature on the equilibrium value of $\mathrm{pH}$. . . . . . . . . . 57

3.9 Total dissolved silica versus different values of initial $\mathrm{pH}$ at at $24^{\circ} \mathrm{C}$ and $150^{\circ} \mathrm{C}$. 58

3.10 Phase trajectories in batch processes for various values of initial pH $\left(T=24^{\circ} \mathrm{C}\right)$. 61

3.11 Effect of ion exchange equilibrium constant and salinity on the relative change of $\mathrm{pH}$ at equilibrium. . . . . . . . . . . . . . . 67

3.12 Effect of salinity on totai dissolved silica at equilibrium. . . . . . . . . . . 68

3.13 Effect of $\mathrm{pH}$ and salinity on the relative change of $\mathrm{pH}$ at equilibrium. . . . . 69

3.14 Relative change of $\mathrm{pH}$ at equilibrium versus ion exchange equilibrium constant for ion exchange, ion exchange and dissolution. . . . . . . . . . . . 70

4.1 $\mathrm{pH}$ and sodium ion concentration profile for $1 \mathrm{~N}$ injected caustic concentration and .02 mole/lit injected NaCL. $(t=0.5$ and 1 pore volume, $L / q=400$ days, $\left.a_{m}=1 m^{2} / g r, k_{i} / k_{w}=10^{5}\right) \ldots \ldots \ldots$

$4.2 \mathrm{pH}$ and sodium ion concentration profile for $1 \mathrm{~N}$ injected caustic concentration and .02 mole/lit injecied NaCL. ( $t=0.5$ and 1 pore volume, $L / q=400$ days, $\left.a_{m}=1 m^{2} / g r, k_{i} / k_{w}=10^{3}\right) \ldots \ldots \ldots$

$4.3 \mathrm{pH}$ and sodium ion concentration profile for $1 \mathrm{~N}$ injected caustic concentration and .02 mole/lit injected NaCL. ( $t=0.5$ and 1 pore volume, $L / q=1000$ days, $\left.a_{m}=1 m^{2} / g r, k_{i} / k_{w}=10^{3}\right) \ldots \ldots \ldots \ldots$

$4.4 \mathrm{pH}$ profile for different values of specific surface area and length/flow rate for $.1 \mathrm{~N}$ injected caustic concentration and .02 mole/lit injected NaCL. $(t=0.5$ and 1 pore volume, $\left.k_{i} / k_{w}=10^{3}\right) \ldots \ldots \ldots \ldots$

4.5 Effect of salinity on $\mathrm{pH}$ profile for $.1 \mathrm{~N}$ injected caustic concentration. $(t=0.5$ and 1 pore volume, $L / q=400$ days, $\left.a_{m}=1 m^{2} / g r, k_{i} / k_{w}=10^{3}\right) \ldots$ 
5.1 Schematic description of chemical-assisted thermal injection. . . . . . . . . 89

5.2 Schematic of alkali recovery process (Reference: 15) . . . . . . . . . . . 91

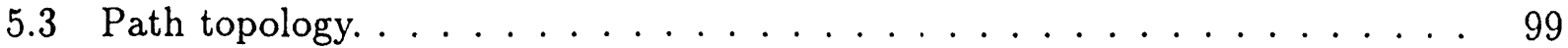

5.4 Solution route, graphical constructoin, and profile for continous injection. (no adsorption $\ldots \ldots \ldots \ldots \ldots \ldots$

5.5 Critical concentration for various values of $g_{1} / a_{3}$ and temperature. . . . 102

5.6 Solution route, graphical constructoin, and profile for continous injection. (case 1). . . . . . . . . . . . . . . . . . . . . . . . . . 104

5.7 Solution route, graphical constructoin, and profile for continous injection (case

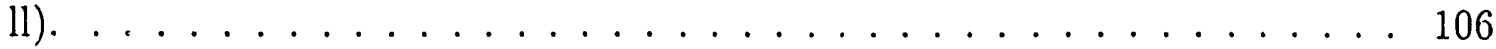

5.8 Recovery curves for continous injection, secondary flooding (20 $\mathrm{API}, g_{1} / a_{3}=$

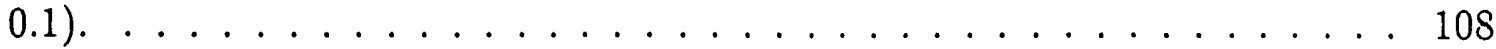

5.9 Recovery curves for continous injection, tertiary flooding ( $20^{\circ}$ API, $\left.g_{1} / a_{3}=0.1\right) .109$

5.10 Recovery performance index for various values of $g_{1} / a_{3}\left(20^{\circ} \mathrm{API}\right) \ldots \ldots 112$

5.11 Recovery performance index for various vAlues of $g_{1} / a_{3}\left(30^{\circ} \mathrm{API}\right) \ldots \ldots 113$ 


\section{List of Tables}

3.1 Effect of the number of reactions on total dissolved silica and equilibrium values of $\mathrm{pH} . \ldots \ldots \ldots \ldots \ldots \ldots \ldots \ldots$

4.1 Typical values of the parameters . . . . . . . . . . . . 77

4.2 Typical values of the parameters . . . . . . . . . . 77 


\section{ABSTRACT}

This report deals with two major issues of chemical assisted flooding - the interaction of caustic, one of the proposed additives to steam flood, with the reservoir rock, and the displacement of oil by a chemical flood at elevated temperatures.

A mathematical model simulating the kinetics of silica dissolution and hydroxyl ion consumption in a typical alkaline flooding environment is first developed. The model is based on the premise that dissolution occurs via hydrolysis of active sites through the formation of an intermediate complex, which is in equilibrium with the silicic acid in solution. Both static (batch) and dynamic (core flood) processes are simulated to examine the sersitivity of caustic consumption and silica dissolution to process parameters, and to determine rates of propagation of $\mathrm{pH}$ values.

The model presented provides a quantitative description of the quartz-alkali interaction in terms of $\mathrm{pH}$, salinity, ion exchange properties, temperature and contact time, which are of significant importance in the design of soluble silicate flooding processes. The latter are shown to minimize or eliminate silica dissolution and caustic consumption, in agreement with recent suggestions. An analysis of the batch processes shows that $\mathrm{OH}^{-}$consumption results from a combination of both iun exchange and silica dissolution. Higher values in the salinity level and in the ion exchange constant lead to a net increase in $\mathrm{OH}^{-}$consumption despite the decrease in the dissolved silica.

The opposite effect arises in core flood processes, where the ion exchange is beneficial in arresting the $\mathrm{OH}^{-}$consumption and the decline of $\mathrm{pH}$ in the upstream region. This (plateau) region is characterized by a constant concentration of $\mathrm{Na}^{+}$, where the silica-alkali interaction follows a batch-like behavior and the $\mathrm{pH}$ profile becomes stabilized. A region of decline to the initial values precedes this ion exchange plateau. For all practical purposes, 
the relevant quantities are the pll level at the front of this platean, determined from the batch analysis, and its velocity of propagation. Thus, the rate of the pH decline increases with the Damkohler number (Da), and equilibrium pH values may be reached well before breakthrough for high enough Da. The equilibrium values are independent of salinity or the ion exchange constant, although the conditions for establishing the equilibrium before breakthrough, and the frontal velocities, are functions of these parameters. For instance, the frontal velocity is found to decrease as the ion exchange constant increases.

The modeling of an adiabatic hot waterflood assisted by the simultaneous injection of a. chemical additive is next presented. The model is also applicable to the hot alkaline flooding under conditions of negligible adsorption of the generated anionic surfactant and of hydroxide adsorption being Langmuirian. The theory of generalized simplo waves (cnlierence) is used to develop solutions for the temperature, concentration, and oil saturation profiles, as well as the oil recovery curves. It is shown that, for Langmuir adsorption kinetics, the chemical resides in the heated region of the reservoir if its injection concentration is below a critical value, and in the unheated region if its concentration exceeds this critical value. Typical results for a chemical slug injection in a tertiary recovery process indicate that recovery performance is maximized when the chemical resides entirely in the heated region of the reservoir. 


\section{Chapter 1}

\section{Introduction}

During primary and secondary stages of oil production from a petroleum reservoir, approximately $30 \%$ of the original oil in place is recovered. ${ }^{1}$ Due to rising crude oil prices coupled with the declining domestic oil production in the United States, there has been an increased interest in the development of enhanced recovery methods to augment oil recovery.

Enhanced oil recovery methods can be divided into two general categories: thermal and chemical. In these processes, capillary forces across the interfaces of immiscible liquids, causing the entrapment of oil in porous media, are overcome by the addition of thermal or chemical energy. ${ }^{2}$

Steam flooding is the most effective and most widely used method for heavy to intermediate gravity oils. In spite of its effectiveness, however, limitations on the utility of steam do arise, particularly because of its tendency to override the lower portion of the formation which is flooded by hot condensate. Field and laboratory studies show that the residual oil saturation in the upper portion of the reservoir invaded by steam, is near zero, while the residual oil saturation in the lower portion, swept by hot water, remains substantial. ${ }^{3}$

Surfactant or chemical flooding processes probably can get the most additional oil out of the ground. ${ }^{4}$ Although they are currently expensivc, they hold promise for future applications. Chemical processes using surfactants, polymers, and alkaline solutions, either separately or in combination, present important economical problems, because the chemicals cost may account for more than $50 \%$ of the total project cost. Thus, the cost efficiency of the chemical used is a key economic factor. Research is currently being done to maximize 
recoveries while minimizing the chemical cost. Polymer floods are less expensive, but they have less recovery potential. Alkaline flooding, which lies probably in between in terms of investment and recovery, appears to be quite a promising technique.

It has been suggested that the poor vertical conformance in steam flooding, due to gravity override, can be improved by using a chemical additive in the steam flood that would reduce oil saturation in the lower part of the reservoir. ${ }^{5,6,7}$ This process takes advantage of the favorable alteration in the viscosity of the fluid phases achieved at high temperatures with the mobility characteristics of the fluid phases resulting from the reduction in the interfacial tension between aqueous and oleic phases.

The feasibility of using certain surfactants at high temperature was first discussed by Handy et $a .^{8}$ They reported on the thermal stability of some surfactants. The results of their experiments show that both sulfonate surfactants and non-ionic surfactants have good thermal stability at normal reservoir temperature. However none was found to be attractive for steam flooding.

Recently, because of economical considerations the addition of caustic with steam has been proposed (Robinson et $a .^{9}$ ). However, one of the major drawbacks in caustic flooding is the reaction of caustic with the reservoir rock. In the first part of this work, which forms the main body of this report, the emphasis is placed on the relevant aspects of the interactions of reservoir rock with caustic. The objective is to develop a model for the reaction and transport processes associated with caustic consumption and silica dissolution during injection of alkaline solution in a sandstone reservoir. A mathematical model can reveal the process variables, although this ability may be also limited by restrictive assumptions. Due to the fact that most of the reservoirs which are likely candidates for caustic or caustic-steam flooding are sandstone reservoirs, the study in this work is limited to the latter. These are highly siliric and often referred to as clean sandstones.

In designing a combined injection of steam and chemical additive, two questions must be answered. Can thermal recovery processes be improved by simultaneous injection of a chemical? What will happen when simultaneous injection is considered? The second part of this work, dealing with the displacement of oil by hot chemical flooding, addresses these questions. 


\section{$1.1 \quad$ Organization}

This study was completed in 1988 and was published in the following three papers:

1. Karakas, M. Saneie, S., Yortsos, Y.C.: "Displacement of a Viscous Oil by the Combined Injection of Hot Water and Chemical Additive," SPE 12560, presented at the 1984 California Regional Meeting, Long Beach, CA, April 11-13.

2. Saneie, S., Yortsos, Y.C.: "A Note on the Application of the Theory of Coherence to Surfactant Flooding," presented at the 1984 AICHE Annual Meetng, San Francisco, California, November. Published in the Soc. Pet. Eng. J. (Jan. 1986).

3. Saneie, S. Yortsos, Y.C.: "Silica Dissolution and Hydroxyl Ion Consumption in Alkaline Flooding," SPE 17410, presented at the 1988 California Regional Meeting of Soc. of Pet. Eng. of AIME, Long Beach, California, March 23-25.

The cumulative of the above work is now being presented in this report which is organized as follows:

Chapter 2 deals at length with the review of the literature related to the caustic flooding and the silicon dioxide (quartz) physical and chemical properties.

Chapter 3 presents the mathematical model describing the kinetics of silica dissolution. It is first proposed that the dissolution mechanism occurs in two elementary steps. One involving rapid formation of a complex (adsorbed silicic acid) on the silica surface, and a slower, rate determining step that governs the partitioning of the complex between the silica surface and the solution. To provide estimates for the proposed kinetic parameters, a comparison of the model with static test data is performed. The effects of the various parameters, for example $\mathrm{pH}$, temperature, area change and salinity on the rate of silica dissolution and hydroxyl ion consumption are examined.

The hydroxyl ion loss due to ion exchange is next combined with the loss due to the dissolution. In this work, ion exchange reaction of hydrogen with sodium ion characterizes the behavior of the system. However, it is proposed that in this case, there exists a competition between sodium ion and silicic acid for adsorption on the sites of the silica surface. Finally, 
appropriate equations are developed to model such a process. The effect of ion exchange constant and salinity on the equilibrium value of $\mathrm{pH}$ and total dissolved silica is also studied.

Chapter 4 deals with the formulation of silica dissolution and hydroxyl ion consumption under dynamic flow conditions. This task is intended to provide an answer as to how far a specified pH level can penetrate into a reservoir at conditions typically encountered in an alkaline flooding process. According to the model, three dimensionless groups control the dissolution behavior of silica under dynamic flow conditions. The variables considered are the ratio of the length over the flow rate, specific surface area and ion exchange equilibrium constant. Sensitivity runs are performed with respect to these groups.

In Chapter 5, the modeling of an adiabatic hot waterflood assisted by the simultaneous injection of a chemical additive is presented. This model is also applicable to the particular case of hot alkaline flooding.The theory of generalized simple waves (coherence) is used to develop solutions for the temperature, concentration, and oil saturation profiles, as well as the oil recovery curves.

Conclusions are drawn and several areas for future research are suggested in Chapter 6. 


\section{Chapter 2}

\section{Fundamentals of Alkaline Flooding}

The history of enhanced oil recovery has witnessed little success in the use of alkaline (caustic) slug since it was first introduced by Squires ${ }^{10}$ (1917), Nutting ${ }^{11}$ (1925) and Atkinson ${ }^{12}$ (1927). Several field tests of caustic flooding have been conducted (Mayer ${ }^{13}$ ). Available field results indicate that caustic floods have been minimally successful and can be applied only to sandstone reservoirs. Soon after the price of oil was increased in 1973, chemical flooding, particularly alkaline flooding, received more attention.

Alkaline flooding refers to processes where an alkaline solution is injected to increase $\mathrm{pH}$ and produce surfactants in situ. ${ }^{14}$ Alkaline flooding is typically considered for reservoirs with lower oil gravity. Normally, oil in these reservoirs has an adequate organic acid content, that reacts in alkaline environments to produce surfactants to lower the interfacial tension (Figure 2-1). For alkaline floods to be effective, the reaction between reservoir rock and alkali must not neutralize all of the hydroxyl ions.

\subsection{Alkaline Chemical}

Alkaline chemicals which have been used in various aspects of enhanced oil recovery processes include sodium silicates, sodium hydroxide, sodium carbonate and sodium phosphates. In solution, these chemicals show significantly different physico-chemical behavior towards hardness ions present in reservoir brines, towards crude oils and towards reservoir rock surfaces. However, due to reservoir heterogeneity and the mineral composition of the rock and reser- 


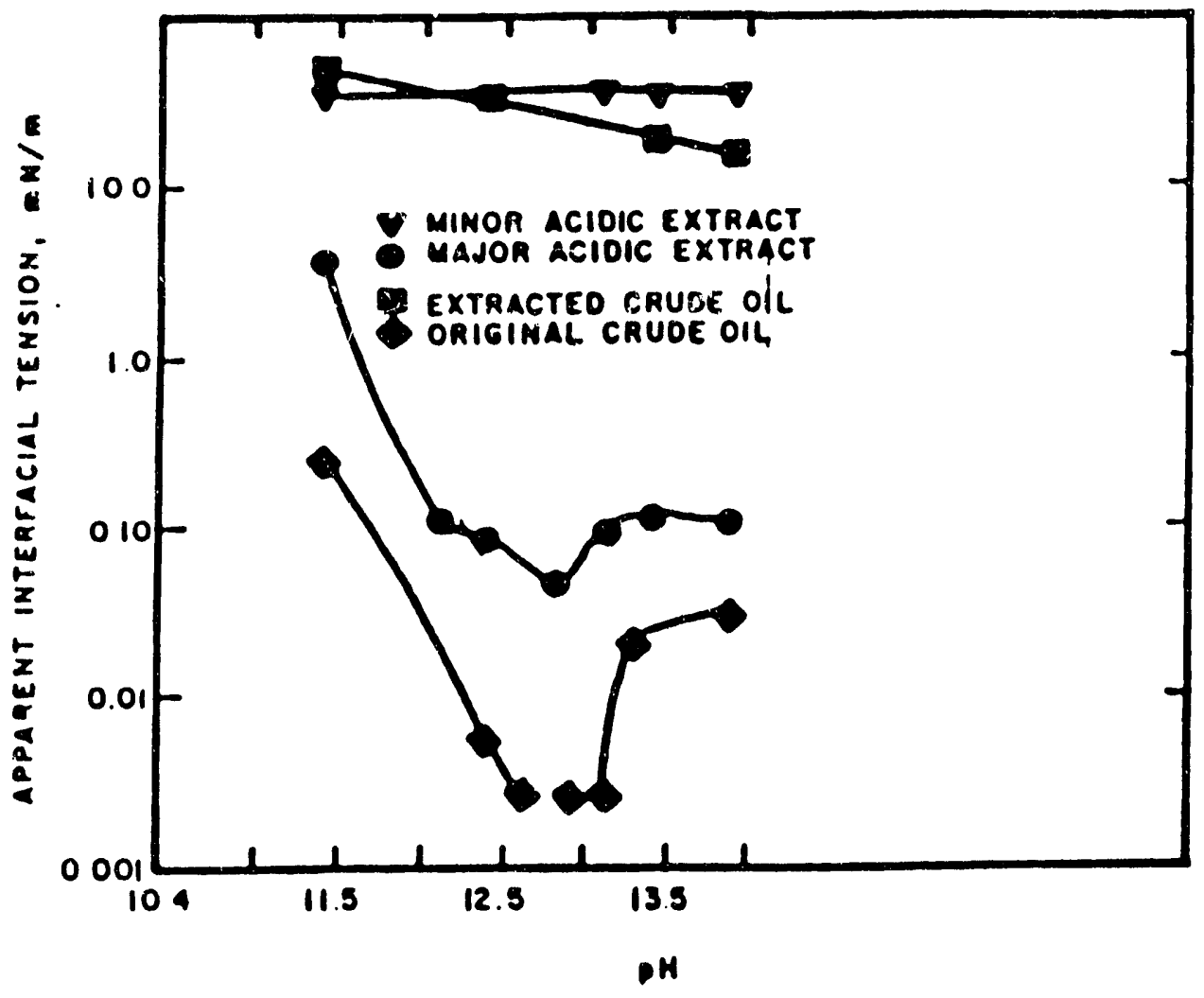

Figure 2.1: Interfacial activities of original and extracted crude oil and extracts ${ }^{16}$. 
voir fluids, the same alkali might induce different mechanisms and oil recoveries in different reservoirs.

Published research results have so far discussed alkali/oil interaction, alkali/water interaction and alkali/rock interaction. While some reactions are necessary, some are of little consequence, and some are harmful. In designing an alkaline flood the most critical, least quantified and least understood phenomenon is the consumption of alkali by the reservoir rock. All three of these loss mechanisms have been considered ${ }^{14}$ in varying levels of detail and will be reviewed in the following sections.

\subsection{Alkali-Oil Reaction}

The common characteristic of all alkaline floods is the reaction of the acidic part of crude oil with caustic, which results in the generation of a surface active agent.

Efforts have been made by several investigators to characterize the surface active component present at the interface. Siefert and Howells ${ }^{16}$ showed that interfacially active species ccnsist of long chain carboxylic acids or phenolic and carboxylic fractions. Dunning ${ }^{17}$ and Dodd et al. ${ }^{18}$ showed that porphyrins, and perphpyrin-metal chelated complexes exhibit strong interfacial activity. Neumann's ${ }^{19}$ work also shows that phenolics are the cause of IFT lowering. Pasquarelli and Wasan ${ }^{20}$ found that the asphaltene fraction of the crude oil generates the surface active compound. Farmanian's ${ }^{21}$ investigation showed that both aromatic and polar components are responsible for surface activity.

The generated surfactant can improve oil recovery by different mechanisms related to changes occurring at the oil-water and liquid-solid interfaces. Several mechanisms responsible for improving recovery over that of conventional water flooding have been suggested in the oil production literature. Although the proposed recovery mechanisms differ in detail, a variable common to all is the IFT between caustic and crude oil. The extent to which any mechanism will be operative as well as the obtainable recovery are highly dependent upon the degree to which interfacial tension is lowered. The recovery improvement depcnds on several factors, like the amount and type of acids present, the initial formation wettability, the reservoir rock pore geometry, and the extent to which caustic is consumed. 


\subsection{Oil Recovery Mechanism}

In 1975 , Johnson ${ }^{22}$ made the first attempt to bring together what was known about alkaline flooding. Recently, good reviews of literature and the proposed mechanisms have been published by Mungan ${ }^{23}$ and Mayer et al. ${ }^{13}$ in 1980 , and again by Mayer et al. ${ }^{24}$ in 1982.

Proposed mechanisms by which alkaline flooding can increase the recovery of acidic crudes are:

1. Emulsification and entrainment. ${ }^{25}$

2. Emulsification and entrapment. ${ }^{26}$

3. Wettability reversal from oil to water wet. ${ }^{2 ?}$

4. Wettability reversal from water to oil wet. ${ }^{28}$

5. Wettability gradient..$^{30,31}$

6. Emulsification and coalescence. ${ }^{32,33}$

7. Disruption of rigid films. ${ }^{34}$

8. - Ultra low tension. ${ }^{22}$

9. Swelling of the oil phase. ${ }^{31}$

Any or all of these can operate in a particular application. Because of this interaction, alkaline flooding is a rather complex recovery process and it is reservoir specific, in terms of process design and the dominant recovery mechanism. ${ }^{13}$ One possible cause for this is that caustic flooding is sensitive to specific caustic-mineral interactions. This shall be discussed in great detail in the following chapters.

\subsection{Alkali-Rock Reaction}

The alkali-roc! interaction has been a subject of interest with respect to alkaline flooding operations. Considerable efforts have been dedicated to the analysis and prediction of alkali 
consumption throughout the flood, the objective being to maintain alkalinity in order to improve recovery efficiency.

Early works ${ }^{25,42}$ in alkaline flooding noted that certain trends are always $s$ en in core flooding experiments. First, hydroxide ion breakthrough is delayed, with the delay being longer, the lower the value of the injected pH. Second, the hydroxide concentration levels off, but at a level slightly lower than the injection concentration.' The increased caustic consumption and reduced oil recovery can be attributed to irreversible (slow) as well as reversible (fast) $\mathrm{NaOH}$-clay and sandstone interactions.

Reversible caustic consumption mechanism leads to chromatographic elution of the $\mathrm{NaOH}$, after the caustic flood is terminated in a normal waterflood reservoirs. It has been observed by many researchers that a significant quantity of $\mathrm{NaOH}$ is eluted from a Berea sandstone, i.e. this portion of caustic consumption is not irreversibly lost.

Caustic consumption resulting from silicate mineral dissolution is characterized as irreversible for EOR flooding purposes. However, reversible ion exchange consumption that requires a large number of pore volume fluid injection to generate meaningful oil production may also be considered irreversible for field application purposes.

Recent studies of alkaline interaction with reservoir rock, both in steam flooding and in caustic flooding, report the importance of slow mineral dissolution. ${ }^{43,44}$ Silica and quartz are fast dissolving minerals, with slower dissolving clays releasing soluble aluminum, which may redeposit with soluble silica as new aluminum silicate mineral. The formation of a new mineral influences the aqueous aluminum and silica concentrations, as well as the hydroxyl ion concentrations.

Caustic consumption can also result from other minerals, such as gypsum anhydrite and certain carbonate minerals (incongruent), which are detrimental to caustic EOR. ${ }^{26,27,45,46}$ Thus, for low concentration, long term EOR flooding with $\mathrm{NaOH}$, a careful examination of the mineralogy in a candidate sandstone reservoir is required, so that unproductive $\mathrm{NaOH}$ consumption can be prevented.

Among the needs of alkaline flooding is to develop reaction rate kinetics for the dissolution of rock in alkaline media as a method for predicting alkaline loss. The emphasis in this work is on the relevant aspects of slow mineral dissolution reaction in alkaline flooding. Let us 
look at the historical development of research concerning alkali-rock interactions.

Early efforts in investigating the alkali-rock interaction were performed by Cookes et al. ${ }^{29}$ They did not distinguish between various alkali-rock $\mathrm{OH}^{-}$consumption mechanisms. Their results of series of tests on alkali consumption by sandstone showed that the rate of the reaction of alkali with minerals considerably decreases with time. The explanation offered by them is that the buildup of a layer of sodium silicate on the surface of the silicate minerals might diminish mass transfer and reaction rates. They also concluded that only the reaction between the alkali and the high surface area plays important roles in the alkaline water displacement process. However, our interpretation is somewhat different, and will be discussed in great detail in the following chapters. Ehrlich and Wygal ${ }^{28}$ studied the caustic consumption of a number of clays and minerals, in an effort to quantify the contribution of each to the overall consumption. They have showed that the consumption rates for most clays are much higher, compared to consumption rates of quartz, calcite and dolomite. However, their results of dynamic flow tests were less than expected from the static tests. An explanation for this discrepancy was not offered. The present work can explain some of these unresolved questions. Results of laboratory studies by Reed ${ }^{43}$ show that the rate of silica dissolution or hydroxyl ion consumption increases significantly with $\mathrm{pH}$ and temperature, and it decreases with increased flow rate. Somerton and Radke ${ }^{47}$ found that alkaline chemicals can cause clay migration and swelling, which could lead to permeability loss. Clay reactivity was found to be significant, but the liberation of aluminum ions from clays was observed to retard the dissolution of soluble silica. Lieu ${ }^{48}$ also studied the long term consumption of caustic and sodium orthosilicate solutions and found that consumption is reduced when silicates are used. Sydansk ${ }^{44}$ has studied the interaction of caustic at elevated temperature with certain sandstones. He found that a considerable amount of silicate is generated during the course of alkaline flooding. The equilibria of dissolved silica in alkaline solutions were also carefully elucidated in a recent work by Southwick. ${ }^{49}$ Aflaki ${ }^{140}$ studied the consumption of alkali, at high temperature, in a sandstone. She observed the liberation of aluminum at the early stage of the flooding process followed by rapid drop of silica concentrations, which implies that clay contribution is relatively significant in the consumption of alkali. Short time dissolution of quartz, different clay minerals and their mixture was also studied by 
Diallo ${ }^{162}$. The result of his experiments showed that on per unit area basis, the dissolution of quartz is faster than kaolinite.

Along with experimental studies, some efforts were also undertaken to model the kinetics of silica dissolution. Bunge and Radke ${ }^{52}$ have studied the migration of alkaline pulses and developed an empirical, single, irreversible first order rate model to explain their movement through reservoirs. However, Dehghani's ${ }^{50}$ experiments on the consumption rate of hydroxyl ion by sandstone showed that dissolution of sandstone can be considered as a first order reaction only for sufficiently low alkali concentrations of sodium hydroxide.

Krumrine ${ }^{51}$ recently made a critical comparison of Bunge and Radke model to the pseudo first order reaction model introduced by O' Connor et al. ${ }^{53}$ This study provided an alternative description to the irreversible model suggested by Bunge and Radke ${ }^{52}$ Similar conclusions were also reached by Mohnot, ${ }^{54}$ who studied the reaction of alkaline chemicals with montmorillonite, kaolinite, illite, and quartz sand. His studies showed that reither hydroxide consumption nor production of dissolved $(\mathrm{Si})$ or $(\mathrm{Al})$ followed a simple kinetic model of a single irreversible reaction. He also reported that after a long term reaction, dissolved silica concentration drops to very low values. This is due to the incongruent dissolution process of kaolinite-alkali reaction, which result into the formation of the new mineral by consuming dissolved $(\mathrm{Si})$ and $\left(\mathrm{OH}^{-}\right)$. Huang's ${ }^{161}$ experiments on the consumption rate of alkali by quartz and different clay minerals show that consumption of alkali is the highest for montmorillonite and it is not a simple reaction. Thornton et al. ${ }^{55}$ have lent additional support to the limitations of a first-order rate model by showing that the rate of hydroxyl ion consumption or silica dissolution decreases as the solubility limit of silica is reached. The rate model developed by Thornton is identical to Stober's ${ }^{92}$ model at neutral $\mathrm{pH}$. In this model it is assumed that the ratio of the silicic acid concentration to the silicic acid concentration at equilibrium is equal to the ratio of total dissolved silica concentration to the total dissolved silica concentration at eqruilibrium. However, we will show that this proportionality constant is also a function of $\mathrm{pH}$. A more complete discussion on the rate of dissolution is presented in a later chapter. 


\subsection{Review of Silica Chemistry}

As mentioned previously, the alkali rock interaction is the most important and least.understood aspect of alkaline flooding. An elemental analysis of rocks and clays by several methods by Crocker et al. ${ }^{56}$ shows that reservoir rocks mainly consist of silicon. We shall review some aspects of the complex chemistry of silica to help us understand silica-alkali interaction in the reservoir.

\subsubsection{Composition}

Silica occurs in amorphous or crystalline forms in many types of gaseous, metamorphic, or sedimentary rocks. Main forms of silica are hydrous opal, crystalline chalcedony, and quartz. There exist three common crystalline forms: quartz, which is thermodynamically stable below $870 \mathrm{C}$ and has the highest density, 2.655; tridymite, which is thermodynamically stable in the range $870-1470 \mathrm{C}$; and cristobalite, which is stable above $1470 \mathrm{C}$. All three forms are found in nature, the latter two being in a thermodynamically unstable state.

\subsubsection{Structure}

Although there has been considerable disagreement regarding the structure of some of the siliceous compounds, considerable details can be offered by infrared spectroscopy, X-ray diffraction and differential thermal analysis. X-ray diffraction studies of silicates show that their basic building block is a tetrahedron with silicon in the center and four oxygen atoms at its corners (Figure 2-2). The Si-O distance has been evaluated at $1.6 \AA$ and the $\mathrm{O}-\mathrm{O}$ distance at $2.6 \AA$.

In the case of quartz, cristobalite, and trydimite, a continuous framework of 3-dimensionally linked tetrahedra must be considered, with oxygen atom bonded to two silicon atoms, so that valency requirements are met (Figure 2-3). If some of the silicon is replaced with aluminum, as is the case with feldspars and zeolites, the structure of linked tetrahedra must be balanced by metallic cations.

Upon addition of water, as a result of hydration and hydrolysis, the exposed oxygen tetrahedra become partial hydroxy tetrahedra. The silica surface which is prepared by 


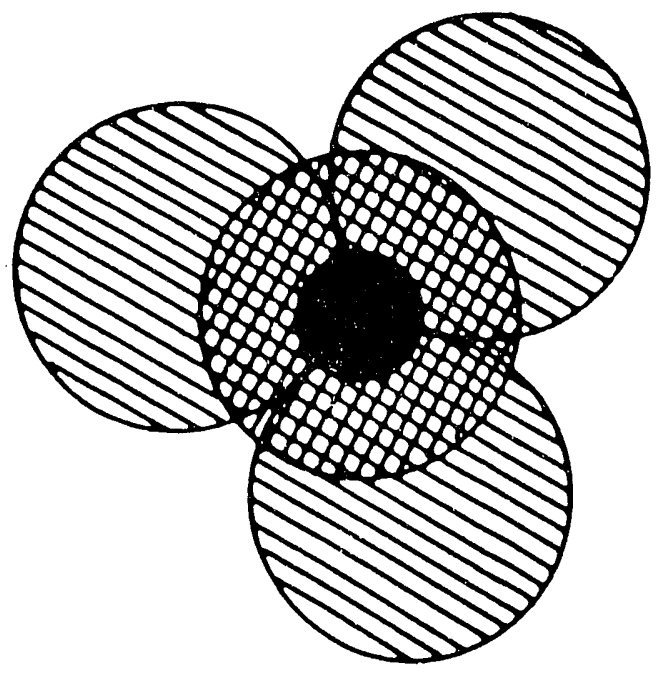

Figure 2.2: Silicon-oxygen tetrahedron (schematic). The oxygen atom on top has been drawn as a cross-hatched sphere to show the location of the silicon atom located in the cavity formed by the four oxygens ${ }^{58}$. 


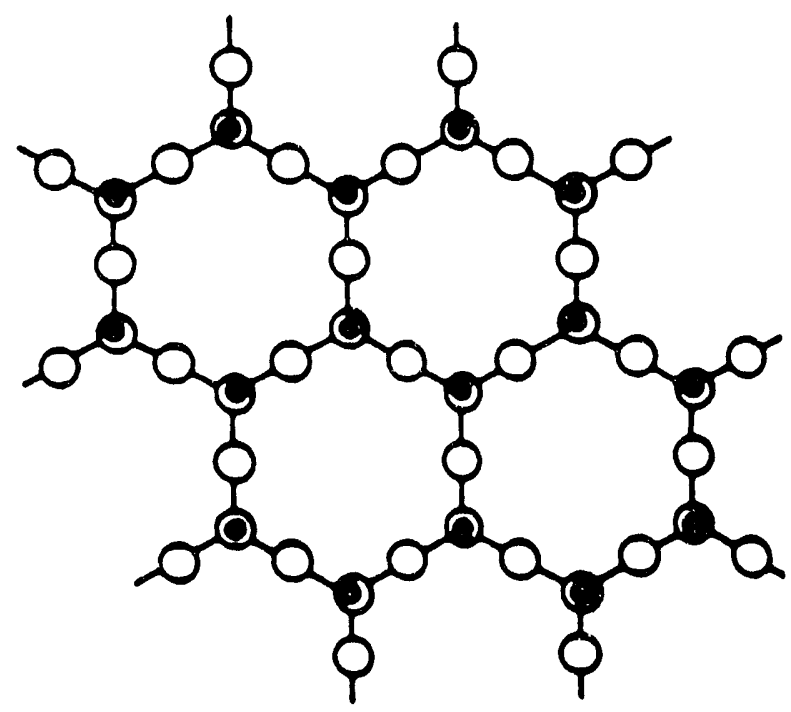

Figure 2.3: Network structure of a symmetric silicon-oxygen tetrahedron sheet (schematic). The dark spots represent silicon, the white circles oxygen or hydroxyl groups ${ }^{58}$. 
fracture in vacuum is shown in Figure 2-4. It is noticed that the surface contains ions which are not fully coordinated and, hence, are electrically charged. Upon addition of water or exposure to water vapor, the charged sites are changed to hydroxide or $\mathrm{Si}-\mathrm{OH}$ groups.

Figure 2-5 shows the different arrangements of $\mathrm{OH}$ groups on the silica surface. It has been found that surface hydroxyls can be replaced by ethoxy, phenyl, and other organic groups. This results into significant changes in the adsorption properties of silica. For example, a silica covered with ethoxy groups is strongly organophilic or hydrophobic, contrary to silica surface which is normally hydrophilic.

The presence of these groups and their exact number have been experimentally measured using many different techniques, including infrared spectroscopy, water vapor adsorption and $\mathrm{D}_{2} \mathrm{O}$ exchange. The exact number depends on the kind of oxide and the pretreatment procedure. Typically, oxide surfaces carry 5 to 15 hydroxyl groups per $100 \AA$ of the surface.

\subsection{Silica-Water System}

Most of the changes that silica undergoes in nature involve interaction with water. Therefore, knowledge of the system $\mathrm{SiO}_{2}-\mathrm{H}_{2} \mathrm{O}$ is very important to the understanding of many industrial processes, including weathering, hydrothermal and, in particular, alkaline flooding processes.

A great deal of experimental as well as theoretical work has been done on this system. In spite of the industry's long interest, however, many properties about this oxide $\left(\mathrm{SiO}_{2}\right)$ are not yet fully understood. Many unsolved problems also exist related to the chemistry of silica.

In contrast to most inorganic solutions, when a silica solution becomes supersaturated, either by cooling, evaporation or neutralization, excess silica does not normally precipitate but remains suspended in the form of colloidal particles. These particles might ultimately precipitate as gelatinous flows or the entire solution may set to a gel. This process is irreversible, meaning the gel will not desegregate into colloidal particles when placed in water, but it would partly dissolve to form monomeric silica $\left(\mathrm{Si}(\mathrm{OH})_{4}\right)$ up to the equilibrium solubility.

Another unusual characteristic of silica is the slowness in both dissolution and polymer- 


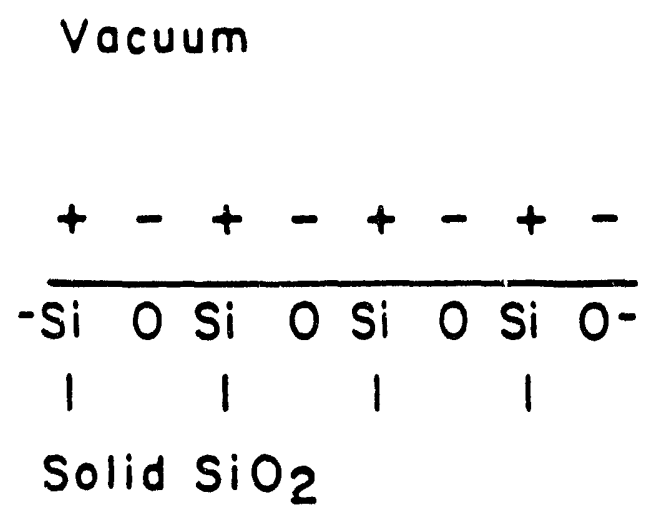

(a)

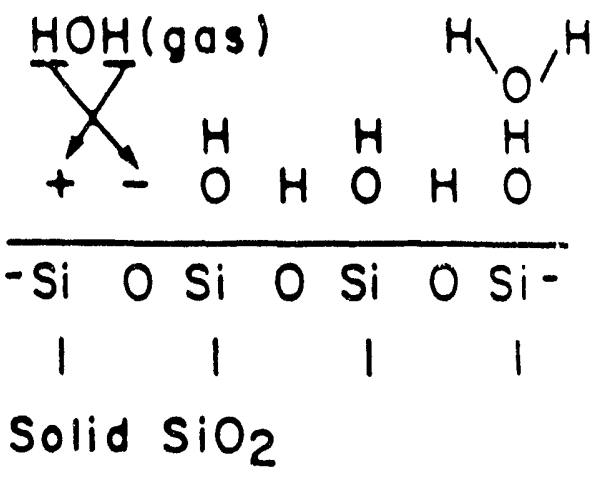

(b)

Figure 2.4: Schematic illustration of a silica surface in a perfect vacuum (a) and in water vapor at low pressure $(b)^{104}$. 


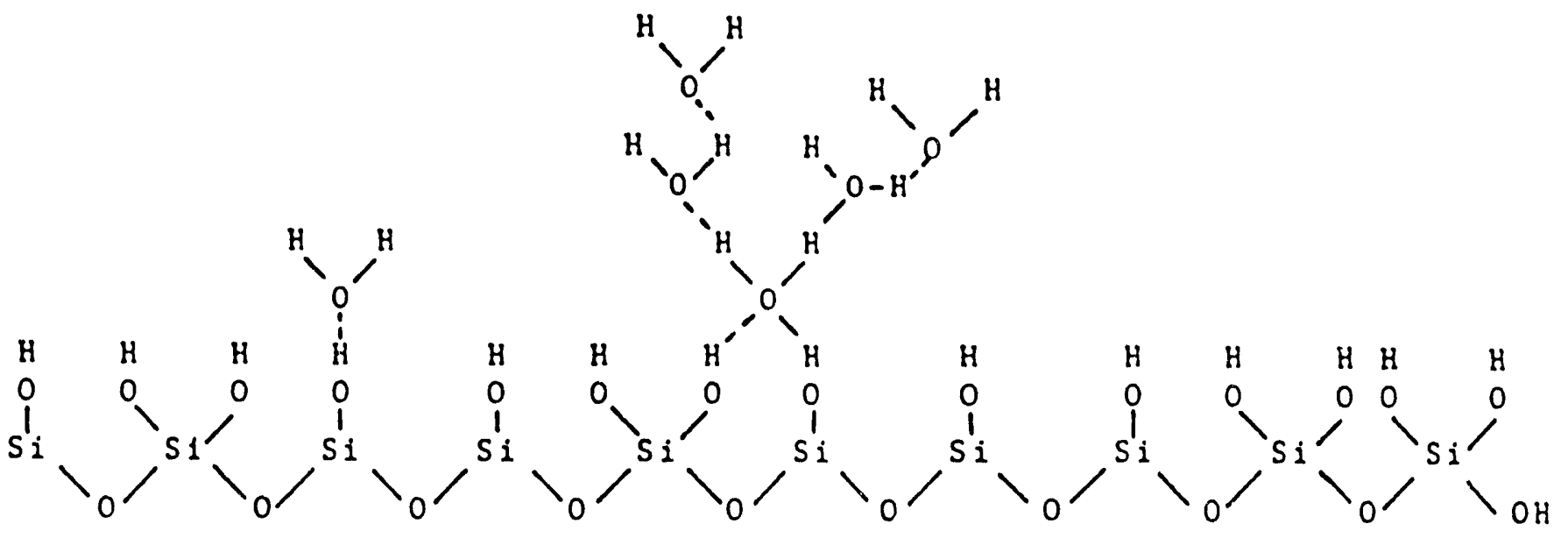

Figure 2.5: Possible arrangements of the $\mathrm{OH}^{-}$groups on the silica surface ${ }^{163}$. 
ization reactions, which determine the solubility equilibrium of silica. Figure 2-6 shows the slow rates for dissolution and polymerization reactions. This means that non-equilibrium solutions (supersaturated solution and solutions containing colloidal silica well below the equilibrium solubility) may exist for a long period of time.

\subsubsection{Silica-Water Interface}

Mineral-water interfacial phenomena are extremely significant to many fields of geochemical processes in nature, the behavior of soil, the processing of mineral raw materials, enhanced oil recovery processes for petroleum production and particularly alkaline flooding. The reason is that under selective or general conditions, solutes in the aqueous phase adsorb at mineralwater surfaces. The silica electrolyte interface has been the subject of more intensive study than any of the other hydrous oxide-water interfaces. ${ }^{120-130}$ This is due to the significant importance of silica, glass, quartz, silicate, etc, in almost all fields of science and technology.

The surface properties of silica vary according to the method of preparation. This results in differences in the number and arrangement of surface silicon groups. As shown earlier, silica surfaces prepared by fracture in vacuum contain ions which are not fully coordinated and hence are electrically charged. After addition of water or exposure to water vapor, the charged sites are changed to hydroxide or Si-OH groups. As shown in Figure 2-7 further adsorption of water vapor results into the formation of a negative surface and diffuse layer of positive ions. The two regions of charge form the electrical double layer.

Since adsorption phenomena at mineral/water interface are usually controlled by the electrical double layer, the factors responsible for the charge on the mineral surface and for the behavior of counter ions to maintain electroneutrality have been studied carefully.

The double layer at an oxide solution interface is investigated by studying the equilibrium distribution of the potential determining ions. For the oxide minerals, hydrogen and hydroxyl ions have long been knowi to be potential determining. Bolt ${ }^{122}$ and Parks and Debruyn ${ }^{126}$ were among the first to apply potentiometric titration to the study of oxide surface equilibria and to confirm the importance of $\mathrm{H}^{+}$and $(\mathrm{OH})^{-}$in the establishment of the electrical double layer at the oxide/water interface. Cpon contact with water, minerals form hydroxylated surfaces. When solid is in equilibrium with an aqueous solution the surface is considered 


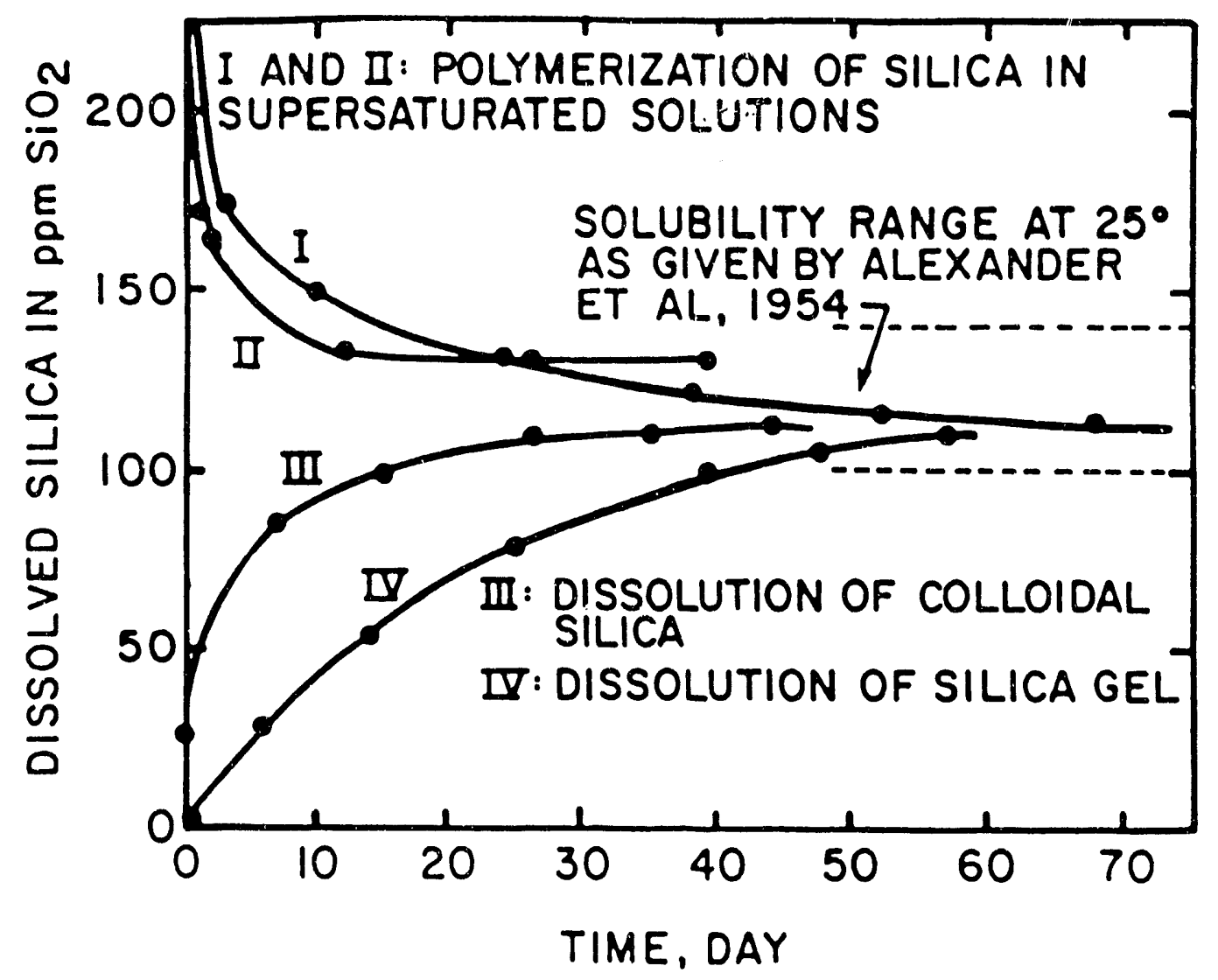

Figure 2.6: Approach to the solubility equilibrium from both sides ${ }^{83}$. 


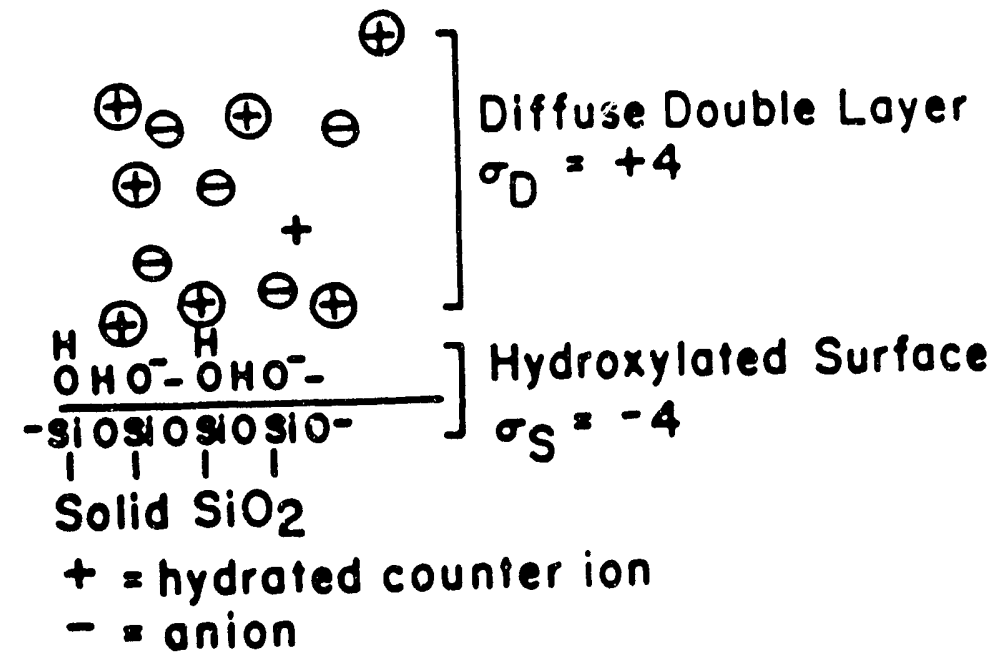

Figure 2.7: Schematic illustration of a silica surface in an electrolyte ${ }^{104}$. 
to be hydroxylated. Adsorption-dissociation of $\mathrm{H}^{+}$from the surface hydroxyl can account for the surface charge in the oxide. The origin of charge at an amphoteric oxide solution interface may be related to the basic or acidic dissociation of the metal hydroxide groups on the surface. The equilibria can be represented as shown in Figure 2-8.

The $\mathrm{pH}$ at which the surface is undissociated is the zero point of charge (Z.P.C), where the charge density is zero. It is shown in the above that addition of the oxide to the solution in the region of acidic dissociation will decrease the $\mathrm{pH}$ of the bulk solution, and the surface obtains a negative charge. However, the opposite is true in the region of basic dissociation, where the surface will have opposite charge. Thus, the resulting surface charge, which depends on an excess of one type of charged site over the other, is a function of the solution $\mathrm{pH}$. For this reason $\mathrm{H}^{+}$and $\mathrm{OH}^{-}$are the potential determining ions.

Mathematical description of the distribution of ions between the fixed and diffuse parts of the double layer, within the diffuse layer and between the diffuse layer and the bulk electrolyte, are well developed and reported in the literature. ${ }^{119,120}$. These models can account for experimental adsorption isotherms, provided that certain values are estimated.

\subsubsection{Solubility of Quartz}

The silica water-system, and specially quartz, has been studied over a wide range of temperature and pressure by Kennedy ${ }^{60}$ He showed that quartz is essentially insoluble below $150^{\circ} \mathrm{C}$, although above this temperature, its solubility increases linearly with temperature (Figure 2-9).

Paterson and Wheatly ${ }^{63}$ found a constant concentration of $1.810^{-4}$ mole/kg for an HF treated quartz sample (0.5- $2 \mu$ in diameter). White ${ }^{64}$ reports experiments giving a value of $7 \mathrm{ppm}$ or slightly higher for quartz at room temperature. Gibb et al. ${ }^{65}$ reported evidence for the existence of a layer of highly disordered structure on the surface of quartz particles. Siever ${ }^{66}$ has calculated from thermochemical data that the solubility from $25^{\circ} \mathrm{C}$ up to $473^{\circ} \mathrm{C}$ should lie between 7 and $14 \mathrm{ppm}$. Van Lier $^{67}$ showed that the soluhility of quartz in water follows the empirical equation,

$$
\log C=0.151-1162 / T
$$




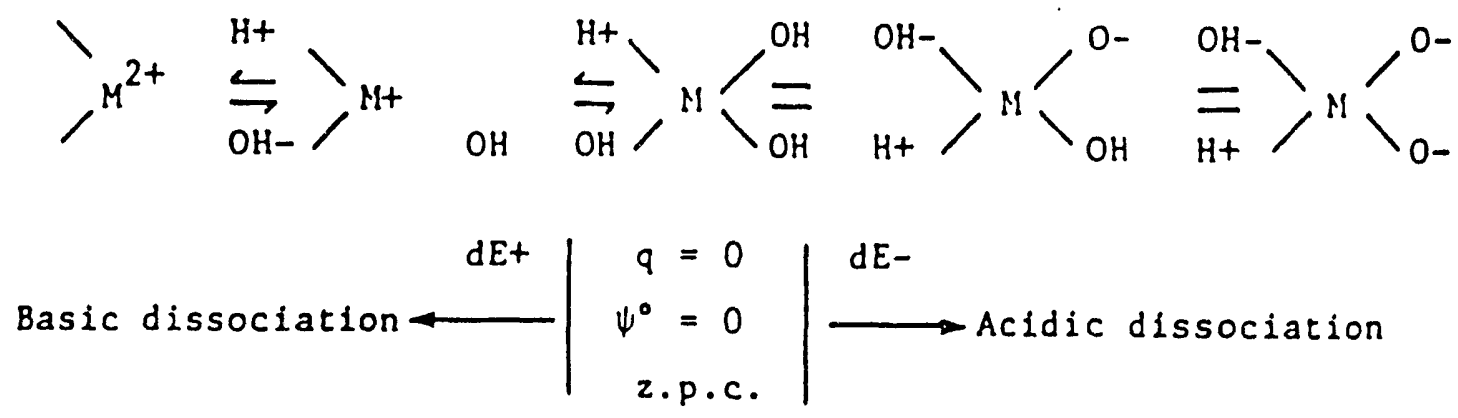

Figure 2.8: Basic and Acidic dissociation of hydroxide groups on the silica surface ${ }^{103}$. 


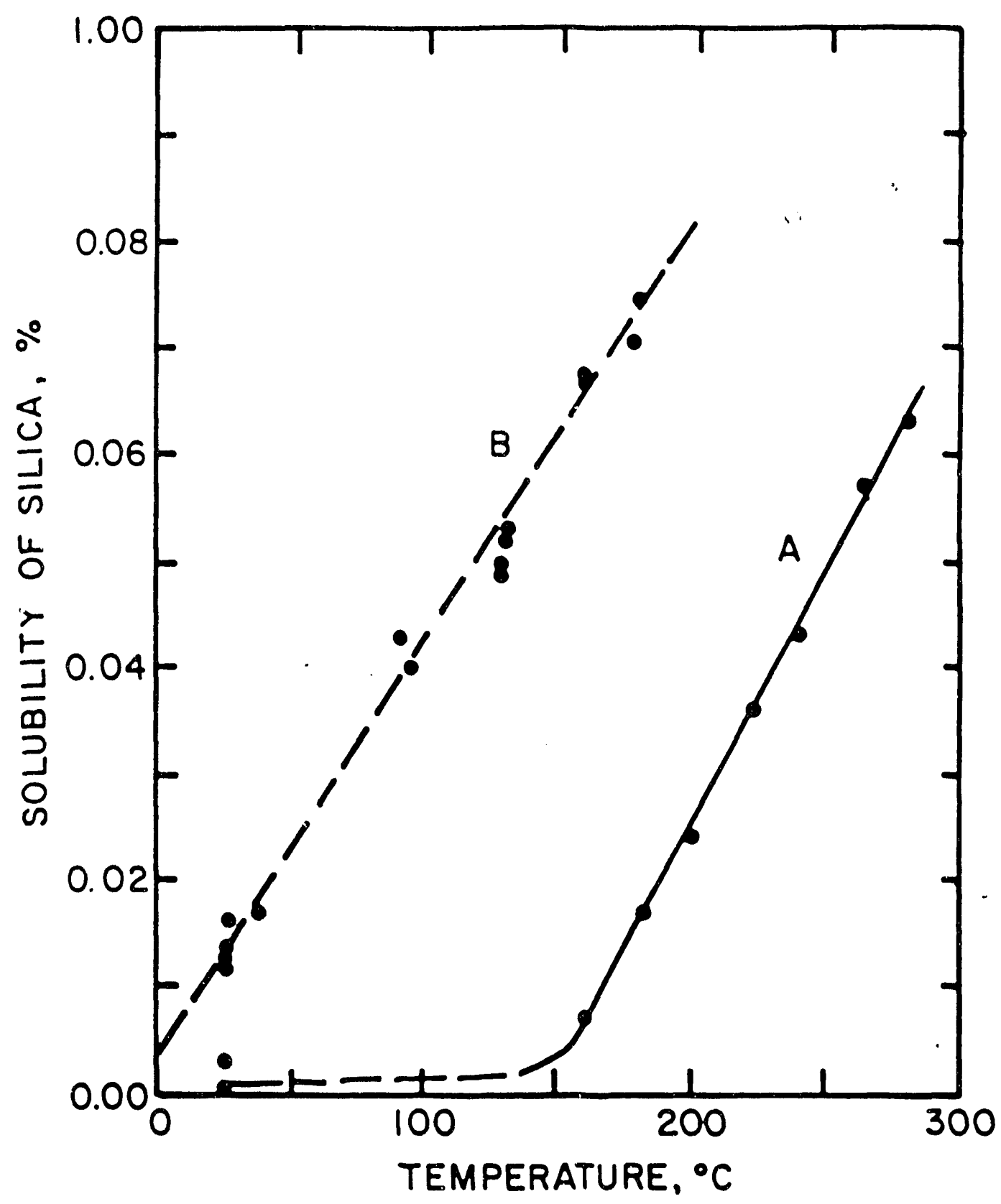

Figure 2.9: Solubility of quartz and amorphous silica at different temperatures ${ }^{74}$. 
In the above equation $C$ is expressed in moles of $\mathrm{SiO}_{2}$ per $\mathrm{kg}$, and $T$ is in degrec Kelvin. The equation reflects a dramatic increase of silica solubility with temperature. Recently, a mathematical descriptions of the diagenesis of silica has been developed by Chang and Yortsos. ${ }^{160}$ This model accounts for dissolution, nucleation and precipitation of the various amorphous and crystalline phases of silica.

One may notice that there is some inconsistency in the literature regarding the reported values of quartz solubility, especially at low temperatures. This may be due to the very low rates of dissolution, which impede attainment of equilibrium in laboratory measurements. The differences in the physical state of silica and in the type of impurities present in the system could be another possible cause for the observed inconsistency.

\subsubsection{Solubility of Amorphous Silica}

Amorphous silica can be considered as a polycondensate product of silicic acid $\left(\mathrm{Si}(\mathrm{OH})_{4}\right)$. The fact that amorphous silica has a definite solubility, determined by equilibrium between rates of dissolution and precipitation, has been questioned for a long time. A considerable amount of work has been carried out on the equilibrium solubility of amorphous silica as described below.

Klemm ${ }^{68}$ presented a summary of the solubility of the various forms of silica in water. He reports that the value for the solubility of silica is about 0.04 percent, and that increases rapidly as the $\mathrm{pH}$ rises. Gardner ${ }^{61}$ found the value of .0126 percent. Lenher and Merrill ${ }^{69}$ 's observations plus other reported solubility values, show that the solubility of amorphous silica varies linearly with temperature and approaches zero at slightly below $0^{\circ} \mathrm{C}$ in (Figure $2-9$, curve B ). Scheel, Fleischer, Klemperer ${ }^{70}$ have reported the value of $0.017 \%$, by conducting experiments, which approach equilibrium from both supersaturated and unsaturated solutions. Such typical examples are illustrated in Figure 2-9.

\subsubsection{Effect of $\mathrm{pH}$}

Due to the fact that silica can easily dissolve in strong alkaline solutions, many researchers concluded that the solubility of silica increases as the pH increases. The first experimental 
support for this idea was offered by Correns (1941). ${ }^{71}$ But comparison with the recent work in this area indicates that Correns and others must have been mistaken. ${ }^{72,73}$ There is considerable evidence that silica can exist in water solution in a monomeric form or hydrated as silicic acid $\left(\mathrm{Si}(\mathrm{OH})_{4}\right){ }^{73}$ It seems that solubility of silica, in terms of silicic acid in solution, is independent of $\mathrm{pH}$. On the other hand, in an alkaline solution, additional silicate ions exist in solution which cause an increase of the absolute solubility. Figure 2-10 shows that the solubility of amorphous silica increases with pH and temperature. Other authors report similarly enhanced solubilities for quartz at high temperature and $\mathrm{pH}{ }^{67,74}$

The solubility of silica has been characterized by Stumm and Morgan ${ }^{78}$ by the following reactions:

$$
\begin{aligned}
\mathrm{SiO}_{2}+2 \mathrm{H}_{2} \mathrm{O} & \rightarrow \mathrm{Si}(\mathrm{OH})_{4} \\
\mathrm{Si}(\mathrm{OH})_{4} & \rightarrow \mathrm{SiO}(\mathrm{OH})_{3}^{-}+\mathrm{H}^{+} \\
\mathrm{SiO}(\mathrm{OH})_{3}^{-} & \rightarrow \mathrm{SiO}_{2}(\mathrm{OH})_{2}^{2-}+\mathrm{H}^{+} \\
4 \mathrm{Si}(\mathrm{OH})_{4} & \rightarrow \mathrm{Si}_{4} \mathrm{O}_{6}(\mathrm{OH})_{6}^{2-}+2 \mathrm{H}^{+}+4 \mathrm{H}_{2} \mathrm{O}
\end{aligned}
$$

Using the equilibrium constants in the above reactions, Stumm and Morgan ${ }^{78}$ calculated the concentrations of different silicate ion at different $\mathrm{pH}$ values. Figure 2-11 shows the relative concentration of different silicate ion versus $\mathrm{pH}$.

The following ionization reactions proposed by Kopeykin and Mikaylov ${ }^{79}$ were used in the work by Southwick ${ }^{49}$

$$
\begin{aligned}
\mathrm{Si}(\mathrm{OH})_{4} & \rightarrow \mathrm{SiO}_{4} \mathrm{H}_{3}^{-}+\mathrm{H}^{+} \\
\mathrm{SiO}_{4} \mathrm{H}_{3}^{-} & \rightarrow \mathrm{SiO}_{4} \mathrm{H}_{2}^{2-}+\mathrm{H}^{+} \\
\mathrm{SiO}_{4} \mathrm{H}_{2}^{2-} & \rightarrow \mathrm{SiO}_{4} \mathrm{H}^{3-}+\mathrm{H}^{+} \\
\mathrm{SiO}_{4} \mathrm{H}^{3-} & \rightarrow \mathrm{SiO}_{4}^{4-}+\mathrm{H}^{+} \\
\mathrm{SiO}_{3} \mathrm{H}_{2}+\mathrm{H}_{2} \mathrm{O} & \rightarrow \mathrm{SiO}_{4} \mathrm{H}_{4} \\
\mathrm{SiO}_{3} \mathrm{H}_{2} & \rightarrow \mathrm{SiO}_{3} \mathrm{H}^{-}+\mathrm{H}^{+} \\
\mathrm{SiO}_{3} \mathrm{H}^{-} & \rightarrow \mathrm{SiO}_{3}^{2}+\mathrm{H}^{+}
\end{aligned}
$$

As will become clear in the following chapter, knowledge of the type of jonization reactions and related equilibrium constants are necessary for the modeling of the rate of silica. 


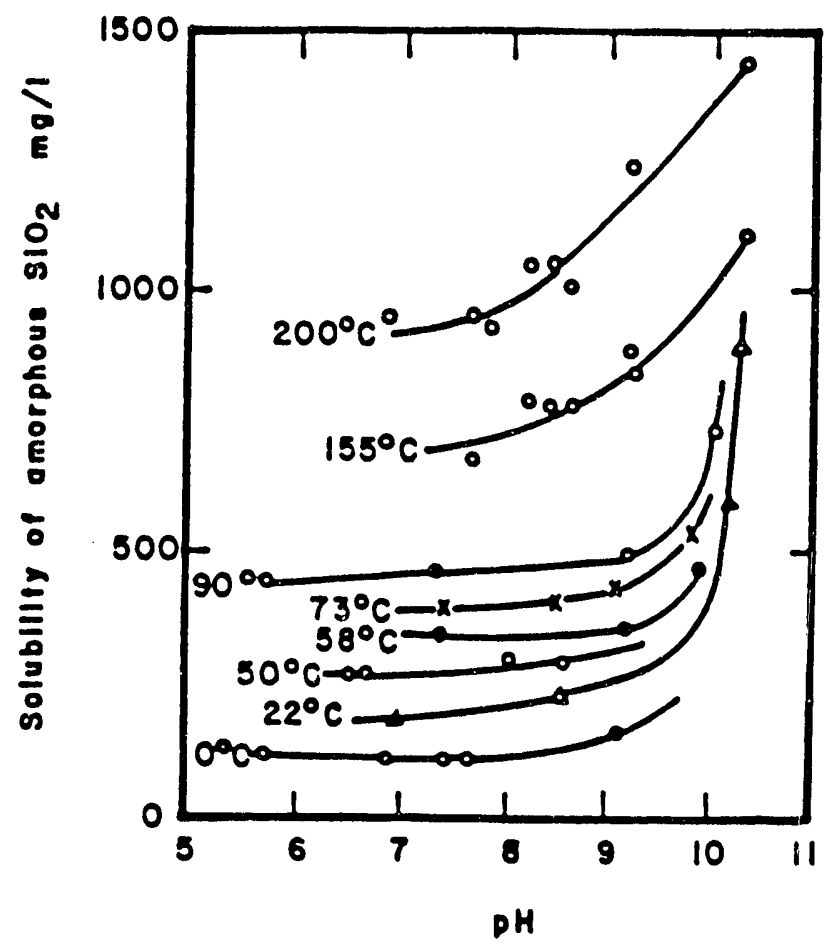

Figure 2.10: Effect of $\mathrm{pH}$ on solubility of amorphous silica at different temperatures ${ }^{75}$. 


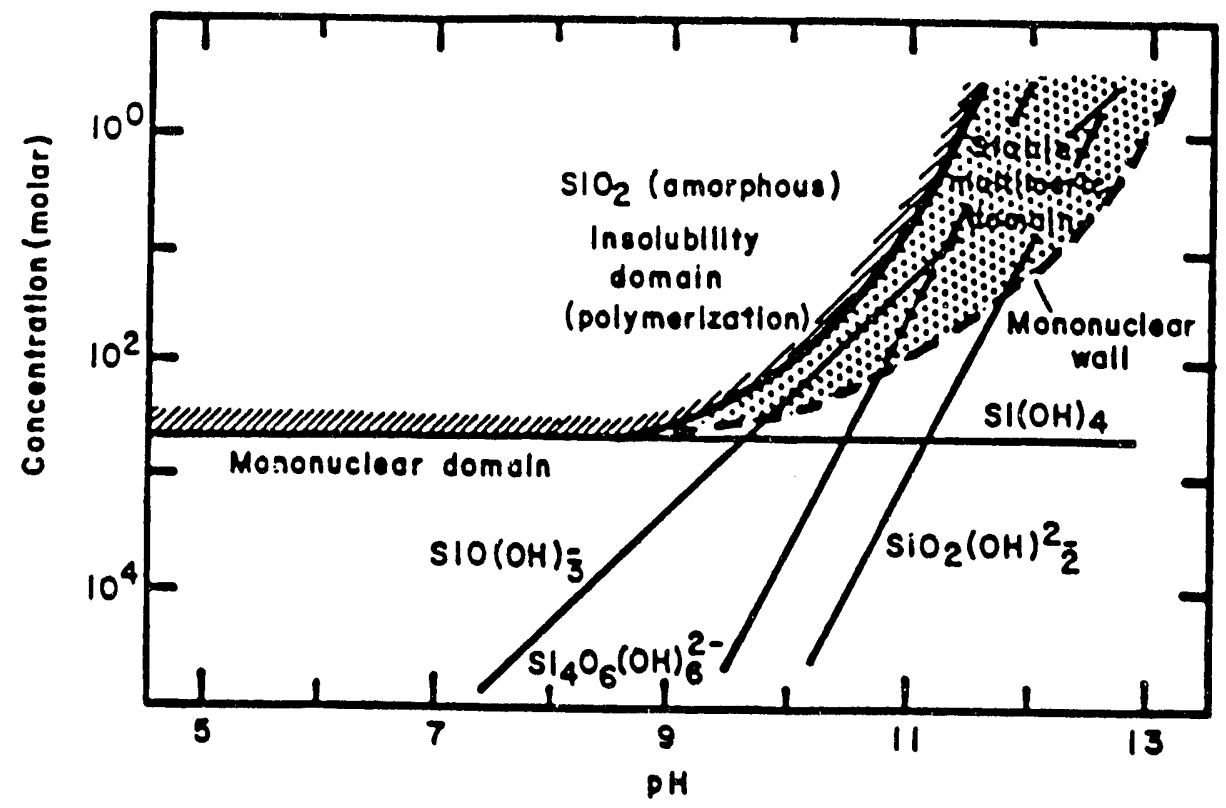

Figure 2.11: Relative concentration of different silicate species caused by solubility of amorphous silica versus $\mathrm{pH}$ at $25^{\circ} \mathrm{C}^{78}$. 
dissolution. The colorimetric method has often been used for the measurement of the amount. of total dissolved silica. In this method, molybdic acid reacts with silicate species to form a yellow colored silica-molybdate complex. However, the rapid formation of the colored complex is only due to the reaction of silicic acid. 'Therefore, the accuracy of this method is limited due to the existence of other polymerized forms of silicic acid, which dissociate slowly to a monomer in order to react with the molybdate acid. The alternative to colorimetric method is atomic adsorption, which measures the total amount of silicon atom in every form. This method is very accurate and should be used instead. Due to this limitation the experimental values of dissolved silica must be considered with certain reservations.

\subsubsection{Effect of Salinity}

There are only few measurements on the solubility of silica in aqueous electrolyte solutions, either at low or high temperatures. Kitahara's ${ }^{80}$ investigations on solubilities of quartz from 140 to $300^{\circ} \mathrm{C}$ show small effects by $0-1.3 \mathrm{~m}$ dissolved sodium chloride. Siever ${ }^{81}$ (1962), Greenberg and Price ${ }^{82}$ (1957) and Krauskopf $f^{83}$ (1956) also mentioned little effects on the solubility of amorphous silica by salt. A $10 \%$ reduction in the solubility of amorphous silica at $25^{\circ} \mathrm{C}$ in $1 \mathrm{M}$ sodium chloride has been noticed by Greenberg and Price. Although, from a geochernical point of view, the salt of most interest is sodium chloride, due to experimental difficulties the effect of $1-1$ salt solution of sodium nitrate was studied instead by Marshall ${ }^{84}$ (1980). A significant reduction in solubility of silica with increasing solubility of the sodium nitrate was observed. This effect is more pronounced at low temperatures. At $25^{\circ} \mathrm{C}$, the solubility of silica is decreased by $60 \%$. while the corresponding decrease is $27 \%$ at $300^{\circ} \mathrm{C}$. Solubilities in sodium chloride are expected to follow the same behavior. Krumrine's ${ }^{51}$ work shows that solubility deceases with $\mathrm{NaCl}$. Heston et al. ${ }^{73}$ also showed that solubility decreases with salinity at high $\mathrm{pH}$. This effect will be discussed in subsequent chapters.

\subsubsection{Rate of Dissolution}

Although the extensive solubility measurements previously mentioned have contributed to a fairly comprehensive understanding of the themodynamics of quartz hydrolysis. its hinetirs 
and mechanisms are incompletely understood.

A common experimental framework for studying such kinetics is to observe the rate of dissolution of the pure oxide in heterogencous solutions. The rate of dissolution of the oxide may be controlled by either chemical or transport mechanisms.

Most of the theoretical models of silica speciation in aqueous solution proposed so far are based on the interpretation of experimental solubility measurements. These investigations support the hypothesis that $\mathrm{SiO}_{2}$ is present in aqueous solution primarily as a monomer species. One of the earliest efforts in studying the dissolution behavior of silica has been performed by Holt et al. ${ }^{85}$ They showed that under equilibrium conditions the water soluble form of silica is orthosilicic acid $\mathrm{Si}(\mathrm{OH})_{4}$. The rate at which orthosilicic acid goes into solution has been shown to be a function of the temperature, the degree of crystallinity, the surface area, the particle size and the amount of mechanical and heat treatment. Holt et al. ${ }^{85}$ expressed their results in terms of concentration of dissolved silica versus time (Figure 2-12).

The rate of dissolution of silica particle was also studied by Bergman and Paterson. ${ }^{86}$ Their results show that in each case the curve approached a straight line within the chosen period. Both the slope and intercept varied considerably for different graphs. However, these values and the presumed existence of "easily soluble layers" are subject to criticism because they were obtained by extrapolation of curves which are not linear. This anomalous solubility behavior of silica has been attributed to the existence of a disorganized amorphous layer on the surface of silica. Clelland and Rilchie ${ }^{87}$ reported that the thickness of the layer is between .02 and $.15 \mu \mathrm{m}$. This has been verified by Nagel Schmidt, Corden, and Griffin. ${ }^{88}$ However, Heavens ${ }^{89}$ using electron diffraction photographic methods on the surface of freshly fractured and acid washed quartz crystal, has proven the absence of any thick layer of noncrystalline silica. It has been shown that the unusual solubility characteristics have been observed after repeated extraction with water. Jotten and Pfefferkorn ${ }^{90}$ suggested that the initial rapid dissolution is due to existence of sharp corners and protruding edges. But a microscopic examination of different samples showed insufficiently small particles to account for the mass which dissolved rapidly. In general, it has been observed that plots of concentration versus time show an initial phase of rapid dissolution, after which the dissolution proceeds 


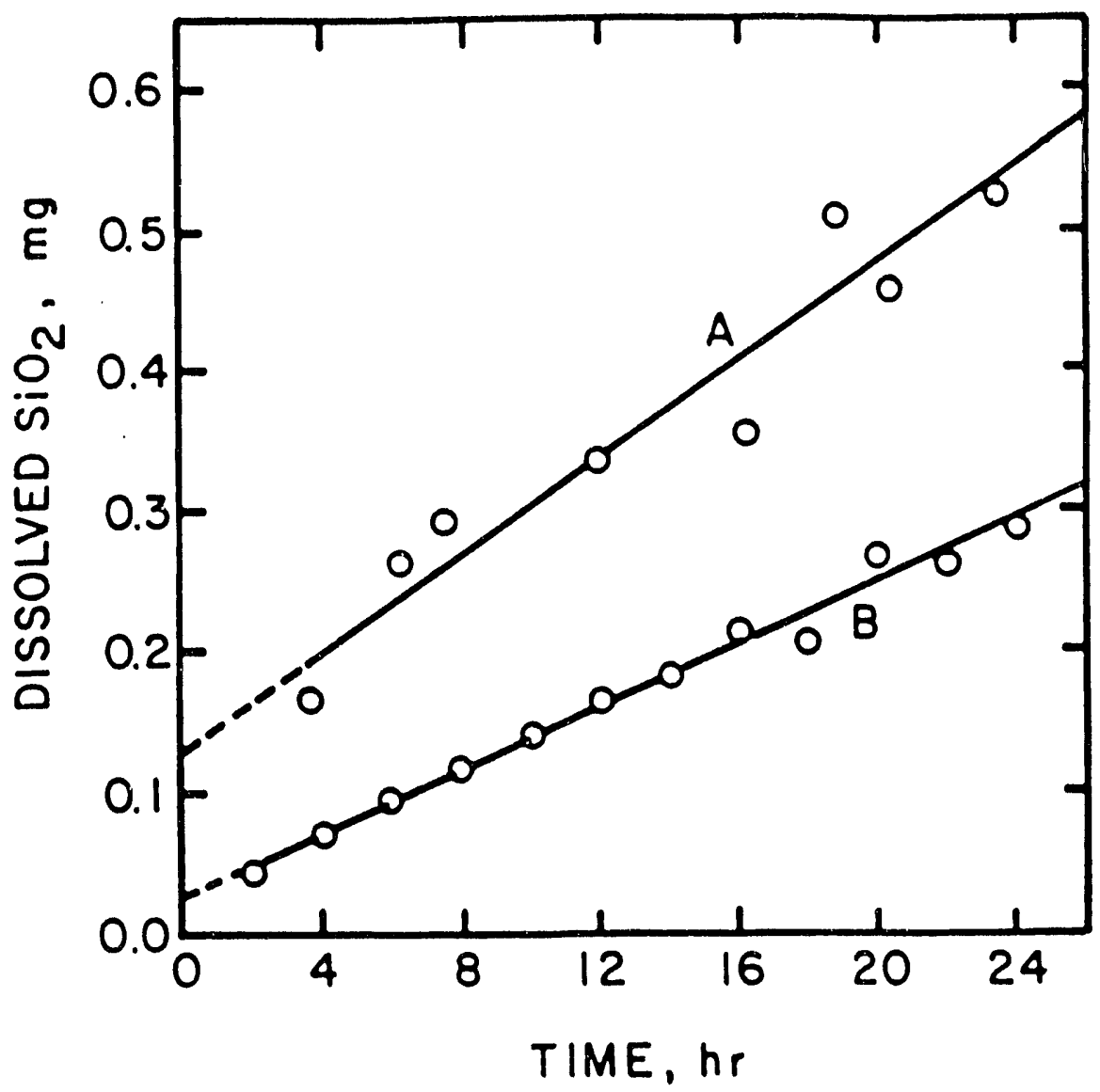

Figure 2.12: Rate of dissolution of silica powder in $0.1 \mathrm{~N}$-sodium hydroxide solution ${ }^{85}$. 
at a much lower rate. The results of the early studies by O'Connor and Greenberg ${ }^{53}$ showed $^{2}$ that the rate of silica dissolution can be represented as

$$
d C / d t=S\left(k_{1}-k_{2} C\right)
$$

where $C$ is the concentration of silica in solution $\left(\right.$ mole $\left./ \mathrm{cm}^{3}\right), S$ is the ratio of surface area of solid silica divided by volume of solution $\left(\mathrm{cm}^{-1}\right), k_{1}$ is the rate constant of dissolution (mole $\left./ \mathrm{cm}^{2} \mathrm{sec}\right)$, and $k_{2}$ is the rate constant of precipitation $(\mathrm{cm} / \mathrm{sec})$. Assuming that equilibrium exists, this equation can be rewritten as

$$
d C / d t=S k_{2}\left(C_{s a t}-C\right)
$$

where $C_{s a t}$ is the equilibrium concentration of $\mathrm{SiO}_{2}$. This equation could represent either chemical-, or diffusion-controlled process. ${ }^{91}$ However, it has been observed that the dissolution and precipitation rates of silica are affected by chemical components in the solution phase, such as hydroxyl ions, cations, and anions. This would point to a chemically controlled mechanism.

Stober ${ }^{92}$ measured the dissolution rate of quartz at $25^{\circ} \mathrm{C}$ and $\mathrm{pH} 8.4$ using a $\mathrm{NaHCO}_{3}$ buffer containing .03 mole/lit $\mathrm{Na}^{+}$. Figure 2-13 by Stober shows the dissolved silica concentration versus time (day) for various quartz samples having different specific surface area. It is shown that the dissolution patterns for equal exposed surface are similar, having final concentration between 11 and $13 \mu \mathrm{g} / \mathrm{cc}$ of dissolved silica. This value is equal to the solubility of silica at room temperature. Stober, however, did not agree that his data, which encompassed nearly the complete approach at equilibrium, could be successfully modeled using $\mathrm{O}^{\prime}$ Connor's model. ${ }^{53}$ He suggested that there is some retardation in the approach to equilibrium which he treated as adsorption of dissolved silicic acid.

Stober $^{92}$ also conducted experiment with quartz suspensions of different total available surface area from supersaturated solutions containing $83 \mu \mathrm{g}$ of silicic acid. He found that the silicic acid concentration decreases to different levels for different available surface area, due to adsorption of silicic acid on the quartz surface. Holt and King ${ }^{85}$ proved the existence of silicic acid by running an exchange reaction between a quartz suspension and dissolved labeled silicic acid. Henderson et al. ${ }^{93}$ measured quartz dissolution kinetics at $25^{\circ} \mathrm{C}$ over 


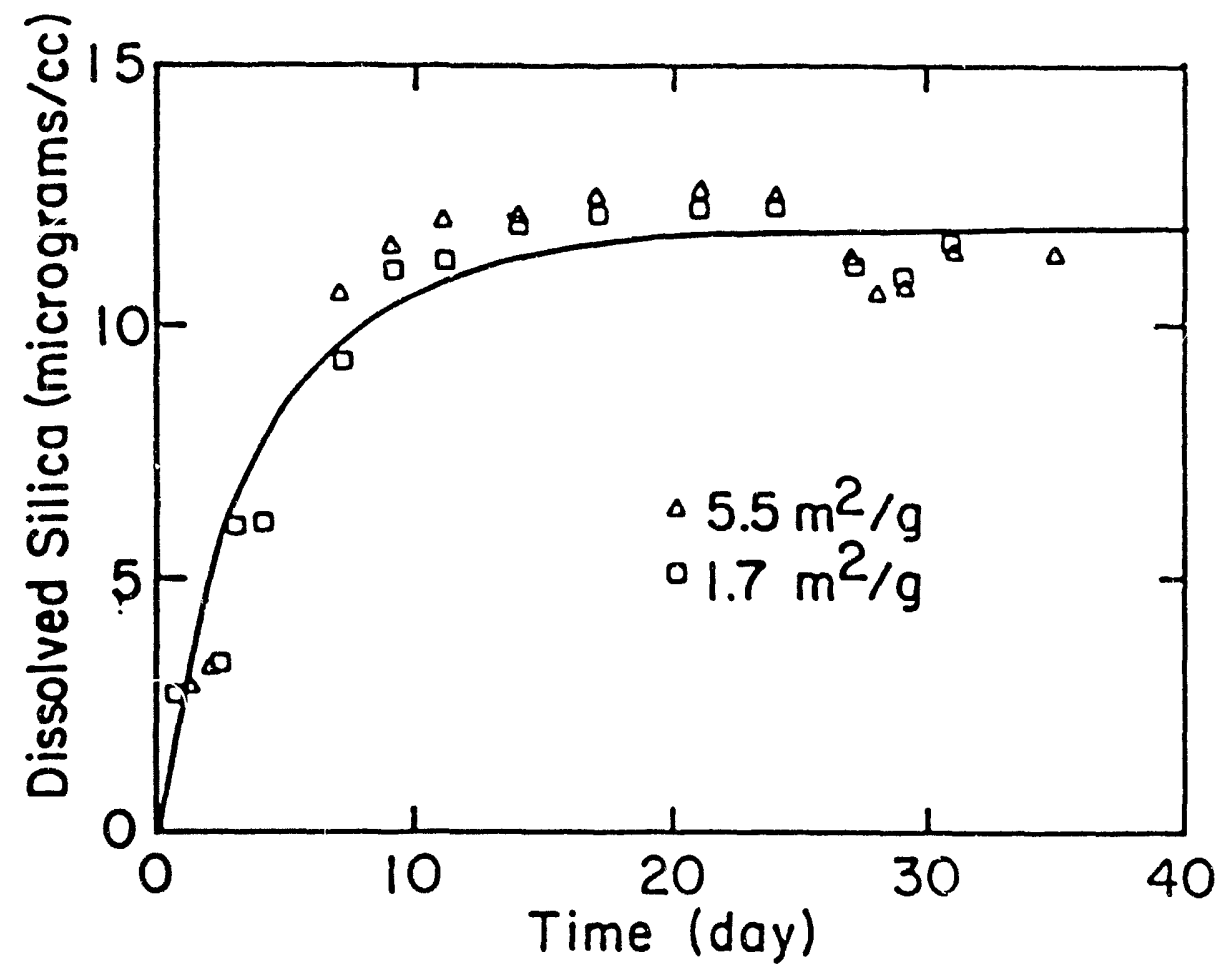

Figure 2.13: Dissolution obtained with quartz samples of different specific surface area. Total surface area Suspended in $500 \mathrm{ml}$. of solvent is $10 \mathrm{sq}$. meters ${ }^{92}$. 
the pH inter:al from $\mathrm{pH} \&$ to $\mathrm{pH} 10$. Their data suggest an increase in the dissolution rate with increasing $\mathrm{pH}$ over the entire $\mathrm{pH}$ range in experiments run with HF-treated quartz. Rimstidt and Barnes ${ }^{94}$ derived a differential rate equation similar to the one proposed earlier by $\mathrm{O}^{\circ}$ Connor and Greenberg. ${ }^{53}$ The basic assumption in their derivation is that the reactants must pass through a maximum free energy before they are converted to the products. The state defined by this maximum energy has been called the activated complex. The rate of reaction is assumed to be directly proportional to the concentration of the activated complex. And the rate determining step in the process is regarded as the decomposition of a surface configuration of atoms corresponding in stochiometry to 1 mole of $\mathrm{SiO}_{2}$ and 2 moles of $\mathrm{H}_{2} \mathrm{O}$. An activated complex with this stoichiometry is consistent with kinetic data reported by Van Lier, de Bruyn and Overbeek. ${ }^{67}$ However, other experimental data indicate a dependence of the rate of quartz dissolution on $\mathrm{pH}$ and on the activity of $\mathrm{Na}$ in solution. ${ }^{95}$ In their study, the activation energies for silica-water reactions were measured. The large measured activation energy $(60-70 \mathrm{~kJ} /$ mole) indicate that the rate limiting step is the breaking of strong Si-O bonds. Recently, similar experiments were done by Bird et al. ${ }^{96}$ Their results are in reasonably good agreement with those of Rimstidt and Barnes. ${ }^{94}$

The results of dissolution experiments at $70^{\circ} \mathrm{C}$ by Knauss et al..$^{97}$ show that the rate of quartz dissolution over the $\mathrm{pH}$ interval of 1 through 6 remains constant, while the rate of dissolution increases with increasing $\mathrm{pH}$ over the $\mathrm{pH}$ interval of 6 through 12 . They believe that there are at least two mechanisms (or at least two forms) for the activated complex controlling quartz hydrolysis over the pH interval investigated. The explanation offered by these authors is that at low $\mathrm{pH}$ (1 through approximately 6), only water is involved in breaking the $\mathrm{Si}-\mathrm{O}$ bond to form an activated complex on the surface of crystal. They speculate that over the $\mathrm{pH}$ range of 6 to $12, \mathrm{OH}^{-}$ion participates in the formation of the activated complex. Such an explanation is not in agreement with the model which is developed in this work.

The above review of the literature shows that much of the work carried out on silica dissolution needs re-interpretation and re-examination. Despite repeated attemps over the past several years to generate rate equations, little progress has been made towards a realistic interpretation of the experimental rates at which silicates dissolve in aqueous solutions, and 
none of the theoretical models, so far, accounts adequately for all experimental observations. This is the object of the next chapter, which deals at length with the development of a model for the dissolution of silica. 


\section{Chapter 3}

\section{Mechanistic Model of Silica}

\section{Dissolution}

This chapter deals at length with the development of a model for the dissolution of silica in a typical alkaline environment. Equilibrium ion exchange reactions at the silica surface are first ignored in this chapter, although they are later included in subsequent sections.

The results of dissolution experiments by Bunge et al. ${ }^{52}$ on various type of clay mineral and quartz at $\mathrm{pH} 13$ and $70^{\circ} \mathrm{C}$ show that the rate of dissolution of quartz is the highest compare to the other clay minerals. Although it has recently been shown that the dissolution of clay minerals might become significant, in this work the silica or quartz-alkali interaction is considered as an approximation to the interaction between real sandstone reservoirs and alkaline solutions.

In order to describe any type of oxide dissolution process, the composition and crystalline state of the oxide must be precisely known. This means that we have to know if the oxide is free from foreign ions that could influence dissolution process. Does the oxide possess long or short-range crystalline order? Are all sites at the surface at which dissolution proceeds structurally equivalent? Does dissolution proceed with identical rates at step, kick, edge, or surface sites on a crystal? Regardless of the site at which dissolution proceeds, the type of bonding present in the oxide, that is whether ionic or covalent, will to a large extent determine the activation energy, hence, the rate of dissolution.

It has been noted that oxides that, are network formers are predominantly covalent in 
character, have $\mathrm{M}-\mathrm{O}$ covalent- bond energy greater than $75 \mathrm{kcal} / \mathrm{mole}$ and can form random three dimensional networks. ${ }^{99-102}$ From ZPC (zero point charge) and IEP (isoelectric point) studies it was determined that as $\mathrm{M}-\mathrm{O}$ bonds become increasingly covalent, the $\mathrm{ZPC}$ becomes more acidic. Results of investigation by $\mathrm{Al}$ med ${ }^{103}$ show that $\mathrm{SiO}_{2}$ has acidic $\mathrm{ZPC}$ equal to 3.6. These observations, in addition to the previous measured activation energy, clearly illustrate that considerably high activation energy is required to break the $\mathrm{Si}-\mathrm{O}$ bond in the quartz crystal. Thus, one can expect that the dissolution process of quartz is limited or controlled by surface reaction. This in turn, means chat the dissolution behavior of silica is kinetically limited, and that the kinetic variables which are involved should be studied very carefully.

\subsection{Quantitative Model}

The dissolution of $\mathrm{SiO}_{2}$ is a complex process, requiring certain simplifying assumptions. Here, a quantitative model is proposed for the dissolution kinetics of quartz crystal. Sterlko's ${ }^{105}$ suggested dissolution mechanism and Stober's model have been utilized as a basic foundation. It has been reported by Taylor ${ }^{106}$ that the formation of quartz as well as the formation of metastable silica modification of higher levels of free energy requires activation energies of the order of $200 \mathrm{kcal} / \mathrm{mole}$. This condition has also been observed in all structural changes involving breaking and reorientation of the covalent Si-O-Si bonding of the solid framework of $\mathrm{SiO}_{4}$ tetrahedrons. This explains the existence of metastable forms of silica like tridymite, cristobalite, vitreous silica, coesite, and stishovite near room temperature, and also the low rate of dissolution of silica in neutral solution. It is proposed here that dissolution of silica in an aqueous solution proceeds through the stage of breaking up the siloxane Si-O-Si bonds. The breaking of Si-O bond has been viewed by Sterlko as a process of nucleophilic SN2 substitution. According to this mechanism, first the formation of an intermediate four center complex develops, as shown in Figure 3-1 This four-center complex, believed to be adsorbed silicic acid, is in dynamic equilibrium determined by the following elementary steps:

1. Dissociation of the complex by desorption of silicic acid into the solution (breaking of Si-O-Si bond). 


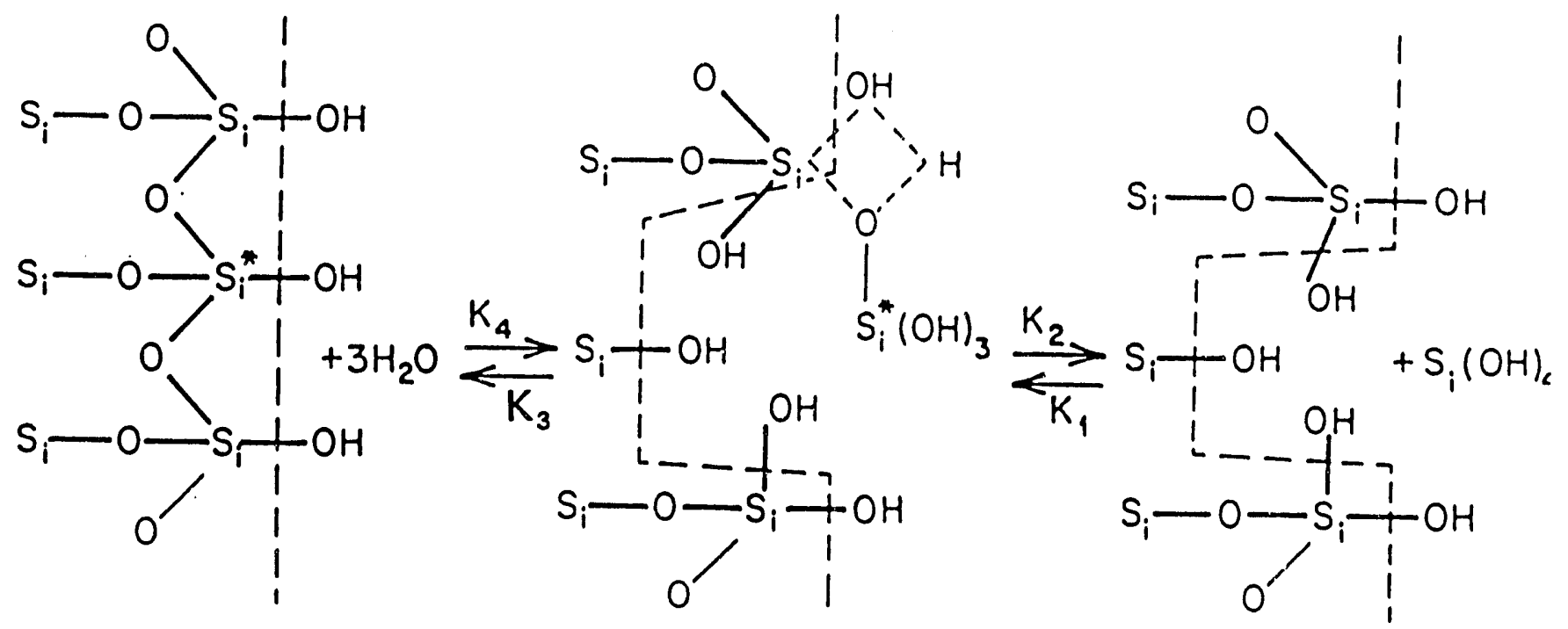

Figure 3.1: Schematic of the dissolution mechanism. 
2. Adsorption of $\mathrm{Si}(\mathrm{OH})_{4}$ from the solution to the silica interface.

3. Condensation of the complex into the surface and addition of $\mathrm{SiO}_{2}$ to the surface.

This model suggests that the important factor for dissolution is the Si-O bond strength. Thus, we consider the dissolution mechanism to occur in two elementary steps, one involving rapid formation of a complex or adsorbed silicic acid and another slower rate determining step (bond breakage) that governs the partition of the complex between the silica surface and solution. Existence of this complex has been proved by some workers. ${ }^{97}$ Holt $^{85}$ showed that silicic acid in solution in a borate buffer at $\mathrm{pH} \delta$ would adsorb on to the surface of a quartz powder and would exchange with a layer of silicic acid adsorbed on the quartz.

Another important chemical reaction that occurs at the silica surface in aqueous media is the acid base reaction involving association- dissociation of hydrogen or hydroxyl ions. This reaction imparts a charge on the silica surface. The surface charge of silica has been extensively investigated by many researchers and will be discussed in great detail in the next chapter. We shall note that the model was also described in a previous publication (Saneie and Yortsos $\left.{ }^{141}\right)$.

\subsection{Formulation}

Denoting by $\left.n_{(} c\right), n_{0}$ the surface concentrations of the complex and the available active sites, respectively, and by $C_{a}$ the silicic acid concentration in solution we obtain the following mass action kinetics. In the absence of subsequent reactions of silicic acid in the solution, that is for neutral $\mathrm{pH}$, the mathematical model is formulated as follows:

$$
\begin{aligned}
\frac{d n_{c}}{d t} & =\left(k_{1} C_{a}+k_{4}\right)\left(n_{o}-n_{c}\right)-\left(k_{2}+k_{3}\right) n_{c} \\
\frac{d C_{a}}{d t} & =\left(k_{2} n_{c}-k_{1} C_{a}\left(n_{o}-n_{c}\right)\right) \frac{A}{V}
\end{aligned}
$$

where $A / V$ is the available surface area of silica per unit solution volume, and the kinetic constants $k_{i}(i=1,2,3,4)$ correspond to the rate processes between complex and solution $(i=1,2)$ and surface and complex $(i=3,4)$. 
When hydrolysis and ionization reactions are considered, the above equations are supplemented by a set of thermodynamic equilibrium conditions involving the various ionic species present. For step (1) being the fast step we have:

$$
\begin{aligned}
\frac{d n_{c}}{d t} & =0 \\
\frac{d C_{a}}{d t} & =\frac{A n_{0} k_{2} k_{4}}{V\left(k_{2}+k_{3}+k_{4}\right)} \frac{\left(1-\left(k_{3} k_{1} / k_{2} k_{4}\right) C_{a}\right)}{1+k_{1} /\left(k_{2}+k_{3}+k_{4}\right) C_{a}}
\end{aligned}
$$

The above equation (3.4), determining the rate of silica dissolution in neutral pH, was solved to obtain the equilibrium value of silicic acid concentration, $C_{a e}$. The latter is

$$
C_{a e}=\frac{k_{2} k_{4}}{k_{1} k_{3}}
$$

If, we further define

$$
K_{1}=\frac{k_{1}}{k_{2}+k_{3}+k_{4}}, \quad K_{4}=\frac{k_{4}}{k_{2}+k_{3}+k_{4}}
$$

the rate of dissolution simplifies

$$
\frac{d C_{a}}{d t}=\frac{A}{V} n_{o} k_{2} K_{4} \frac{1-C_{a} / C_{a e}}{1+K_{1} C_{a}}
$$

The solution of equation (3.6) is trivially obtained as

$$
A / V n_{o} k_{2} K_{4} C_{a e} t=-K_{1} C_{a}-\left(1+K_{1} C_{a e}\right) \ln \frac{C_{a e}-C_{a}}{C_{a e}}
$$

At large value of $A / V$, this expression for the rate of silica dissolution is identical to Stober's. Taking a best fit estimate of reported experimental data at room temperature (Figure 2-13) we obtain the following values for kinetic constants.

$$
C_{a e}=12 \mu \mathrm{gr} / \mathrm{cc}, \quad K_{1}=1.53 \mathrm{cc} / \mu \mathrm{gr}, \quad k_{2} K_{4}=.4041 / \mathrm{day}
$$

\subsubsection{Dissolution in Alkaline Media}

In this section, we consider possible hydrolysis and ionization reactions of silicic species in solution, thus implicitly accounting for the effect of $\mathrm{pH}$ on the rate of silica dissolution and hydroxyl ion consumption.

The following ionization reactions proposed by Kopeykin and Mikaylov ${ }^{79}$ are used 


$$
\begin{aligned}
\mathrm{Si}(\mathrm{OH})_{4} & \rightarrow \mathrm{SiO}_{4} \mathrm{H}_{3}^{-}+\mathrm{H}^{+} \\
\mathrm{SiO}_{4} \mathrm{H}_{3}^{-} & \rightarrow \mathrm{SiO}_{4} \mathrm{H}_{2}^{2-}+\mathrm{H}^{+} \\
\mathrm{SiO}_{4} \mathrm{H}_{2}^{2-} & \rightarrow \mathrm{SiO}_{4} \mathrm{H}^{3-}+\mathrm{H}^{+} \\
\mathrm{SiO}_{4} \mathrm{H}^{3-} & \rightarrow \mathrm{SiO}_{4}^{4-}+\mathrm{H}^{+} \\
\mathrm{SiO}_{3} \mathrm{H}_{2}+\mathrm{H}_{2} \mathrm{O} & \rightarrow \mathrm{SiO}_{4} \mathrm{H}_{4} \\
\mathrm{SiO}_{3} \mathrm{H}_{2} & \rightarrow \mathrm{SiO}_{3} \mathrm{H}^{-}+\mathrm{H}^{+} \\
\mathrm{SiO}_{3} \mathrm{H}^{-} & \rightarrow \mathrm{SiO}_{3}^{2-}+\mathrm{H}^{+}
\end{aligned}
$$

Although, as reported by many investigators, the concentration of polynuclear species is significant at high silica concentration and low $\mathrm{pH},{ }^{107-110}$ for the range of $\mathrm{pH}$ and low total dissolved silica of interest in this work their presence is neglected. It must be noted that their presence does not affect the relative concentrations of the mononuclear ions, although it does increase the total dissolved silica. This might become significant in practical applications of alkaline flooding.

To proceed, we define the total concentration of dissolved silica

$$
C=\mathrm{SiO}_{4} \mathrm{H}_{4}+\mathrm{SiO}_{4} \mathrm{H}_{3}^{-}+\mathrm{SiO}_{4} \mathrm{H}_{2}^{-2}+\mathrm{SiO}_{4} \mathrm{H}^{-3}+\mathrm{SiO}_{4}^{-4}+\mathrm{SiO}_{3} \mathrm{H}_{2}+\mathrm{SiO}_{3} \mathrm{H}^{-}+\mathrm{SiO}_{3}^{-2}
$$

which shows that the actual solubility of quartz is the summation of the concentrations of all of the produced silicate species. At neutral $\mathrm{pH}$, all of the silica in solution is undissociated silicic acid. As the $\mathrm{pH}$ increases, however, the concentration of the other silicate ions becomes significant, and silicic acid is progressively removed from the system. In turn, as more and more silicic acid is removed by the increasing $\mathrm{pH}$, more and more silica dissolves in the system.

The data available in the literature on the structure of silicate ions formed upon complete dissolution of silica in alkalis confirm the fact that these ions cannot participate in the back reaction in which new $\mathrm{Si}-\mathrm{O}$ bonds are formed. ${ }^{105}$ This implies that when the $\mathrm{pH}$ level increases, generated silicate ions and the ionized $\mathrm{Si}^{-} \mathrm{O}^{-}$surface group appearing in the system are not capable of participating in the back reaction, which, therefore results in a shift of equilibrium to the right. 
Next, we proceed to develop a model that also accounts for subsequent reactions of silicic: acid in solution, in order to provide an expression for the rate of silica dissolution as well as for the hydroxyl ion consumption. To carry out this task, material balances are written for all of the produced silicate ions as follows:

$$
\begin{aligned}
\frac{d C_{a}}{d t} & =\frac{A n_{0} k_{2} K_{4}\left(1-C_{a} / C_{a e}\right)}{V\left(1+K_{1} C_{a}\right)}+r_{-1}-r_{1}+r_{5} T r_{-5} \\
\frac{d C_{b}}{d t} & =r_{1}-r_{-1}-r_{2}+r_{-2} \\
\frac{d C_{c}}{d t} & =r_{2}-r_{-2}-r_{3}+r_{-3} \\
\frac{d C_{d}}{d t} & =r_{3}-r_{-3}-r_{4}+r_{-4} \\
\frac{d C_{j}}{d t} & =r_{4}-r_{-4} \\
\frac{d C_{f}}{d t} & =r_{-5}-r_{5}+r_{-6}+r_{-6} \\
\frac{d C_{g}}{d t} & =r_{6}-r_{-6}+r_{-7}-r_{7}-r_{-7}-r_{8}-r_{-8} \\
\frac{d C_{i}}{d t} & =r_{7}-r_{-7}
\end{aligned}
$$

In the above, $r_{i}$ and $r_{-i}$ represent rates of forward and backward reactions, respectively, while subscripts $a, b, c, d, j, f, g$ and $i$ refer to the species $\mathrm{SiO}_{4} \mathrm{H}_{4}, \mathrm{SiO}_{4} \mathrm{H}_{3}^{-}, \mathrm{SiO}_{4} \mathrm{H}_{2}^{-2}, \mathrm{SiO}_{4} \mathrm{H}^{-3}, \mathrm{SiO}_{4}$, $\mathrm{SiO}_{3} \mathrm{H}_{2}, \mathrm{SiO}_{3} \mathrm{H}^{-}$, and $\mathrm{SiO}_{3}^{-2}$, respectively.

All these reactions, being ionic in nature, are assumed to be in equilibrium. The corresponding equilibrium products are:

$$
\begin{array}{ll}
K_{e 1}=\frac{C_{h} C_{b}}{C_{a}}, \quad k_{e 2}=\frac{C_{h} C_{c}}{C_{b}}, & K_{e 3}=\frac{C_{h} C_{d}}{C_{e}} \\
K_{e 4}=\frac{C_{h} C_{j}}{C_{d}}, & K_{e 5}=\frac{C_{a}}{C_{f}}, \quad K_{e 6}=\frac{C_{h} C_{g}}{C_{f}}, \quad K_{e 7}=\frac{C_{h} C_{i}}{C_{g}}
\end{array}
$$

Experimental studies and theoretical considerations suggest that no significant error is introduced by regarding the activity coefficient of the aqueous silica and of water in dilute aqueous electrolyte solutions as unity. ${ }^{102-108}$ Therefore, in this work $C_{i}$ denotes concentration rather than activity. Combining all of the equations representing the material balance for the produced silicate ions (3.16 through 3.23 ), results into the following

$$
\frac{d C}{d t}=\frac{A n_{0} k_{2} K_{4}}{V} \frac{\left(1-C_{a} / C_{a e}\right)}{\left(1+K_{1} C_{a}\right)}
$$


where

$$
C=C_{a}+C_{b}+C_{c}+C_{d}+C_{j}+C_{f}+C_{g}+C_{i}
$$

Along with the electroneutrality balance

$$
C_{N a}+C_{H}=C_{b}+2 C_{c}+3 C_{d}+4 C_{j}+C_{g}+2 C_{i}+C_{O H}+C_{c l}
$$

The above equations were solved simultaneously.

In the above, we have allowed for brine salinity by accounting for the presence of chloride in the electroneutrality balance. In a solution at equilibrium, the silicate species partition according to the above, with $C_{a}$ equal to $C_{a e}$. At neutral $\mathrm{pH}$, all of the silica in solution is undissociated silicic acid, while as the $\mathrm{pH}$ increases, the concentrations of other silicate ions also become significant.

The above equations provide expressions for the rate of $\mathrm{OH}^{-}$ion consumption as well as the rate of silica dissolution for a batch system in the absence of ion exchange. The distinctive features of the model are that the rate of dissolution can be expressed in terms of $\mathrm{pH}$ level, available surface area, volume, time, number of ionization reactions of silicic acid in the solution.

Substituting the corresponding values for silicate ions in terms of the hydrogen ion concentration equation (3.26) yields the following:

$$
\begin{aligned}
C_{H} & =C_{a}\left[K_{e 1} / C_{H}+2 K_{e 1} K_{e 2} / C_{H}^{2}+3 K_{e 1} K_{e 2} K_{e 3} / C_{H}^{3}\right. \\
& \left.+4 K_{e 1} K_{e 2} K_{e 3} K_{e 4} / C_{E^{r}}^{4}+K_{e 6}^{\prime} / K_{e 5} 1 / C_{H}+2 K_{6} K_{7} / K_{5} 1 / C_{H}^{2}\right]+K_{w} / C_{H}-C_{N(3}
\end{aligned}
$$

where $K_{w}$ is the water dissociation constant.

$$
K_{w}=C_{H} C_{O H}
$$

For convenience, we may also further define

$$
\begin{aligned}
& P K_{1}=K_{e 1} / C_{H} \\
& P K_{2}=K_{e 1} K_{e 2} / C_{H}^{2} \\
& P K_{3}=K_{e 1}^{\prime} K_{e 2} K_{e 3} / C_{H}^{3} \\
& P K_{4}=K_{e 1}^{\prime} K_{e 2} K_{e 3} K_{e 4} / C_{H}^{4}
\end{aligned}
$$




$$
\begin{aligned}
& P K_{5}=K_{e 6} /\left(K_{e 5} C_{H}\right) \\
& P K_{6}=2 K_{e 6} K_{e 7} /\left(K_{e 5} C_{H}^{2}\right) \\
& P K_{7}=1 / K_{e 5}
\end{aligned}
$$

and

$$
\begin{aligned}
T P & =P K_{1}+2 P K_{2}+3 P K_{3}+4 P K_{4}+P K_{5}+2 P K_{6} \\
T P 1 & =P K_{1}+4 P K_{2}+9 P K_{3}+16 P K_{4}+P K_{5}+4 P K_{6} \\
T P 2 & =1+P K_{1}+P K_{2}+P K_{3}+P K_{4}+P K_{5}+P K_{6}+P K_{7}
\end{aligned}
$$

The total dissolved silica and the silicic acid are functions of hydrogen ion concentration according to the foliowing relationships:

$$
\begin{aligned}
C_{u} & =\left(C_{H}-K_{w} / C_{H}+C_{N a} / T P\right. \\
C & =C_{a} T P 2
\end{aligned}
$$

therefore,

$$
\begin{aligned}
\frac{d C_{a}}{d C_{H}} & =\frac{\left(1+K_{w} / C_{H}^{2}\right)(T P)-d T P / d C_{H}\left(C_{H}-C_{O H}+C_{N a}\right)}{T P^{2}} \\
\frac{d C}{d C_{H}} & =C_{a} d(T P 2) / d C_{H}+d C_{a} / d C_{H}(T P 2)
\end{aligned}
$$

where

$$
\begin{aligned}
\frac{d(T P)}{d C_{H}} & =\frac{-T P 1}{C_{H}} \\
\frac{d(T P 2)}{d C_{H}} & =\frac{-T P}{C_{H}}
\end{aligned}
$$

Thus, according to equation (3.24) one finally obtains:

$$
\frac{d C}{d t}=F\left(C_{a}\right)
$$

Alternatively, we may express the above as

$$
\frac{d C}{d C_{H}} \cdot \frac{d C_{H}}{d t}=F\left(C_{H}\right)
$$


where the dependence of $C$ and $C_{a}$ on $C_{H}$ is implicitly given above.

$$
\begin{aligned}
C & =G\left(C_{a}, C_{H}\right) \\
C_{a} & =F\left(C_{H}\right)
\end{aligned}
$$

By further denoting $C=Z, C_{a}=Y^{\prime}, C_{H}=X^{\prime} \mathrm{t}^{\prime}$ rate of dissolution is expressed as

$$
\frac{\left(1+K_{1} Y\right)}{(1+b Y)} d Z=A_{c} d t
$$

where we have denoted

$$
\begin{aligned}
b & =-1 / C_{a e} \\
A_{c} & =\left[A n_{o} k_{2} K_{4}\right] /\left[V\left(k_{2}+k_{3}+k_{4}\right)\right]
\end{aligned}
$$

Therefore, by simple expansion, we finally get

$$
\frac{\left(K_{1} F(X)+1\right)}{1+b F(X)}\left[\frac{\partial G \partial F}{\partial Y \partial X}+\frac{\partial G}{\partial X}\right] d X=A_{c} d t
$$

and, in compact notation

$$
H(X) d X=d t
$$

The latter can be integrated to give:

$$
t=\int_{X_{1}}^{X} H(X) d X
$$

For a batch process in the absence of ion exchange, the above equations can be used to simulate the batch performance of a system, where solid silica is exposed to an aqueous solution of fixed initial alkalinity $\left(\mathrm{pH}_{i}\right)$. The final equilibrium values can be calculated directly from the electroneutrality balance and thermodynamic equilibria with $C_{a}=C_{a e}$ and $C_{N a}$ held constant. The time required to reach to equilibrium is obtained by integration of $(3.51)$.

Numerical solutions of this equation give the values of the hydrogen ion concentration versus time for different values of original $\mathrm{pH}$, specific area, temperature, shape and size of the silica particle. 


\subsection{Theoretical Predictions}

\subsubsection{Effect of the Number of Ionization Reactions}

Typical values for equilibrium hydrogen ion concentration, total dissolved silica and the time required to reach equilibrium as a function of number of ionization reactions are shown in Table 3-1. It is observed that dissolved silica decreases with an increase in the number of reactions, while the hydrogen ion concentration or the hydroxyl ion consumption increases. This effect is more pronounced at higher original pH level, where the rate of change of $\mathrm{OH}^{-}$ concentration is not necessarily equal to the rate of change of dissolved silica concentration.

\subsubsection{Effect of $\mathrm{pH}$}

The effect of the initial pH on the total dissolved silica, and its time dependence is shown in - Figure 3-2 for typical values corresponding to room temperature $\left(24^{\circ} \mathrm{C}\right)$. It is noted that the total dissolved silica, the rate of silica consumption as well as the time to reach equilibrium, all increase with an increase in the initial $\mathrm{pH}$. The slope of the curve at the origin is finite and different than zero, suggesting a first order reaction scheme at low silica concentrations. As the dissolution process continues, the rate of dissolution decreases until equilibrium is eventually reached. But the longer tinies required for equilibrium at higher initial $\mathrm{pH}$ reflect the ultimately higher amount of total dissolved silica, not lower rates. Similar plots for the evolution of the pH are shown in Figure 3-3, which portrays similar behavior. Also plotted in Figure 3-3 are experimental results by Southwick. ${ }^{49}$ Fairly good agreement is noted with the present model for the numerical values $n_{0}=6.25 \mathrm{~mole} / \mathrm{m}^{2}$ and specific surface area of 1 $\mathrm{m}^{2} / \mathrm{gr}$. However additional evidence is necessary for the validation of the present model.

Figure 3-4 presents equilibrium values of $\mathrm{pH}$ versus different values of original $\mathrm{pH}$ level at room temperature. As noticed, due to the low solubility of quartz which leads to low concentration of produced silicate ions even at high $\mathrm{pH}$ level, there is no significant drop of equilibrium pH. Figures 3-5a and 3-5b also illustrate the behavior of total dissolved silica (mole/lit) for various values of initial pH. These figures show that the solubility of silica increases significantly with increasing initial pH level. 


\begin{tabular}{|c|c|c|c||}
\hline $\begin{array}{c}\text { Initial } \\
\mathbf{p H}\end{array}$ & $\begin{array}{c}\text { Number of } \\
\text { Reactions }\end{array}$ & $\begin{array}{c}\text { Total Dissolved } \\
\text { Silica } \\
\text { Mole/Lit }\end{array}$ & $\begin{array}{c}\text { Equilibrium } \\
\mathbf{p H}\end{array}$ \\
\hline \hline 11 & 1 & $8.83 \times 10^{-4}$ & 10.38 \\
\hline 11 & 7 & $8.83 \times 10^{-4}$ & 10.38 \\
\hline 12.5 & 1 & $2.41 \times 10^{-2}$ & 11.88 \\
\hline 12.5 & 7 & $2.26 \times 10^{-2}$ & 11.78 \\
\hline
\end{tabular}

Table 3.1: Effect of the number of reastions on total dissolved silica and equilibrium values of $\mathrm{pH}$. 


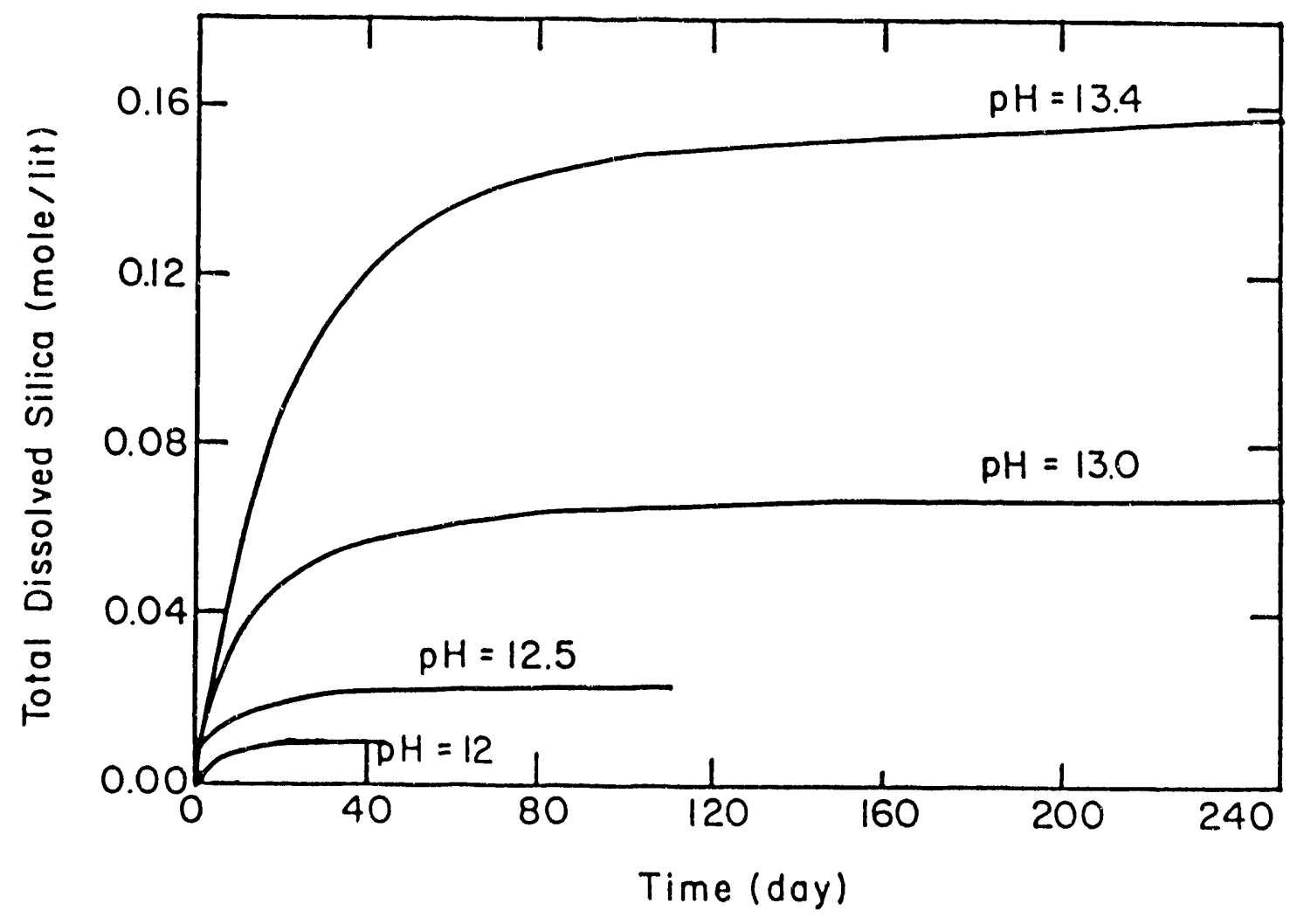

Figure 3.2: Effect of the initial $\mathrm{pH}$ on the time required to reach equilibrium $\mathrm{pH}$ and the total dissolved silica at $T=24^{\circ} \mathrm{C}$. 


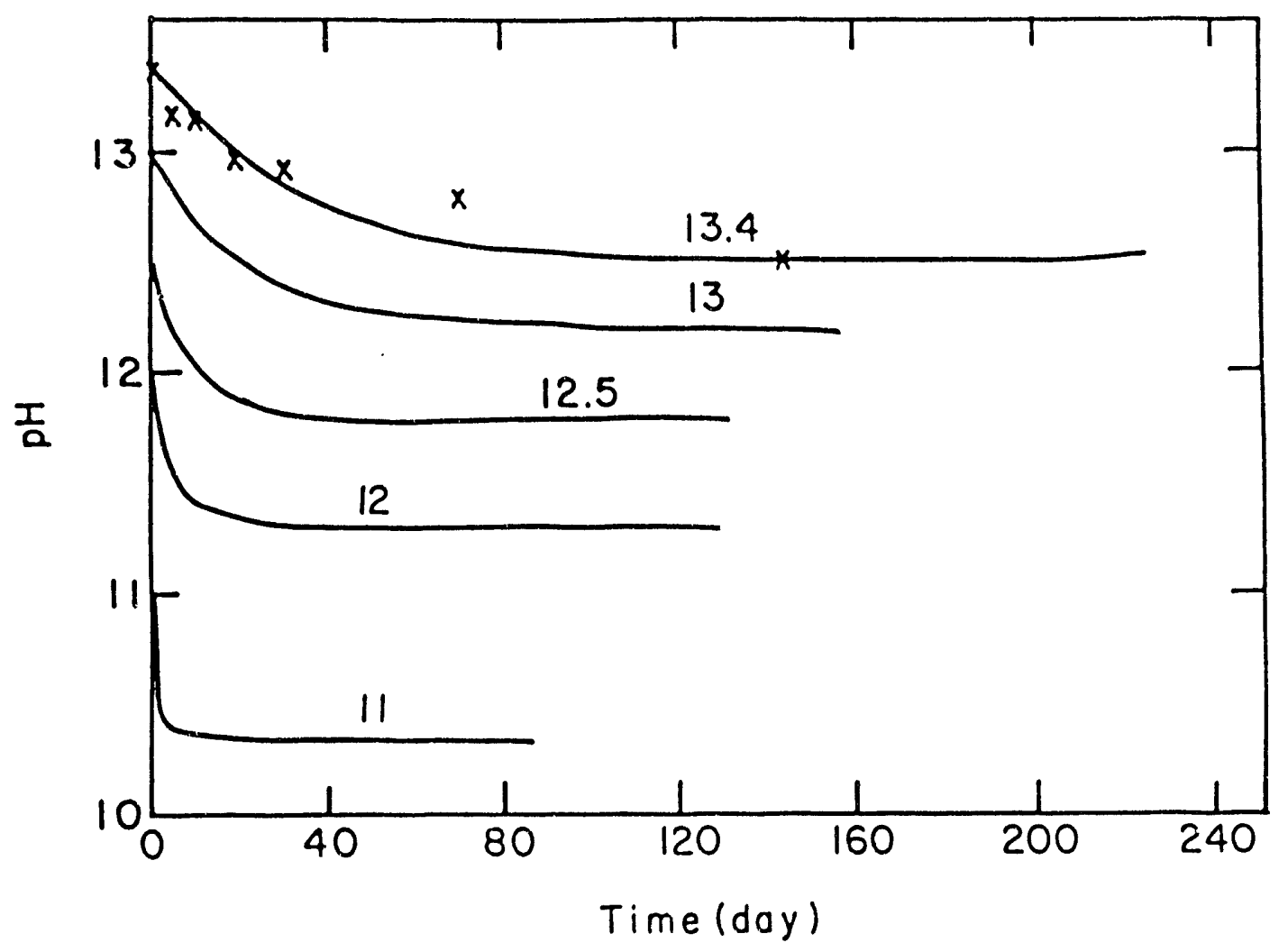

Figure 3.3: Effect of the initial $\mathrm{pH}$ on the time required to reach equilibrium at $T=24^{\circ} \mathrm{C}$. 


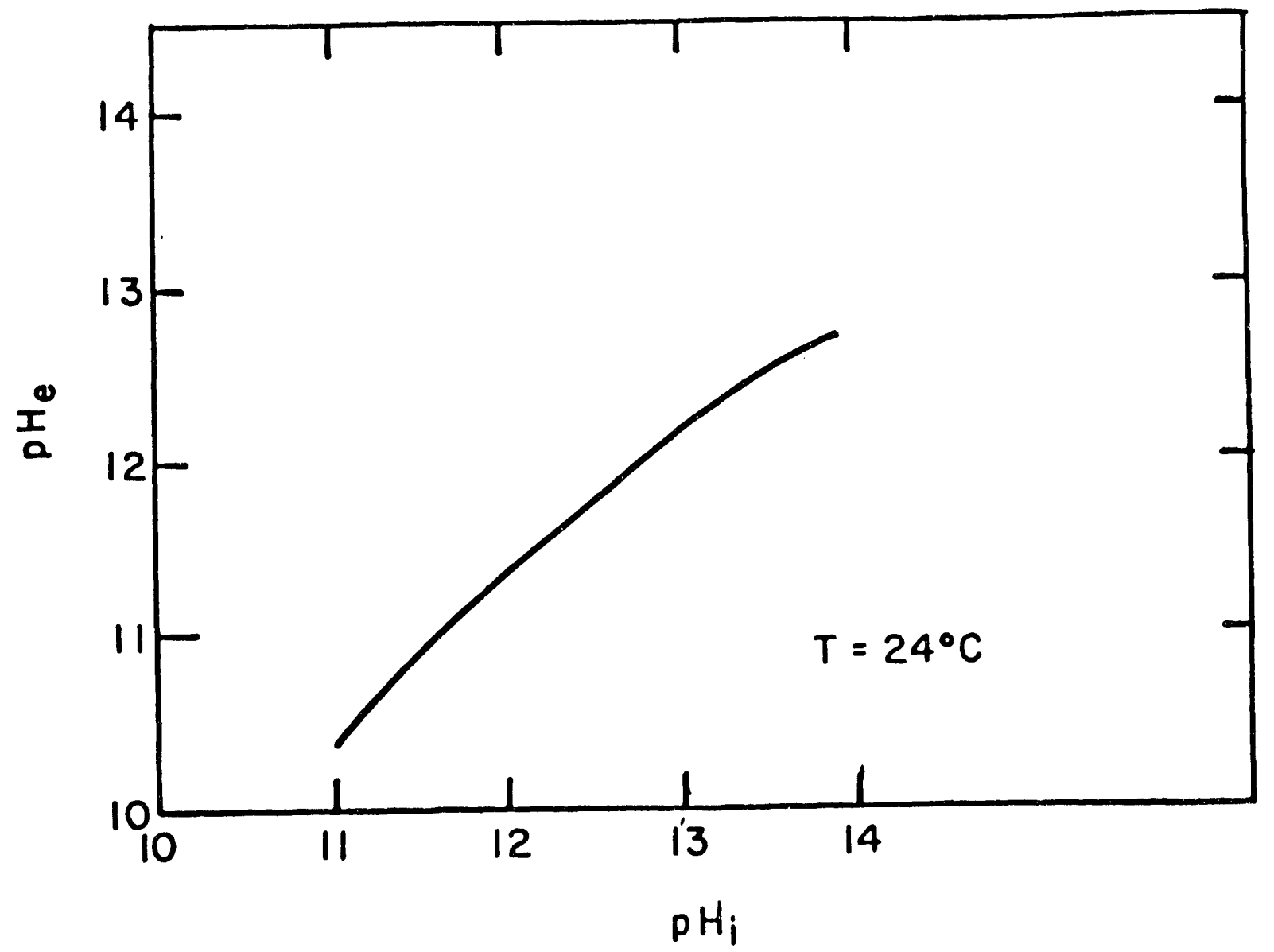

Figure 3.4: Equilibrium values of $\mathrm{PH}$ versus different values of initial $\mathrm{pH}$ at room temperature. 

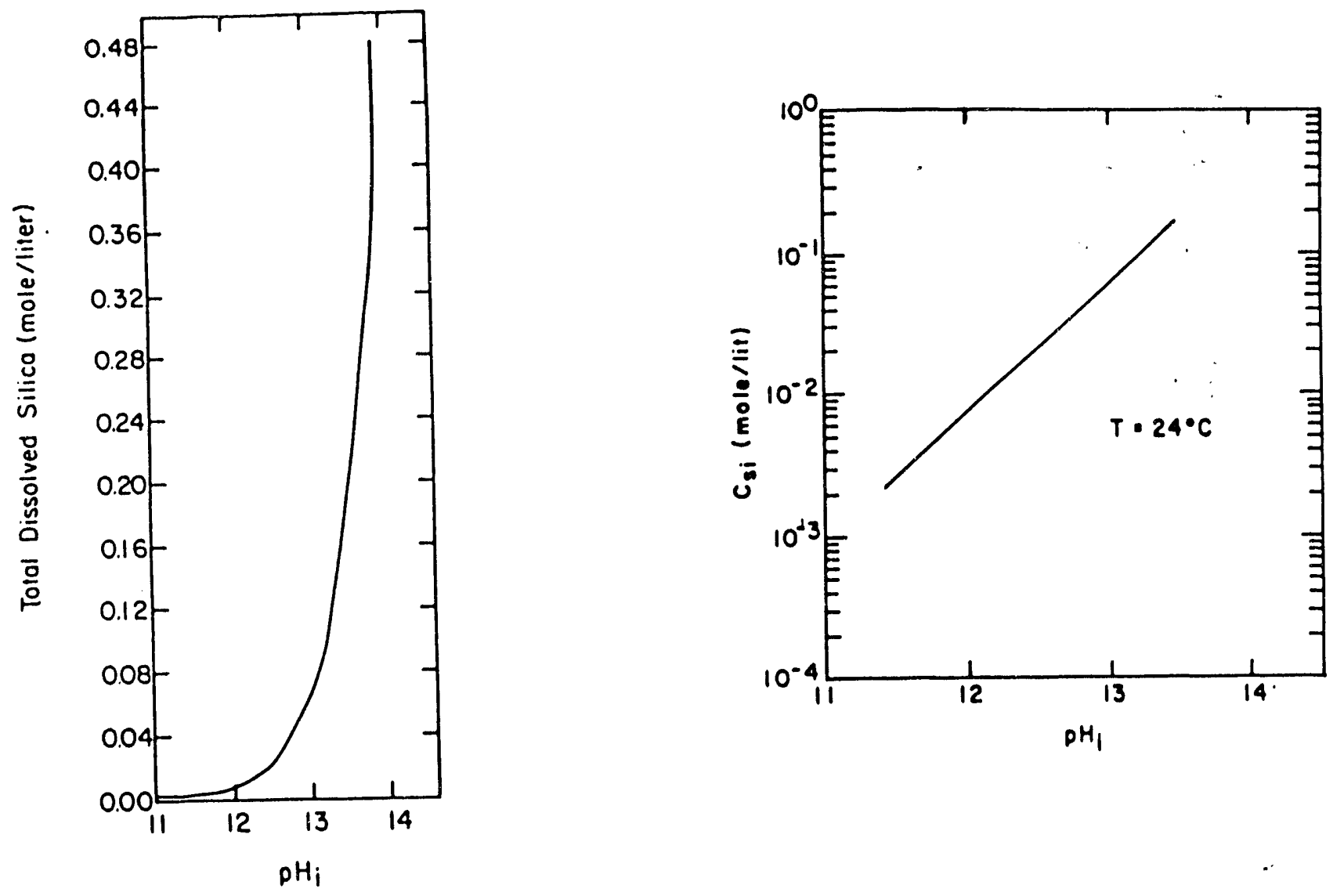

Figure 3.5: Total dissolved silica versus different values of initial $\mathrm{pH}$ at room temperature. 


\subsubsection{Efiect of Specific Area}

The principal assumption in the model developed here is that the complex formation step is rapid, and that the silicic acid adsorption-desorption is rate determining. One sigaificance of this assumption is that it leads to kinetics that are sensitive to the surface area of silica, specifically to the ratio of surface to solution volume.

Figure 3-6 presents the effect of area/vol ratio on the dissolution behavior of silica. It is shown that the time required to reach equilibrium is very sensitive to this ratio. At high values, equilibrium is reached at relatively short periods of time. This means that extrapolation of short time dissolution rates to reservoir times as proposed earlier ${ }^{52}$ will result into an overestimation of $\mathrm{OH}^{-}$loss. ${ }^{50}$

Consequently, it is inferred that capillary-like geometries, equilibrium is reached faster in smaller radius capillaries, while the opposite is true for spherical-like particles. In the latter case, complete dissolution of particles is likely, before thermodynamic equilibrium is reached (the system is undersaturated).

\subsubsection{Effect of Temperature}

The model obtained can also be used to determine the effect of temperature on the kinetic constants, by comparison with experimental results at higher temperatures. To carry out this work, knowledge of the temperature dependence on the ionization constant of silicic acid is essential. Limited data are available for the first and second ionization constants of silicic acid, while no data are available for the rest of the ionization reactions. To examine temperature effects, the following relationships have been utilized

$$
\begin{aligned}
K_{e 1} & =\frac{3405.9}{T}-6.368+.016346 T \\
K_{e 2} & =\frac{8949.2}{T}-33.11+.049581 T \\
\log C_{a} & =.151-1162 T^{-1}
\end{aligned}
$$

These suggest that the solubility of silica increases dramatically with increasing temperature. ${ }^{67}$

Dehghani's experiment (Figure 3-7) on hydroxyl ion consumption by sandstone at high temperature showed that the equilibrium can be reached in a few days. However, as showed 


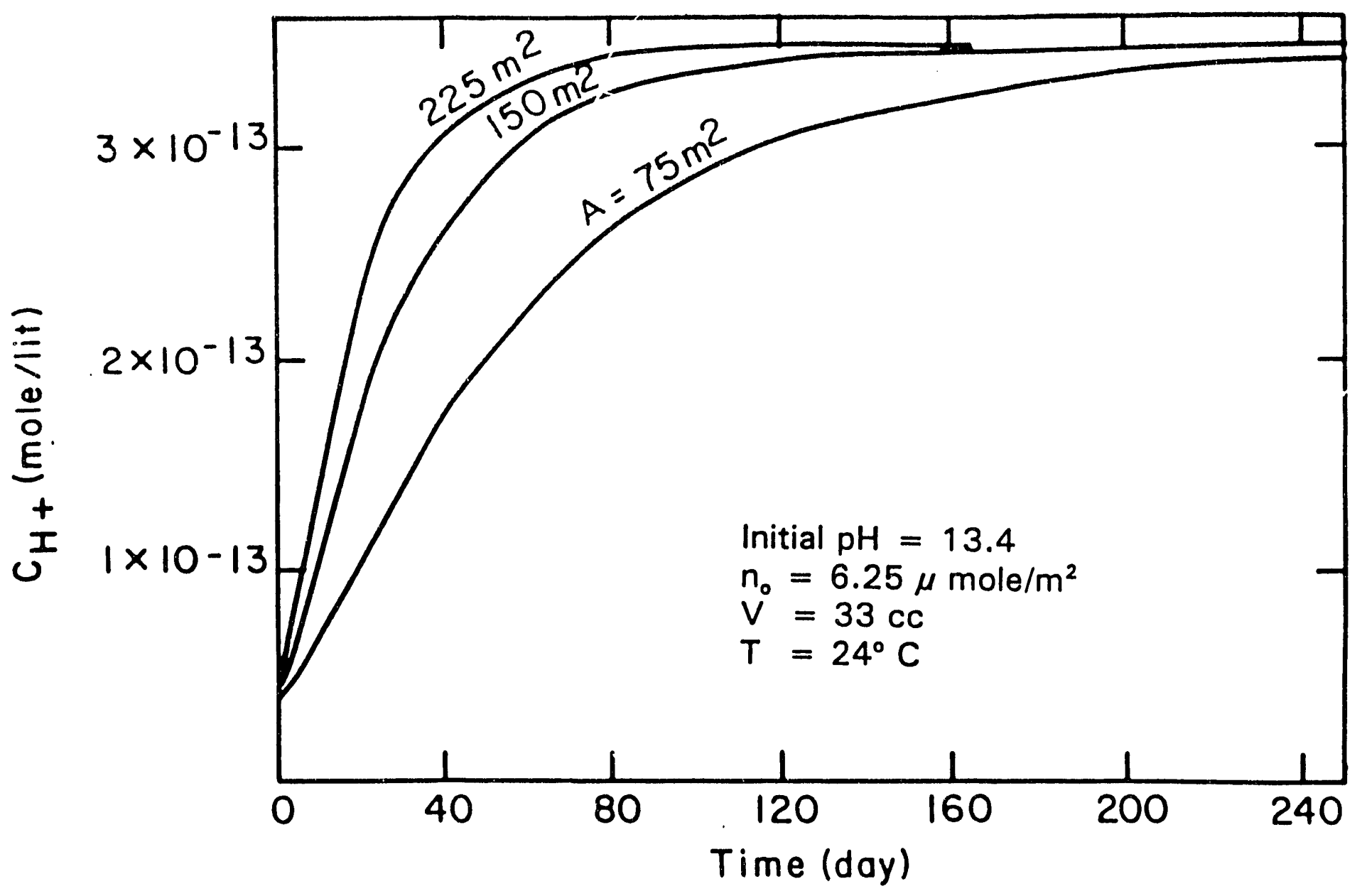

Figure 3.6: Effect of area/volume ratio on the time required for equilibrium. 
earlier it could take months or even years to reach to the equilibrium at room temperature. Comparing the model with experimental data by Dehghani ${ }^{50}$ at $\mathrm{T}=150^{\circ} \mathrm{C}$ resulted in the following values for the kinetic constants (in parentheses are the values obtained at $24^{\circ}(y)$

$$
\begin{gathered}
K_{1}=\frac{k_{1}}{k_{2}+k_{3}+k_{4}}=.004(1.5) \\
k_{2} K_{4}=\frac{k_{2} k_{4}}{k_{2}+k_{3}+k_{4}}=\delta(.404)(\text { day })^{-1}
\end{gathered}
$$

The relation between final (equilibrium) and initial $\mathrm{pH}$ values is shown in Figure 3-8 for two temperatures. For processes at room temperature we observe an almost linear dependence. A similar relationship appears to also exist for higher process temperatures, although for the latter case only two ionization reactions were considered, due to lack of experimental information. This figure also shows that if caustic is to be used as a steam additive in steam injection and if the objective is the sustained propagation in a sandstone reservoir of high enough $\mathrm{pH}$ values, such process has questionable validity at high temperatures, where the final equilibrium $\mathrm{pH}$ is considerably reduced. On the other hand, in contrast to $\mathrm{pH}$, the total amount of dissolved silica at equilibrium appears not to vary significantly with temperature, for high enough values of $\mathrm{pH}_{i}$ (Figure 3-9). This finding is somewhat surprising, since it implies that silica solubility, measured in terms of total dissolved silica, increases with temperature, only for low initial $\mathrm{pH}$ values and it is practically insensitive to temperature for high $\mathrm{pH}_{i}$ values. Thus, for alkaline solutions of high initial $\mathrm{pH}$, the effect of increasing process temperatures in a batch system is to reduce the equilibrium $\mathrm{pH}$, thus, increasing the $\mathrm{OH}^{-}$loss, while keeping the total silica solubility approximately constant. It is clear that equilibrium values of $\mathrm{pH}$ and silica solubility in such systems follow a different temperature dependence.

This behavior can be explained by equations (3.40). According to these, total dissolved silica is defined as the product of two terms, the solubility of silica in pure water at a given temperature multiplied by another term (TP2), which is a function of the equilibrium constant of ionization reactions as well as the activity of $\mathrm{OH}^{-}$. Although solubility in pure water increases with temperature, the value of (TP2), for certain range of $\mathrm{pH}$ and temperature, seems to decrease with temperature. At low range of $\mathrm{pH}$ and high temperature, the solubility 


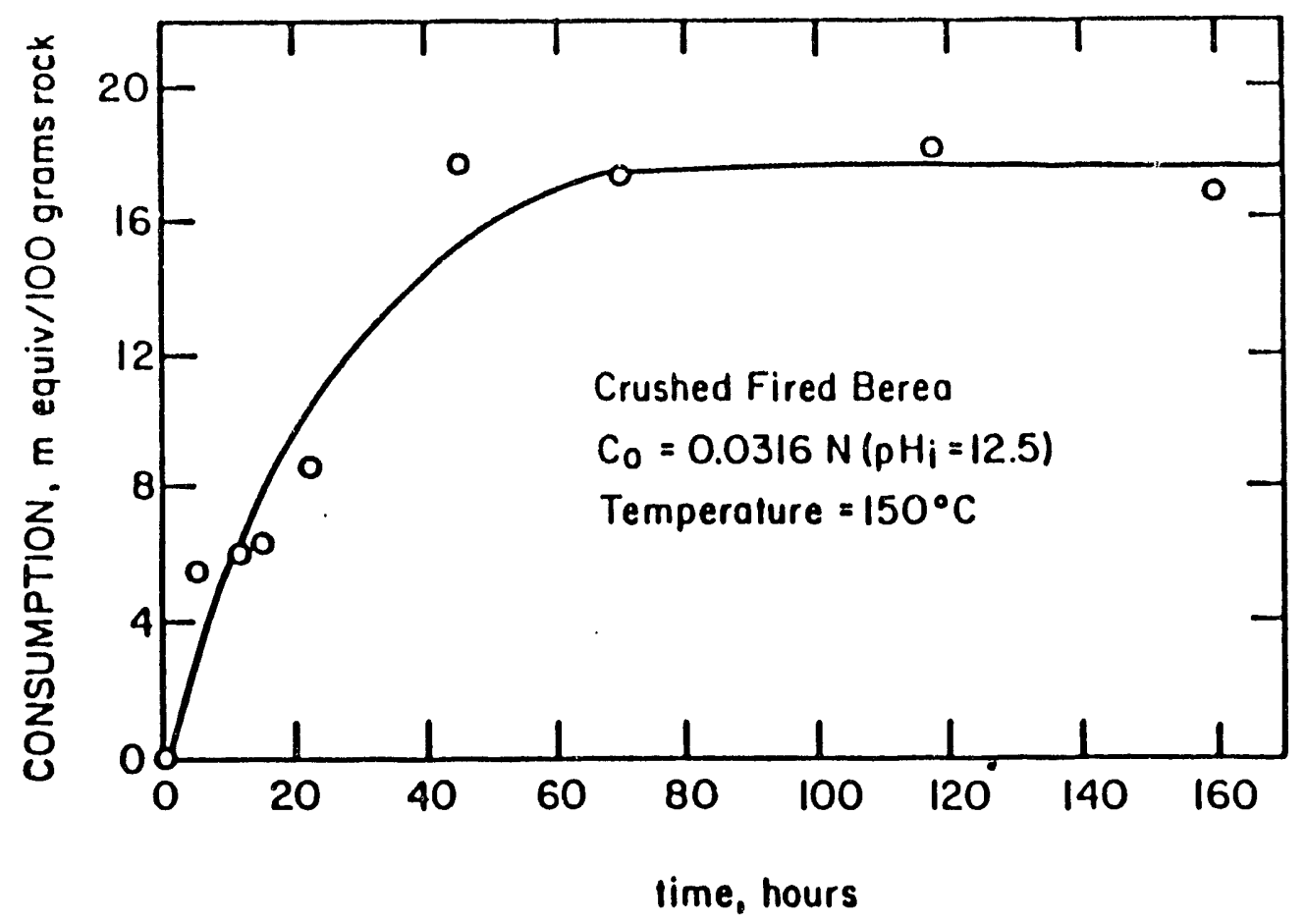

Figure 3.7: Hydroxyl ion consumption with crushed fired brea sandstone ${ }^{50}$. 


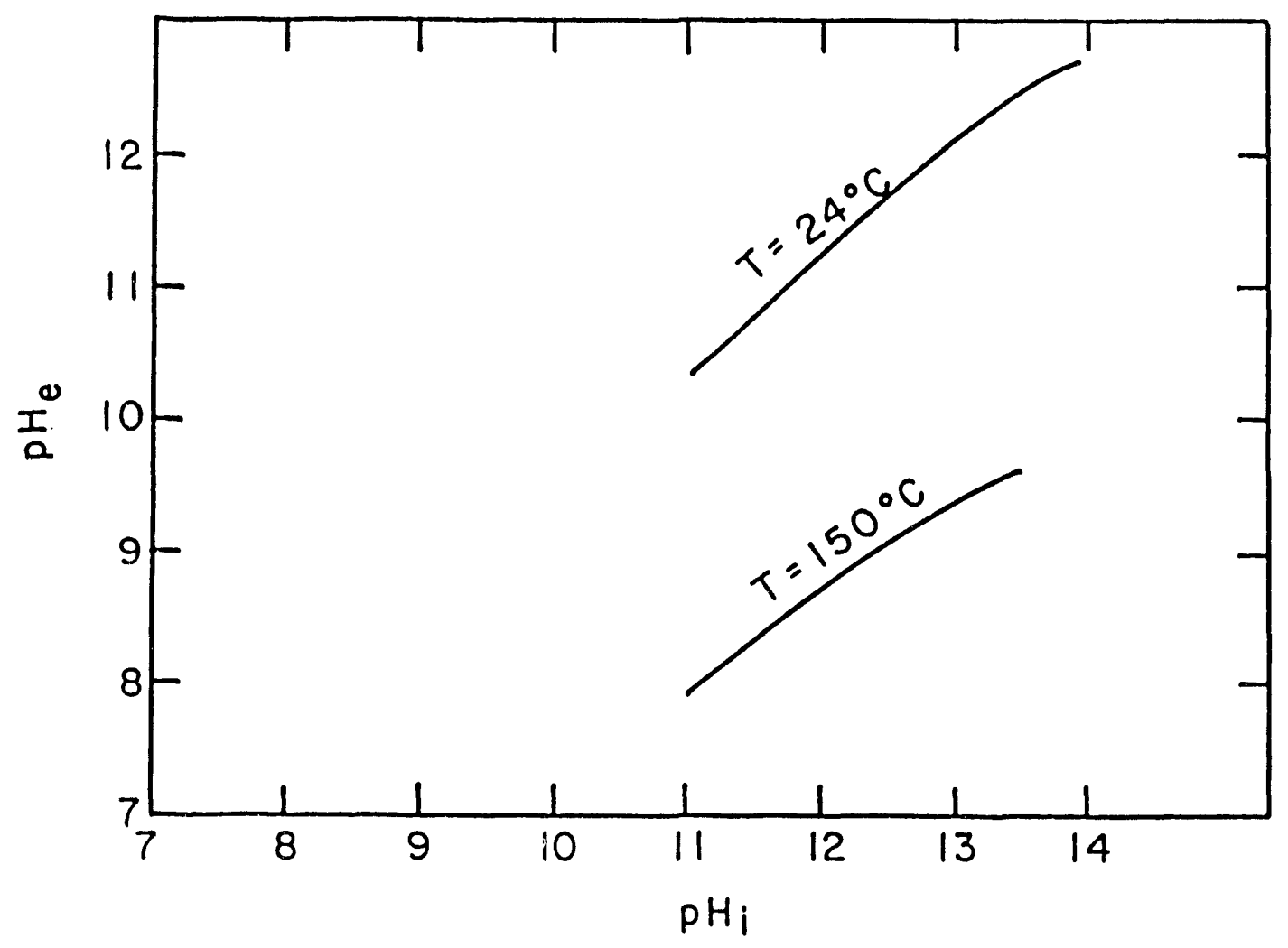

Figure 3.8: Effect of temperature on the equilibrium value of $\mathrm{pH}$. 


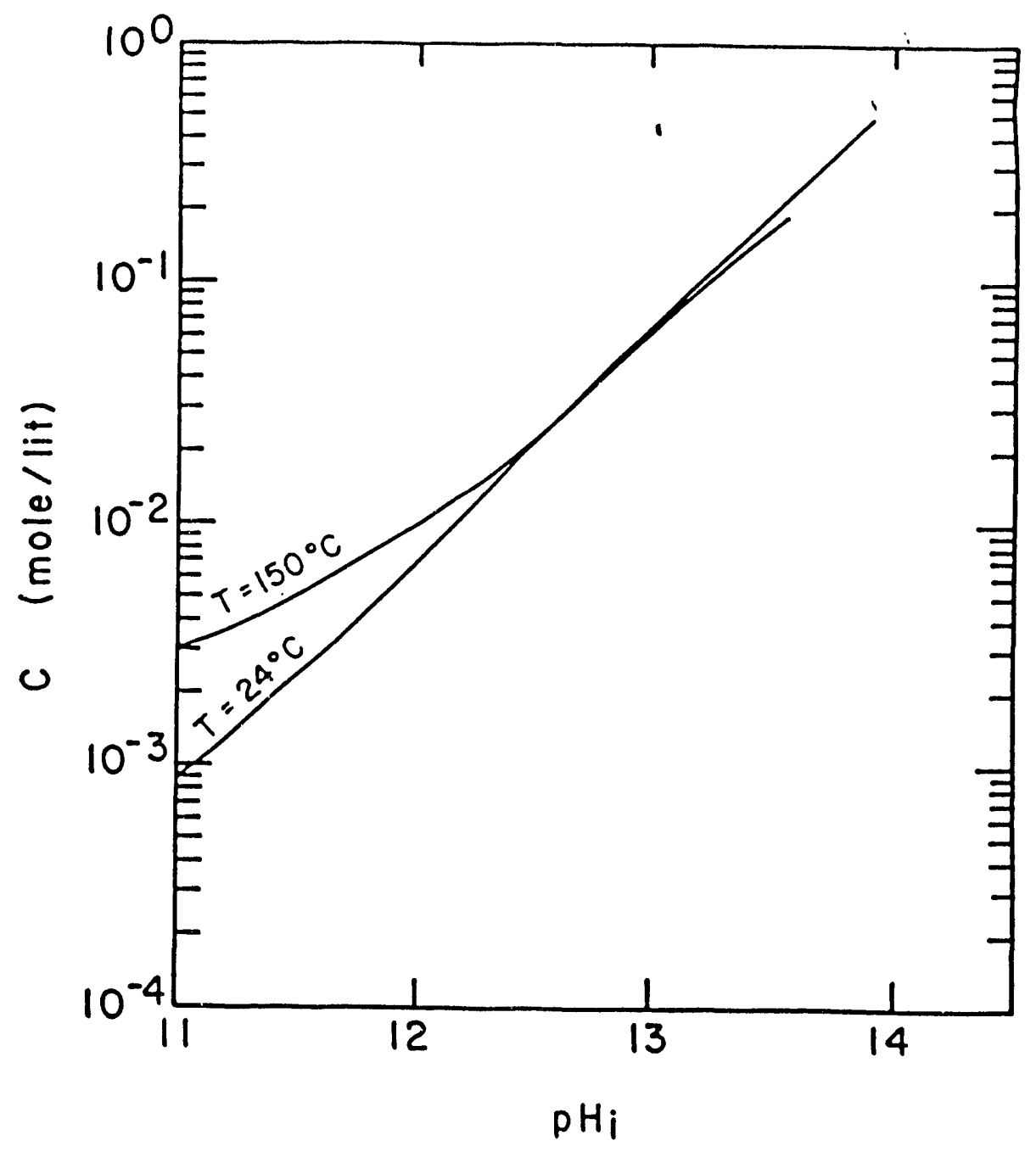

Figure 3.9: Total dissolved silica versus different values of initial $\mathrm{pH}$ at at $24^{\circ} \mathrm{C}$ and $150^{\circ} \mathrm{C}$. 
of silica is the dominant effect, while at higher $\mathrm{pH}$ values and low temperature, hydrolysis and ionization reactions of silicic species are important.

Implicit in the preceding discussion is the assumption that the contribution of the ionization reactions (3.10)-(3.14) is negligible for the determination of the equilibrium values for pH and total dissolved silica. Although we are unable to support this hypothesis for higher process temperatures, sufficient data exist for a conclusive test for room temperature processes. As discussed earlier (Table 3-1), reaction time, equilibrium pH and total dissolved silica are practically dominated by the first ionization reaction (3.8), particularly for lower values of $\mathrm{pH}_{i}$. This effect is not surprising, since at the rather low equilibrium $\mathrm{pH}$ values the contribution of reactions (3.10)-(3.14) to the partition of the silicic species is negligible. Similar trends for the higher process temperature are anticipated.

It should be pointed out that, since present $\mathrm{pH}$ electrode technology does not allow for accurate $\mathrm{pH}$ measurement at high temperatures, the available experimental data to date have been collected by increasing the $\mathrm{pH}$ of the solution after it has been cooled to room temperature. For a meaningful quantitative study of the effect of the temperature on silica dissolution, it is necessary to adjust the available experimental results to the respective values corresponding to higher temperature. This process can be readily implemented if the temperature dependence of the equilibrium constants is known, provided that the total amount of dissolved silica remains constant. The validity of the hypothesis is questionable, as during the cooling process some dissolved silica is expected to precipitate from the solution. On the other hand as will be discussed in the following section hydoxyl ion consumption due to silica dissolution under static conditons is overstimated due to the fact that the loss due to ion exchange can not be differentiated from the loss due to dissolution.

In summary, the numerical results of this model showed that dissolution reaction generates in situ significant amount of sodium silicates, which depend on the original $\mathrm{pH}$, the temperature. A summary of the phase trajectories in batch processes with zero initial dissolved silica at room tempetature $\left(T=24^{\circ} \mathrm{C}\right)$ is shown in Figure 3-10. Such diagrams are helpful in determining the evolution of batch systems when the initial solution consists of alkali and soluble silicates, as suggested by Krumrine. ${ }^{51}$ Given the values of the initial pH and the total dissolved silica, the relevant trajectory can be identified and followed until 
equilibrium is reached.

\subsection{Silica Dissolution In The Presence of Ion Exchange}

Previous investigations considered dissolution and ion exchange individually. However, since both phenomena occur in alkaline flooding, this section expands on the previous model to account for ion exchange as well as the dissolution of silica in alkaline media.

When a soluble oxide is added to an electrolyte solution, the following reactions occur: ${ }^{120-127}$

a-Hydrolysis and complex formation of the surface atoms and dissociation of the surface groups as a primary step.

b- Dissolution of the oxide leading to secondary reactions such as hydrolysis, complex formation, dissociation of the dissolved complex, adsorption of the dissolved complex on the surface, and also precipitation.

Whereas the primary equilibrium of the surface with the potential determining ions $\left(\mathrm{H}^{+}\right.$ and $\left.\mathrm{OH}^{-}\right)$is known to be complete within minutes after the addition of the oxide to the solution, secondary reactions arising from the solubility of the material are known to be very slow and may last for days and weeks. The primary oxide - solution equilibrium (fast, type a) depends on the dissociation constants of the surface $\mathrm{OH}$ groups in contact with the electrolyte solutions. In this section we focus on the primary surface reaction or fast replacement of hydrogen ion by sodium ion on the silica surface.

\subsubsection{Model Development and Formulation}

For the case of alkaline flooding, the sodium ion participates in an ion exchange process with the hydrogen ion on the silica surface. Therefore, the sites available for ion exchange are also candidates for complex formation that leads to silica dissolution, suggesting that a competition between ion exchange and dissolution is possible.

For simplicity, in this work a simple ion exchange reaction, previously proposed and investigated for California Wilmington and Huntington sands, has been employed. This model qualitatively reveals all the essential features of the more complicated treatment proposed by Davis et al ${ }^{28}$ and Yates et al. ${ }^{129}$ According to this approach, the mechanism for the 


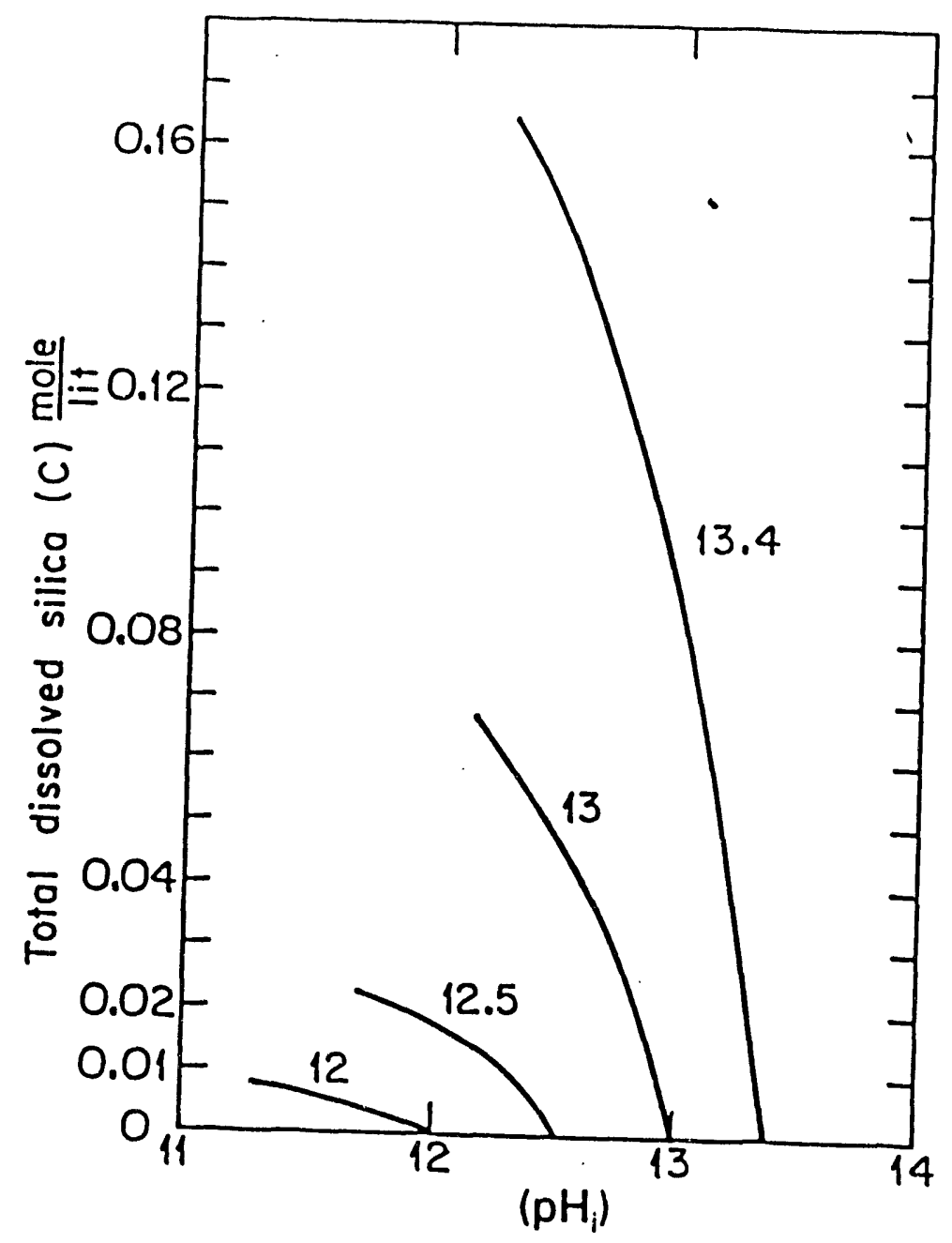

Figure 3.10: Phase trajectories in batch processes for various values of initial $\mathrm{pH}\left(T=24^{\circ} \mathrm{C}\right)$. 
reversible rock alkali interaction can be described as follows:

$$
\begin{gathered}
\mathrm{MoH}+\mathrm{Na}^{+}=\mathrm{MoN}_{\mathrm{a}}+\mathrm{H}^{+} \\
\mathrm{H}^{+}+\mathrm{OH}^{-}=\mathrm{H}_{2} \mathrm{O}
\end{gathered}
$$

$\mathrm{MoH}$ represents available hydroxylated site on the surface of silica. This mechanisrn, known to be fast and reversible, represents simultaneous and equal uptake of sodium and hydroxyl ion. However, Novasad \& Novasad ${ }^{130}$ noted that the local ion exchange equilibrium does not establish at fast flow rate. Their experimental results show that ion exchange can be a kinetically slow reaction under normal core flood conditions, implying that the kinetics of ion exchange should be included when alkaline floods are modelled.

In the present model, the surface is neutral, bulk and surface concentrations are equal. Using the law of mass action kinetics we get

$$
n_{N a}=\frac{n_{o} K_{I}\left[\mathrm{Na}^{+}\right]}{\left[\mathrm{H}^{+}\right]+K_{I}\left[\mathrm{Na}^{+}\right]}
$$

Values between $10^{-12}$ to $10^{6}$ have been reported for the ion exchange dissociation constant, $K_{l}{ }^{131}$

In the above hydroxyl ion consumption increases as either $\mathrm{pH}$ or salt concentration increases. ancreasing the $\mathrm{pH}$ or salt (sodium ion) concentration shifts the equilibrium towards increased dissociation of surface groups. However, in most adsorption measurements, the adsorption isotherm is measured relative to a reference or initial state $\left(n_{N a}^{o}\right)$. What the dynamic method or static bottle method actually measures is $\left(n_{N a}-n_{N a}^{o}\right)$. Bunge ${ }^{131}$ has shown that the effect of salt concentration on the change and direction of hydroxyl ion uptake depends on the reference $\mathrm{pH}$ and on the specific adsorption isotherm curves. Therefore, an apparent contradiction to this conclusion can arise.

When ion exchange is present, the previously derived equations for the rate of complex formation and silica dissolution must be modified as follows. Let $n_{c}, n_{N}, C_{N a}, C_{N a i}$ denote adsorbed silicic acid (complex), adsorbed sodium ion, sodium ion concentration, and initial sodium ion concentration respectively, The mass balance for the complex on the surface is now written as follows: 


$$
d n_{c} / d t=\left(k_{1} C_{a}+k_{4}\right)\left(n_{o}-n_{c}-n_{N}\right)-\left(k_{2}+k_{3}\right) n_{c}
$$

or

$$
d n_{c} / d t=-n_{c}\left[k_{1} C_{a}+k_{4}+k_{2}+k_{3}\right]-\left(k_{1} C_{a}+k_{4}\right)\left(n_{0}-n_{N}\right)
$$

As discussed earlier $d n_{c} / d t=0$, thus

$$
n_{c}\left[1+K_{1} C_{a}\right]=\left(n_{o}-n_{N}\right)\left[K_{4}+K_{1} C_{a}\right]
$$

and

$$
n_{N}=\frac{K_{l}\left[n_{o}-n_{c}\right] C_{N a}}{C_{H}+K_{l} C_{N a}}
$$

where

$$
\begin{aligned}
& K_{4}=k_{4} /\left(k_{2}+k_{3}+k_{4}\right) \\
& K_{1}=k_{1} /\left(k_{2}+k_{3}+k_{4}\right)
\end{aligned}
$$

Further, if we define $K_{a}=K_{l}\left(1-K_{4}\right)$, substitution of (3.63) into (3.62) results into:

$$
n_{c}=\frac{n_{0} C_{H}\left[K_{4}+K_{1} C_{a}\right]}{C_{H}\left(1+K_{1} C_{a}\right)+K_{a} N}
$$

and

$$
n_{N}=\frac{n_{o} K_{a} C_{N a}}{C_{H}\left(1+K_{1} C_{a}\right)+K_{a} C_{N a}}
$$

Note that $K_{a}=0$ results into $n_{N}=0$, and

$$
n_{c}=\frac{n_{o}\left[K_{4}+K_{1} C_{a}\right]}{\left(1+K_{1} C_{a}\right)}
$$

Thus,

$$
n_{N}+n_{c}=\frac{n_{0}}{C_{H}\left(1+K_{1} C_{a}\right) k+K_{a} C_{N a}}\left[K_{a}+C_{H} K_{4}+C_{H} K_{1} C_{a}\right]
$$

A mass balance on species $C_{N a}$ yields

$$
C_{N a i}-C_{N a}=A / V n_{N}
$$

Substituting equation 3.65 into the above yields the following

$$
\left(C_{N a i}-C_{N a}\right)\left[C_{H}\left(1+K_{1} C_{a}\right)+K_{a} C_{N a}\right]=A / V n_{o} K_{a} C_{N a}
$$


or

$$
K_{a} C_{N a}^{2}+C_{N a}\left[A / V n_{o} K_{a}+C_{H}\left(1+K_{1} C_{a}\right)-K_{a} C_{N a i}\right]-C_{N a i} C_{H}\left(1+K_{1} C_{a}\right)=0
$$

It can be easily inferred from the above equation that, as long as $C_{a} 0$, there exists only one positive root which determines the value for sodium ion concentration at any time during the course of dissolution.

Denoting the salinity concentration by $C_{C L}$, from electroneutrality we obtain

$$
C_{a}=\left(C_{H}+C_{N a}-C_{O H}-C_{C L}\right) / T P\left(C_{H}\right)
$$

Substituting into equation (3.69) we further find

$$
\begin{gathered}
C_{N a}^{2}\left[K_{a}+K_{1} C_{H} / T P\right]+C_{N a}\left[A / V n_{o} K_{a}+C_{H}\left(1+K_{1} / T P\left(C_{H}-C_{O H}-C_{C L}\right)\right.\right. \\
\left.\left.-C_{N a i}\left(K_{a}+K_{1} C_{H} / T P\right)\right)\right]-C_{N a i} C_{H}\left(1+K_{1}\left(C_{H}-C_{O H}-C_{C L}\right) / T P\right)=0
\end{gathered}
$$

At equilibrium $C_{H}=C_{H e}$ and $C_{a}=C_{a e}$ hence

$$
K_{a} C_{N a e}^{2}+C_{N a e}\left[A / V n_{o} K_{a}-K_{a} C_{N a i}+C_{H e}\left(1+K_{1} C_{a e}\right)\right]-C_{N a i} C_{H e}\left(1+K_{1} C_{a e}\right)=0
$$

Likewise, the rate expression for silica dissolution must be modified to yield

$$
\frac{d C}{d t}=A / V\left[k_{2} n_{c}-k_{1} C_{a}\left(n_{o}-n_{c}-n_{N}\right)\right]
$$

Substituting for $n_{c}$ and $n_{N}$ gives the result

$$
\frac{d C}{d t}=\frac{A n_{o} k_{2} K_{4} C_{H}}{K_{a} C_{N a}+C_{H}\left(1+K_{1} C_{a}\right)}\left[1-C_{a} / C_{a e}\right]
$$

This equation, along with the equations for the thermodynamic equilibria and electroneutrality balance, describe a batch process. The effect of ion exchange on the decrease of the rate of silica dissolution is apparent. Since the number of the sites available for dissolution decreases with ion exchange, an increase in the values of ion exchange equilibrium constant or cation concentration $C_{N a}^{\prime}$ leads to lower rates of silica dissolution. There are few reported experiments to determine the effect of electrolyte on the rate of dissolution of silica. Results of experiments by Wirth and Gieskes ${ }^{91}$ show that the rate of dissolution of silica decreased 
by $30 \%$ due to the ion exchange of $\mathrm{Mg}^{++}$. However, Van Lier et al. ${ }^{66}$ showed an increase in the dissolution rate with increasing $\mathrm{Na}^{+}$concentration. One might suggest that $\mathrm{Na}^{+}$might participate in the formation of an activated complex controlling the rate of dissolution. However, the results of Van Lier's experiments are questionable, because of the extremely small silica particles (2-5 micron) used.

Of course, in the limit $K_{a}=0$, the above rate expression reduces to the previous in the case of no ion exchange. At equilibrium $C_{H}=C_{H e}$ and $C_{a}=C_{a e}$, thus

$$
K_{a} C_{N a e}^{2}+C_{N a e}\left[A / V n_{o} K_{a}-K_{a} C_{N a i}+C_{H e}\left(1+K_{1} C_{a e}\right)\right]-C_{N a i} C_{H e}\left(1+K_{1} C_{a e}\right)=0
$$

The equilibrium value of $\mathrm{pH}$ and the total dissolved silica can be obtained by solving the above equation. Note that in this equation, $C_{N a e}=C_{N a i}$ for $K_{a}=0$.

To carry out sensitivity runs with respect to various parameters, and to investigate the effect of ion exchange on the performance of a batch system, equations (3.69) and (3.70) were solved.

\subsubsection{Results}

First, we have examined the effect of ion exchange equilibrium constant on the performance of the batch system. Figure 3-11 shows the results for the variation of the equilibrium value of $\mathrm{pH}$ with the ion exchange equilibrium constant, $K_{l}$, for different values of initial salinity. The competition between ion exchange and dissolution appears to be quite subtle. Increasing the value of $K_{l}$, which decreases the number of site available for dissolution, increases the $C_{O H}$ ion consumption to a point beyond which it remains constant. This occurs when the ion exchange sites are completely satisfied and the amount of $\mathrm{H}$ ions released by ion exchange is constant. The curves obtained have two asymptotes, corresponding respectively to highest and lowest $\mathrm{COH}_{\mathrm{OH}}$ consumption. For the particular conditions of Figure 3-11, the relative change between initial and final pH varies between $10 \%$ (largest effect of ion exchange) to about $6.2 \%$ (dissolution only). The effect of initial salinity on the consumption of $\mathrm{C}_{O H}$ is predictable, higher values of salinity leading to higher loss, up to a limiting $K_{l}$. Similarly, the effect of salinity on the equilibrium concentration of total dissolved silica is predictable (Figure 3-12), higher values of salinity leading to lower silica dissolution, hence to smaller 
amounts of dissolved silica, in agreement with experimental observations.

Figure 3-13 illustrates the variation of the equilibrium value of pll versus salinity for two different $\mathrm{pH}$ values of 12.5 and 13 , for surface area of $375 \mathrm{~m}^{2}, K_{l} / K w=10^{5}(\mathrm{~mole} / \mathrm{lit})^{-2}$. It is noticed that at low salinity the relative change of $\mathrm{pH}$ is higher for higher value of $\mathrm{pH}$ but the opposite is true for high value of salt concentration.

A schematic summarizing the above competition between ion exchange and dissolution is shown in Figure 3-14 for a batch process at equilibrium. The upper curve pertains to a silica dissolution process in the presence of ion exchange, while the lower curve pertains to a process of ion exchange alone. The difference between the two curves is a measure of dissolution. These results show that in contrast to dynamic flow experiments which will be discussed in the following chapter, the $C_{O H}^{-}$loss due to dissolution cannot be differentiated from that due to ion exchange in batch experiment. Thus, considerable care should be exercised in the interpretation of experiments under such conditions as also noted previously by Dehghani. ${ }^{50}$ 


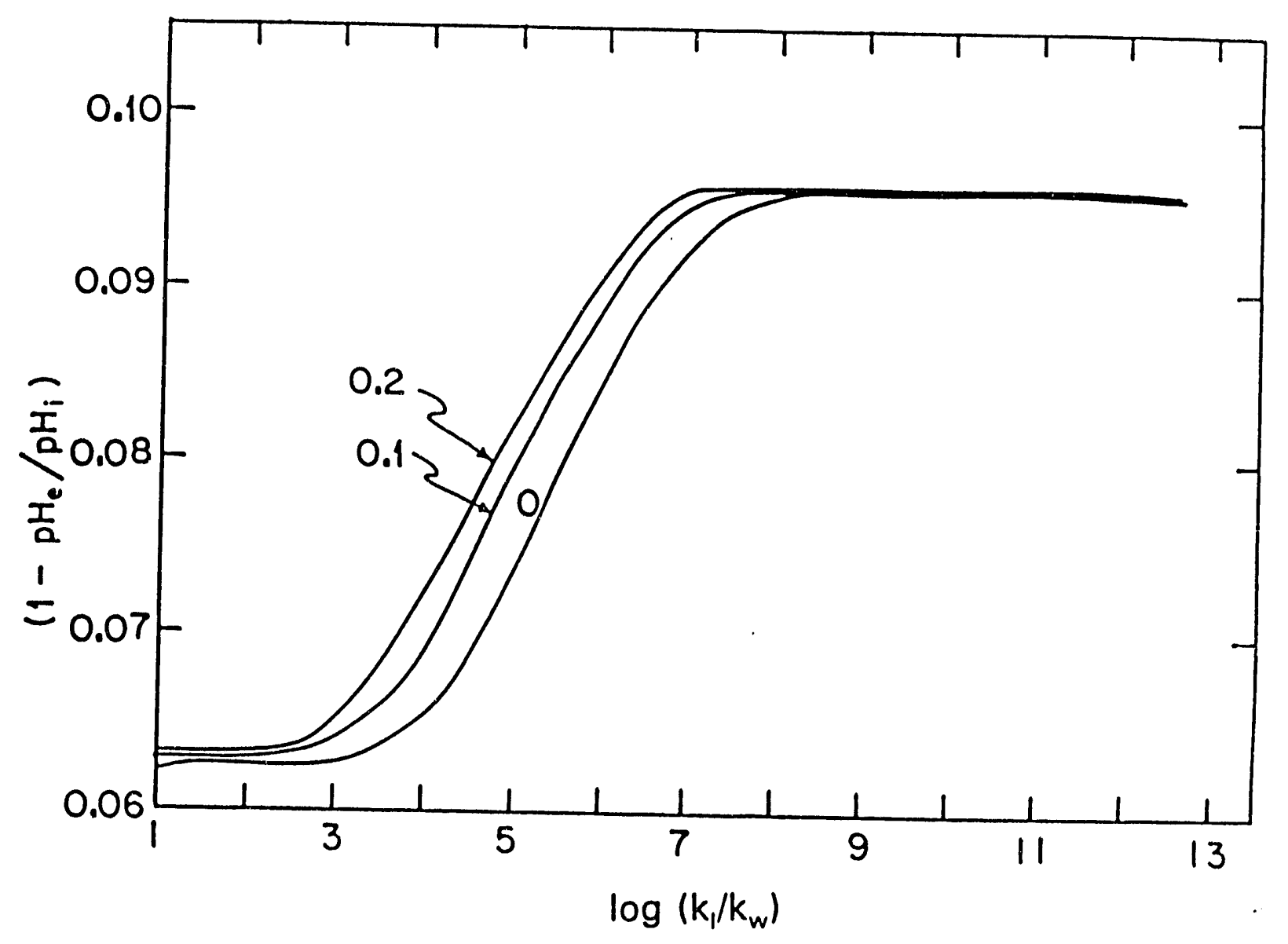

Figure 3.11: Effect of ion exchange equilibrium constant and salinity on the relative change of $\mathrm{pH}$ at equilibrium. 


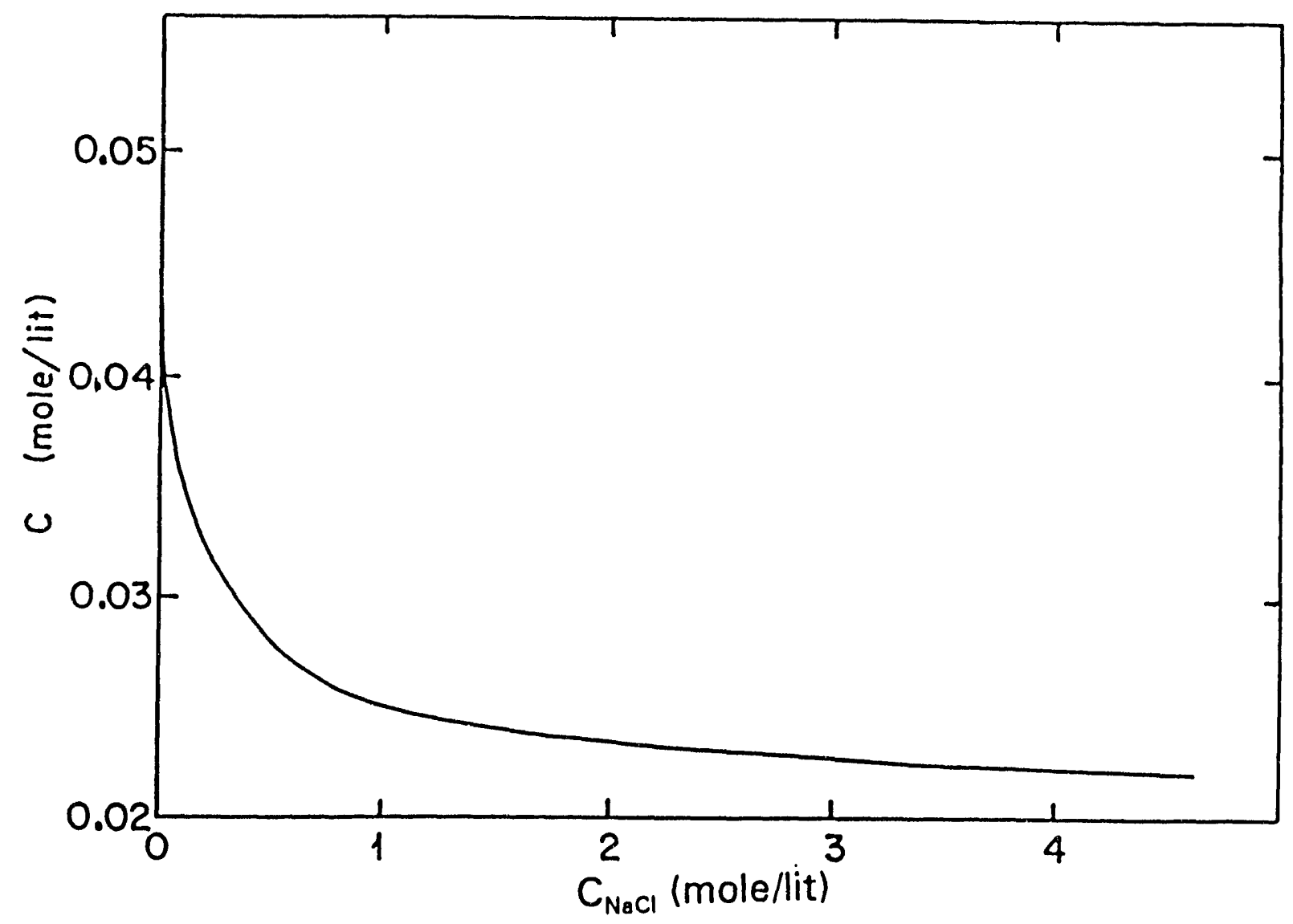

Figure 3.12: Effect of salinity on total dissolved silica at equilibrium. 


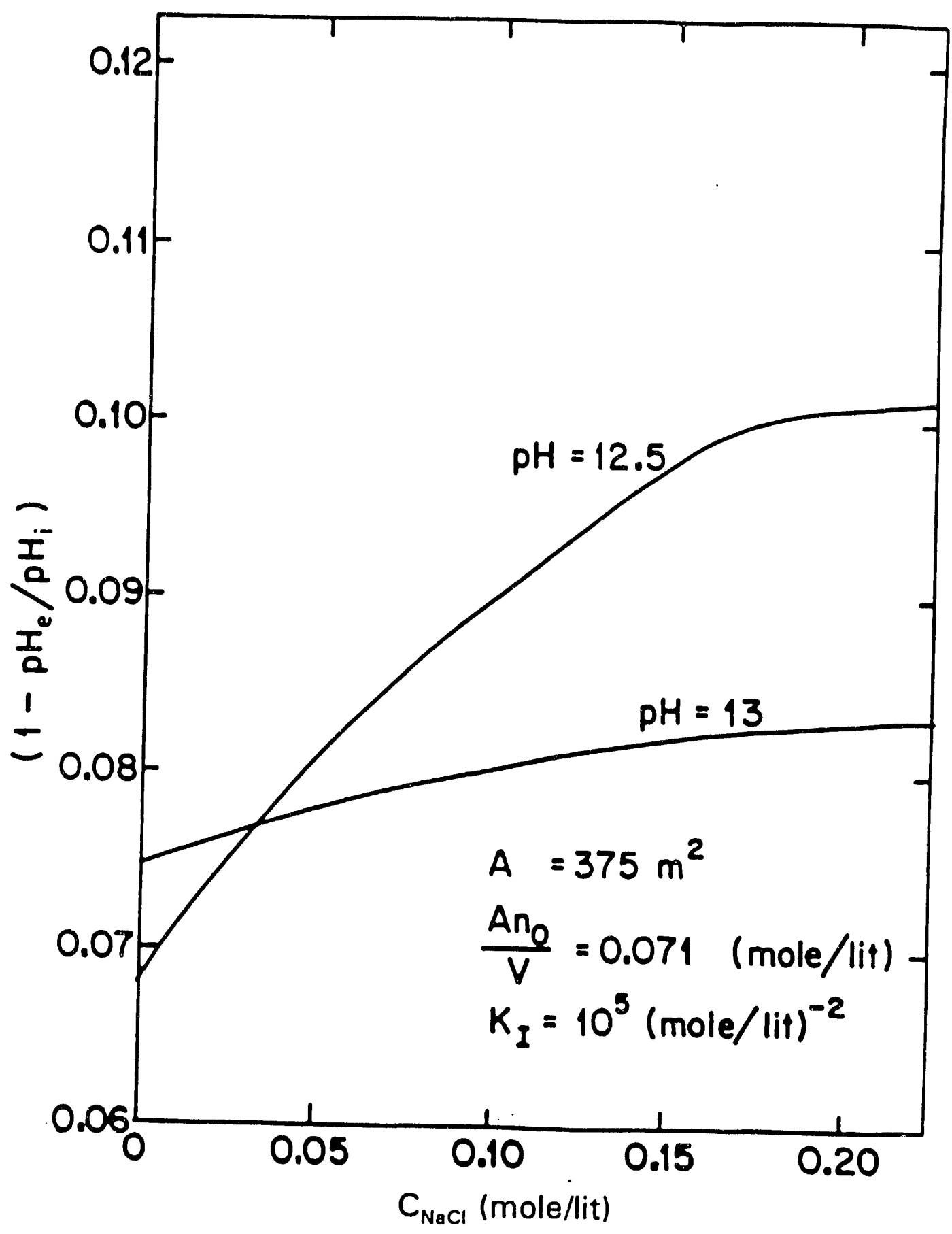

Figure 3.13: Effect of $\mathrm{pH}$ and salinity on the relative change of $\mathrm{pH}$ at equilibrium. 


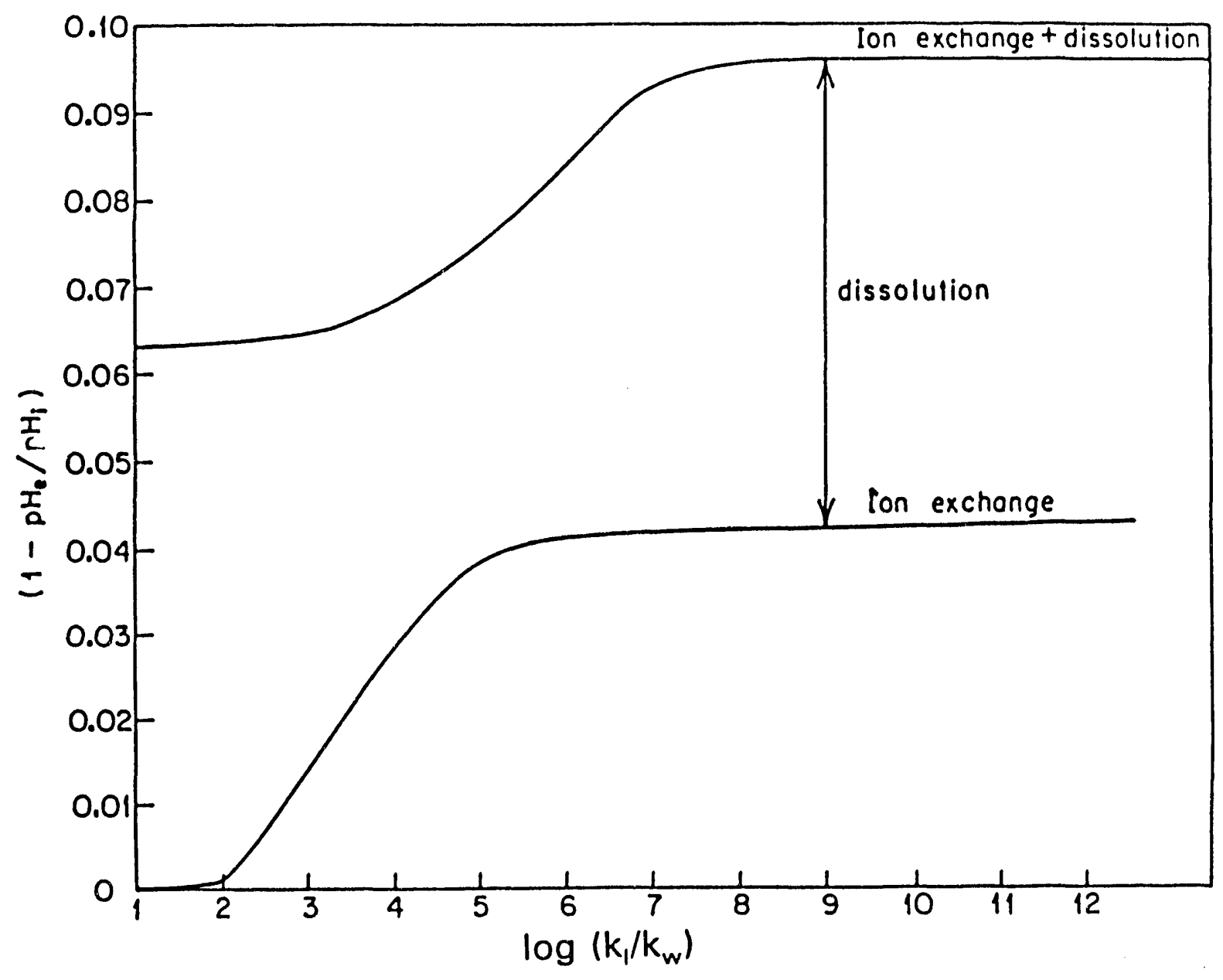

Figure 3.14: Relative change of $\mathrm{pH}$ at equilibrium versus ion exchange equilibrium constant for ion exchange, ion exchange and dissolution. 


\section{Chapter 4}

\section{Silica Dissolution Under Dynamic}

\section{Flow Conditions}

In the previous chapter, the dissolution of silica was described for a batch process. In this chapter a numerical model applicable for the dissolution process at dynamic flow conditions is developed. This investigation provides an answer as to how far a specified $\mathrm{pH}$ level, required to mobilize the trapped oil, can penetrate into a reservoir during an alkaline flooding process. Numerical results are presented that relate the rate of propagation of $\mathrm{pH}$ levels to consumption and adsorption parameters, salinity level and flow rates. This chapter deals with single-phase fluid flow only at a constant temperature. Extension to non-isothermal is presented in the next chapter.

\subsection{Mathematical Development}

Many physical and chemical factors influence flow in permeable media. Altering the fluid content of a medium by displacement depends primarily on physical parameters such as fluid densities and viscosities, relative permeabilities, and heterogeneity of the medium. On the other hand, altering the composition of the fluid in flow or the medium itself depends primarily on chemical interactions, such as adsorption or mineral dissolution. Thus, a completely general model of flow in permeable media must account for both the chemistry and the physics of the problem, a computationally expensive undertaking. 
Fortunately, many practical problems permit some simplifying assumptions. For many single phase flow applications, the chief interest lies in compositional changes caused by the flow. In this chapter we present a single phase flow model that allows for dissolution of mineral and ion exchange.

This developments make the following assumptions:

1. There is negligible dispersion.

2. The variation in surface area and porosity is neglected.

3. The system is one-dimensional, single phase flow.

These assumptions, while they significantly simplify the mathematics, require more careful justifications. 1) Physical dispersion is usually small and can be approximated by numerical dispersion, since the system of partial differential equations describing the distribution of various chemical species are solved numerically. 2) However, neglecting changes in surface area and porosity is not as easily justifiable, since such changes might be significant when high $\mathrm{pH}$ and temperature are involved. 3) In this chapter we are primarily concerned with the transport of alkaline agent which is mainly affected by chemical interaction with the reservoir rock. The presence of oil does not prevent contact of the alkaline agent with the reservoir rock.

\subsubsection{Conservation Equations}

The mathematical formulation of the system consist of the partial differential equations describing mass balances for each of the species in the fluid phase flowing through the reservoir. The transport of sodium ion and total dissolved silica in an one dimensional reservoir is described as follows. Denoting by $C_{a}$ the silicic acid concentration (mole/lit), by $\mathrm{H}^{*}$ the hydrogen ion concentration (mole/lit), by $\mathrm{N}^{*}$ the concentration of $\mathrm{Na}^{+}$(mole/lit), by

$\mathrm{n}_{0}^{*}$ the original available site mole/(solid rock volume), by $\mathrm{q}$ the volumetric flow rate $\mathrm{ft} / \mathrm{day}$ and by $\phi$ the porosity, the sodium species balance is

$$
\frac{\partial N^{*}}{\partial t^{*}}+\frac{(1-\phi)}{\phi} \frac{\partial n_{N}^{*}}{\partial t^{*}}+\frac{q \partial N^{*}}{\phi \partial x^{*}}=0
$$


where

$$
n_{N}^{*}=n_{o}^{*} \frac{K_{a}^{\prime} N^{*}}{H^{*}\left(1+K_{1} C a\right)+K_{a}^{\prime} N^{*}}
$$

and

$$
K_{a}^{\prime}=K_{l}^{\prime}\left(1-K_{4}\right)
$$

It is again assumed here that in the absence of clays, ion exchange and dissolution reaction occur at the same surface sites, implying a competition between ion exchange and reaction.

In order to convert the above to a dimensionless form, the following were employed

$$
t=t^{*} q / \phi L, x=x^{*} / L, N_{(x=0)}^{*}=N_{o}^{*}, H_{(x=0)}^{*}=H_{o}^{*}
$$

The dimensionless parameters are

$$
\begin{aligned}
N=N^{*} / N_{c}^{* *}, H & =H^{*} / H_{0}^{*}, A=C_{a} / C_{a e} \\
E & =\frac{H_{0}^{*}}{K_{I} N_{o}^{*}} \\
D & =\frac{H_{0}^{*}\left(1-K_{4}\right)}{K_{a} N_{o}^{*}} \\
F & =K_{1} C_{a e} \\
G & =\frac{H_{0}^{*}}{K_{a} N_{o}^{*}} \\
\lambda & =\frac{(1-\phi)}{(\phi)} \frac{n_{0}^{*}}{N_{o}^{*}}
\end{aligned}
$$

Then, the mole balance and the adsorbed $\mathrm{Na}^{+}$species in dimensionless notation become:

$$
\frac{\partial N}{\partial t}+\lambda \frac{\partial n}{\partial t}+\frac{\partial N}{\partial x}=0
$$

where

$$
n=\frac{N(N+D H)}{(N+E H)(N+G(1+F A) H)}
$$

\subsubsection{Conservation of Silicic Species}

In dimensional notation the balance of silicic species yields

$$
\phi \frac{\partial C_{T}^{*}}{\partial t^{*}}+q \frac{\partial C_{T}^{*}}{\partial x^{*}}=r^{*}
$$


where

$$
r^{*}=\frac{(1-\phi) n_{0}^{*} k_{2} K_{4} H^{*}}{K_{a} N^{*}+H^{*}\left(1+K_{1} C_{a}\right)}\left[1-C_{a} / C_{a e}\right]
$$

Here $r^{*}$ is the rate of silica dissolution in mole/(time $\times$ total volume). Total dissolved silica $C_{T}^{*}$ which has been defined earlier as the summation of the dissolved silicate species is represented as

$$
C_{T}^{*}=C_{a}+C_{b}+C_{c}+C_{d}+C_{e}+C_{f}+C_{g}+C_{j}^{\prime}
$$

As previously mentioned, $C_{T}^{*}$ is function ol hydroxyl ion concentration through the equilibria expressions.

To facilitate the analysis, the following dimensionless variables are also defined

$$
\begin{aligned}
\Pi_{1} & =\left(P_{1}+P_{6}\right) / H_{o}^{*}, \Pi_{2}=\left(P_{2}+P_{7}\right) / H_{o}^{* 2}, \\
\Pi_{3} & =P_{3} /\left(H_{o}^{*}\right)^{3}, \Pi_{4}=P_{4} /\left(H_{o}^{*}\right)^{4}, \Pi_{5}=P_{5}, \\
C_{T_{0}}^{*} & =\left(P_{1}+P_{6}\right) / H_{o}^{*}, Y=C_{a e} / C_{T_{0}}^{*}
\end{aligned}
$$

Therefore, the silicate balance finally becomes

$$
\frac{\partial C_{T}}{\partial t}+\frac{\partial C_{T}}{\partial x}=\frac{\tau H(1-A)}{N+G H(1+F A)}
$$

where

$$
\begin{gathered}
C_{T}=A(1+M) Y \\
M=\Pi_{5}+\frac{\Pi_{1}}{H}+\frac{\Pi_{2}}{H^{2}}+\frac{\Pi_{3}}{H^{3}}+\frac{\Pi_{4}}{H^{4}}
\end{gathered}
$$

and

$$
\tau=\frac{(1-\phi) L k_{2} K_{4} n_{o}^{*} H_{o}^{*}}{q C_{T_{0}}^{*} K_{a} N_{o}^{*}}
$$

In addition, electroneutrality must be fulfilled, which in dimensionless notation yields

$$
H R_{\circ}+N=R_{1} / H+R_{2} C L+R_{3} A T
$$

In the above, the following additional dimensionless parameters were defined

$$
\begin{aligned}
& R_{0}=H_{o}^{*} / N_{o}^{*}, \\
& R_{1}=\Pi w / N_{o}^{*} H_{o}^{*}, \\
& R_{2}=C L_{i}^{*} / N_{o}^{*}, \\
& R_{3}=C_{a e} / N_{o}^{*} \\
& T=\Pi_{1} / H+2 \Pi_{2} / H^{2}+3 \Pi_{3} / H^{3}+4 \Pi_{4} / H^{4}
\end{aligned}
$$


The final set is summarized below

$$
\begin{gathered}
\frac{\partial N}{\partial t}+\lambda \frac{\partial n}{\partial t}+\frac{\partial N}{\partial x}=0 \\
\frac{\partial C_{T}}{\partial t}+\frac{\partial C_{T}}{\partial x}=\tau \frac{H(1-A)}{N+G H(1+F A)}
\end{gathered}
$$

where

$$
H R_{o}+N=R_{1} / H+R_{2} L+R_{3} A T
$$

where

$$
n=\frac{N}{N+G(1+F \cdot A) H}
$$

and

$$
C_{T}=A / \Pi_{1}\left(1+\Pi_{2}+\Pi_{3}+\Pi_{4}+\Pi_{5}\right)
$$

The appropriate initial and boundary conditions are

$$
\begin{gathered}
\text { B.C. at } x=0: H=1, N=1, C L=1 \\
\text { I.C. at } t=0: N=N_{i}=N_{i}^{*} / N_{o}^{*} \\
H=H_{i}=H_{i}^{*} / H_{o}^{*} \\
C L=C L_{i}=C L_{i}^{*} / C L_{o}^{*}
\end{gathered}
$$

where subscript $i$ refers to the initial condition.

From the above formulation the following dimensionless groups appear control the dissolution behavior of silica under dynamic flow conditions:

$$
\frac{(1-\phi)^{n_{o p_{0} a_{m}}}}{(\phi) N_{o}}
$$

which expresses the ratio in total site capacity versus the capacity for $\mathrm{Na}^{+}$adsorption;

$$
\frac{\rho_{s} a_{m}(1-\phi) n_{o} L k_{2} K_{4}}{q C_{T_{o}}^{*}}
$$

which is the Damkohler number, and

$$
\frac{H_{o}^{*}}{K_{a} N_{o}^{*}}
$$

which is the ratio between the rates of reaction and adsorption. Here, subscript $(o)$ refers to injected condition, $\rho_{s}$ is the silica density, $m$ is the specific surface area, $L$ is the length of reservoir and $n_{o}$ is the original available site (mole/rock area). The dissolution process at dynamic flow conditions can be characterized by these three parameters. 


\subsubsection{Numerical Solution}

The above set of equations was solved by a numerical technique, proposed by Von Rosenberg 1963. The technique is based on centered differences as follows

$$
\begin{aligned}
& \frac{\partial(U)}{\partial t}=1 / 2 \frac{U_{k, t+1}-U_{k, t}}{\Delta t}+1 / 2 \frac{U_{k-1, t+1}-U_{k-1, t}}{\Delta t} \\
& \frac{\partial(J)}{\partial(X)}=1 / 2 \frac{U_{k, t+1}-U_{k-1, t+1}}{\Delta X}+1 / 2 \frac{U_{k, t}-U_{k-1, t}}{\Delta X}
\end{aligned}
$$

The sodium and total silicate ions differential mole balances were numerically integrated using $\Delta X=\Delta t$.

In order to determine the sensitivity of the dissolution rates with respect to the three dimensionless groups, the above set of two nonlinear equations (4.9 and 4.11) was solved simultaneously. At each tıme step, the mole balances were numurically solved for the length of the reservoir, and the resulting concentration profiles were used for the next computation at the new time step.

In this fully implicit model, it is usually expected that stability would not be a problem. But for certain values of the parameters some numerical difficulties were encountered. The source of the problem appeared to be the extreme nonlinearity of the equations. Roots to these nonlinear equations appears to vary by several orders of magnitude. This difficulty was resolved by assuming that th silicic acid concentration is equal to its equilibrium value in cases where the computed silicic concentration exceeded such equilibrium values. This assumption although reasonable, was not rigorously justified.

\subsection{Model Predictions}

In this section we present sensitivity results for the proress describing silica dissolution upon injection in an 1-D core of an alkaline solution at a constant flow rate. The core was originally supposed to be saturated with brine and at equilibrium with respect to silica dissolution. Tables 4-1 and 4-2 list the values of the reservoir and injection parameters used in the simulation. 
Table 4.1: Typical values of the parameters

$$
\begin{aligned}
a_{v} & =2.6 .10^{+4} \mathrm{~cm}^{-1} \\
F & =K_{1} C_{a e}=11.5 \\
n_{o a}^{*} & \approx 6.25 \times 10^{-6} \text { moles } / \mathrm{m}^{2} \\
K_{1} & =92076 \mathrm{lit} / \text { (mole.time) } \\
n_{0}^{*} & =1.625 \times 10^{-2} \text { moles } / \text { lit } \\
P_{1} & =10^{-9.6} \\
P_{2} & =10^{-22.6} \\
P_{3} & =10^{-37.6} \\
P_{4} & =10^{-54.6} \\
P_{5} & =10^{-1.58} \\
P_{6} & =10^{-11.24} \\
P_{i} & =10^{-22.44}
\end{aligned}
$$

Table 4.2: Typical values of the parameters

$$
\begin{aligned}
\lambda & =.406 \\
G & =1.66 \times 10^{-12} / K_{a} \\
R_{o} & =8.3 \times 10^{-13} \\
R_{1} & =.83 \\
R_{2} & =.166 \\
R_{3} & =1.04 \times 10^{-3} \\
R_{4} & =2.66 \\
\Pi_{0} & =\left(1+\Pi_{5}\right) / \Pi_{1}=1.52 \times 10^{-2} \\
\Pi_{1} & =2.56 \times 10^{3} \\
\Pi_{5} & =38 \\
\tau & =5.10^{-14} L k_{2} / q K_{a}
\end{aligned}
$$




\subsubsection{Effect of Ion Exchange Rate}

The effect of ion exchange equilibrium constant, $K_{l}$, on the dynamic flow simulations is shown in Figures 4-1 and 4-2. Upon an increase in the ion exchange constant, $K_{l}$, a decrease of the front propagation velocity and a sharper decline of concentrations in the preceding region is observed. In contrast to the batch processes, however, the consumption of $\mathrm{OH}^{-}$ in the plateau region decreases with an increase in the ion exchange constant. Indeed, in the plateau region the ion exchange has been completed, the $\mathrm{OH}^{-}$loss associated with the ion exchange travels ahead of the front, and the fraction has diminished. An increase in $K_{l}$ amplifies all these processes. Clearly, at such conditions ion exchange is expected to benefit considerably the alkaline process by retarding the $\mathrm{OH}^{-}$consumption.

\subsubsection{Effect of Damkohler Number}

The sensitivity of the results to changes in the Damkohler number $\mathrm{Da}$ is as anticipated. Higher values in $\mathrm{Da}$ for instance an increase in the ratio $\mathrm{L} / \mathrm{q}$, result into steeper decline of the $\mathrm{pH}$ values in the plateau region and into a faster approach to equilibrium (compare Figures 4-2 and 4-3). It is interesting to note, however, that the rate of the advance of the front is insensitive to variations in $\mathrm{Da}$.

\subsubsection{Effect of Adsorption Exchange Capacity}

The effect of the other dimensionless groups was next examined. Results are shown in Figures $4-3,4-4$. It is noted that by increasing $a_{m}$ (and equivalently the total number of available sites) the $\mathrm{Na}$ plateau region becomes shorter, its velocity increasing, while the region of $\mathrm{Na}$ concentration decline becomes wider and the $\mathrm{Na}$ concentration variation smoother. Correspondingly, the region where the $\mathrm{pH}$ profile follows the batch behavior is narrower and the overall $\mathrm{pH}$ profile appears to be more diffuse. These results illustrates the competition between ion exchange and reaction and their interdependence on the total number of available sites. The implication is that the overall $\mathrm{pH}$ decline is larger as $a_{m}$ increases, hence a lower effective value of $\mathrm{pH}$ is propagated through the reservoir. Comparison of Figures 4-3 and 4-4 shows that this effect is more pronounced at higher values of the Damkohler number. 


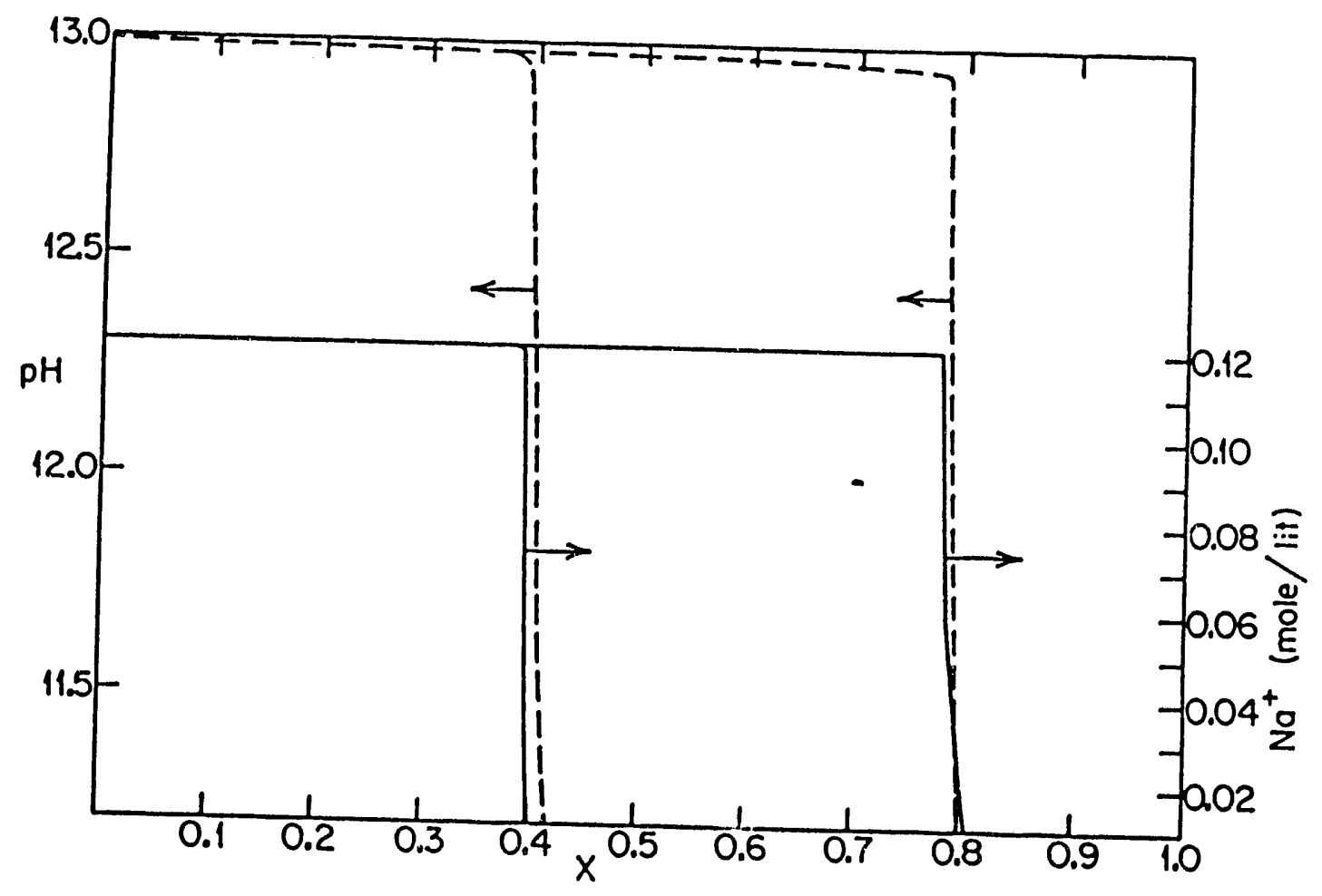

Figure 4.1: $\mathrm{pH}$ and sodium ion concentration profile for $.1 \mathrm{~N}$ injected caustic concentration and $.02 \mathrm{~mole} /$ lit injected NaCL. $\left(t=0.5\right.$ and 1 pore volume, $L / q=400$ days, $a_{m}=1 \mathrm{~m}^{2} / \mathrm{gr}$, $\left.k_{i} / k_{w}=10^{5}\right)$ 


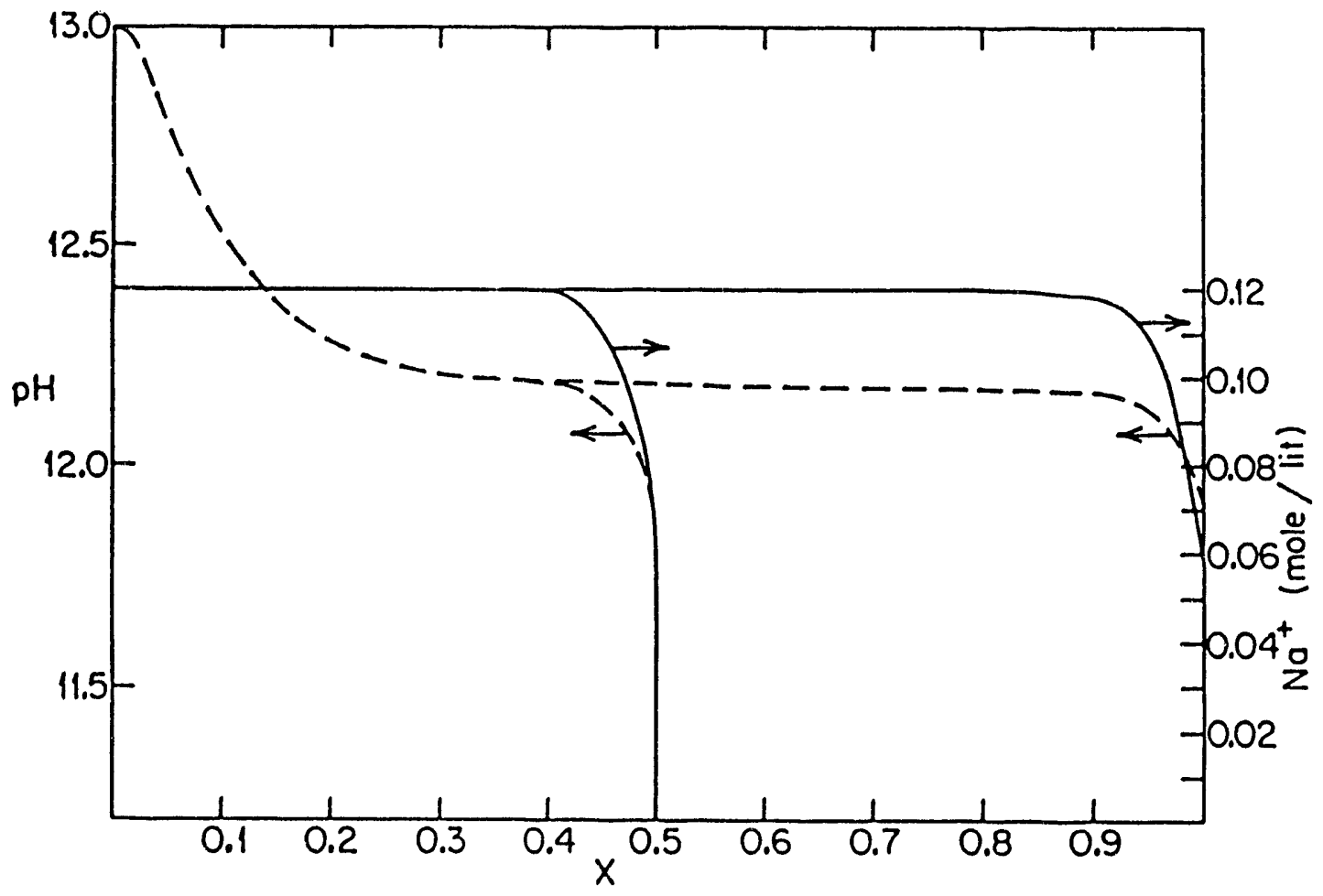

Figure 4.2: $\mathrm{pH}$ and sodium ion concentration profile for $.1 \mathrm{~N}$ injected caustic concentration and $.02 \mathrm{~mole} /$ lit injectea $\mathrm{NaCL}$. $\left(t=0.5\right.$ and 1 pore volume, $L / q=400$ days, $a_{m}=1 \mathrm{~m}^{2} / \mathrm{gr}$, $k_{i} / k_{w}=10^{3}$ ) 


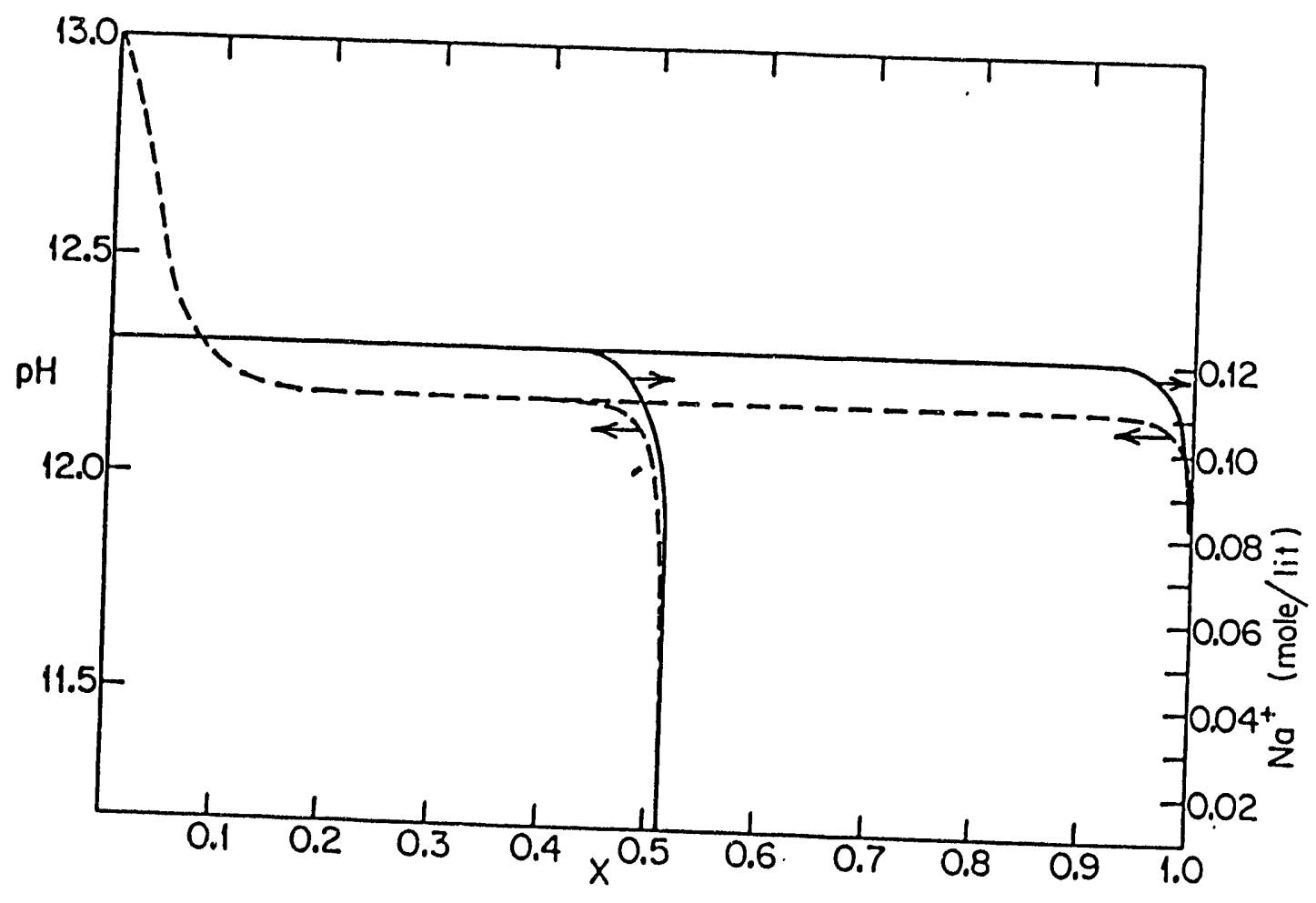

Figure 4.3: $\mathrm{pH}$ and sodium ion concentration profile for $.1 \mathrm{~N}$ injected caustic concentration and $.02 \mathrm{~mole} /$ lit injected NaCL. ( $t=0.5$ and 1 pore volume, $L / q=1000$ days, $a_{m}=1 \mathrm{~m}^{2} / \mathrm{gr}$, $k_{i} / k_{w}=10^{3}$ ) 


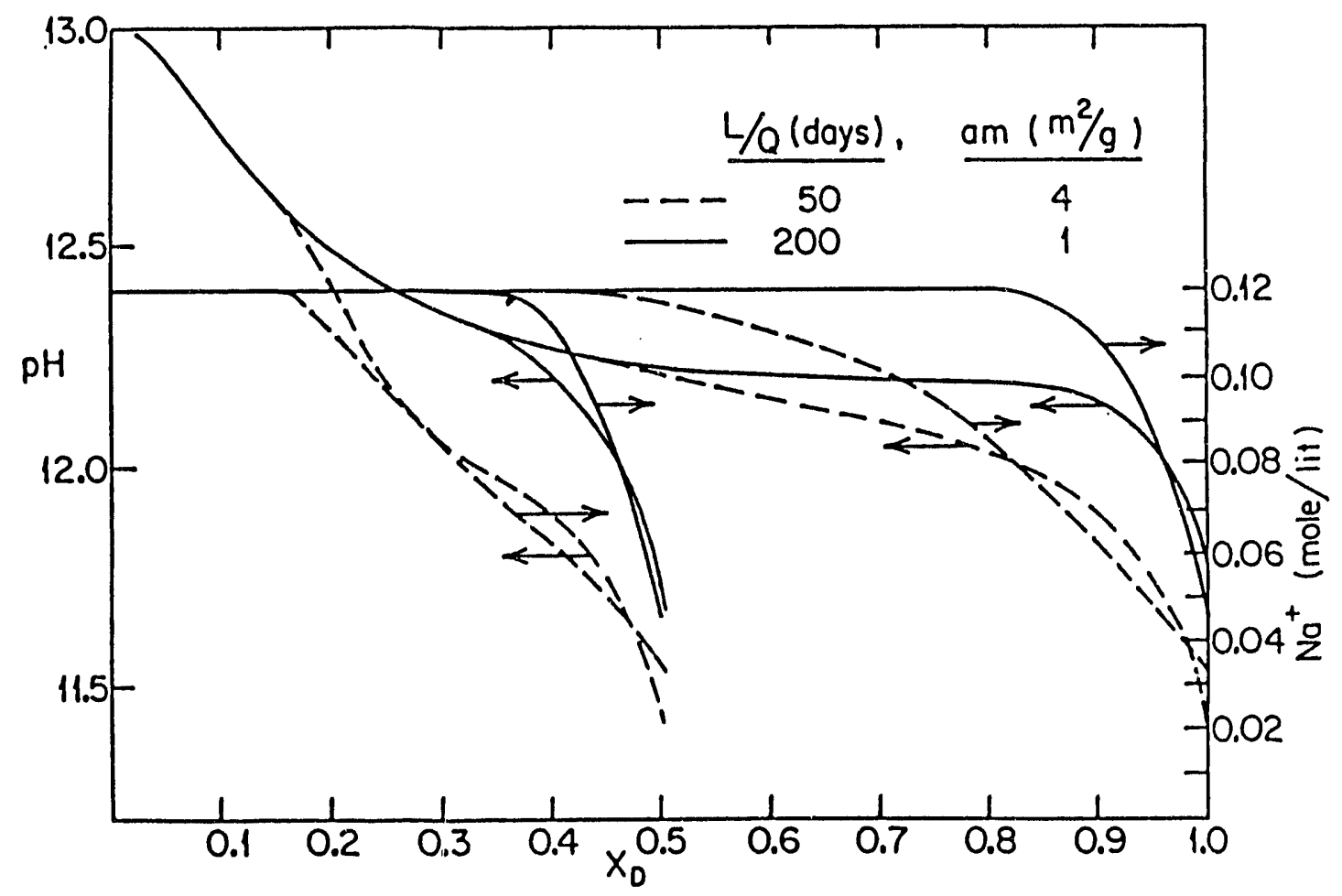

Figure 4.4: $\mathrm{pH}$ profile for different values of specific surface area and length/flow rate for 1 $\mathrm{N}$ injected caustic concentration and .02 mole/lit injected NaCL. $(t=0.5$ and 1 pore volume, $\left.k_{i} / k_{w}=10^{3}\right)$ 


\subsubsection{Effect of Salinity}

The effect of the salinity content of the injected fluids is shown in Figure 4-5. All runs in Figure 33 were carried out at constant injected $\mathrm{OH}$ concentration. It is observed that higher values of salinity result into more effective ion exchange, with an accompanying beneficial reduction of the $\mathrm{OH}^{-}$consumption. These results are in agreement with experimental works, as discussed earlier.

Recently, kinetic experiments by Wirth and Gieskes ${ }^{91}$ were designed to examine the effect of ion exchange on the dissolution behavior of silica. The results of their experiments showed that the rate of dissolution decreased by 30 to the solution.

In view of the above, a preflush of an optimun concentration of metal cation, which will be chemisorbed to the silica surface, might result in an improvement of the alkaline flooding process performance. However, detrimental effects of these cations due to the reactions with surfactants should also be considered.

\subsection{Hot Alkaline Flooding}

The above dynamic model can also be applied to hot alkaline flooding but lack of thermodynamic data and experimental details do not warrant it. However, as stated earlier, the time to reach to equilibrium decreases with temperature. This implies that at high temperatures silica dissolution can be treated as an instantaneous equilibrium dissolution reaction, where equilibrium $\mathrm{pH}$ travels through the medium undepleted. The final equilibrium $\mathrm{pH}$ value can be calculated directly from the electroneutrality balance and thermodynamic equilibria with $C_{a}=C_{a e}$ (Eq. 4.54). It has been shown by several investigators that the assumption of equilibrium is justified for several laboratory alkaline floods. ${ }^{139}$

In alkaline flooding it is not the alkali that enhances the oil recovery but rather the hydrolyzed anionic surfactant products. Adsorption of anionic surfactant at the rock surface can be neglected due to electrostatic repulsion of the negatively charged minerals. Knowing the equilibrium value, one can easily obtain the generated surfactant concentration from the available developed model. ${ }^{15}$ However, due to sodium-hydrogen ion exchange on the silica surface, the corresponding $\mathrm{OH}^{-}$ion uptake causes chromatographic lag in the $\mathrm{pH}$ 


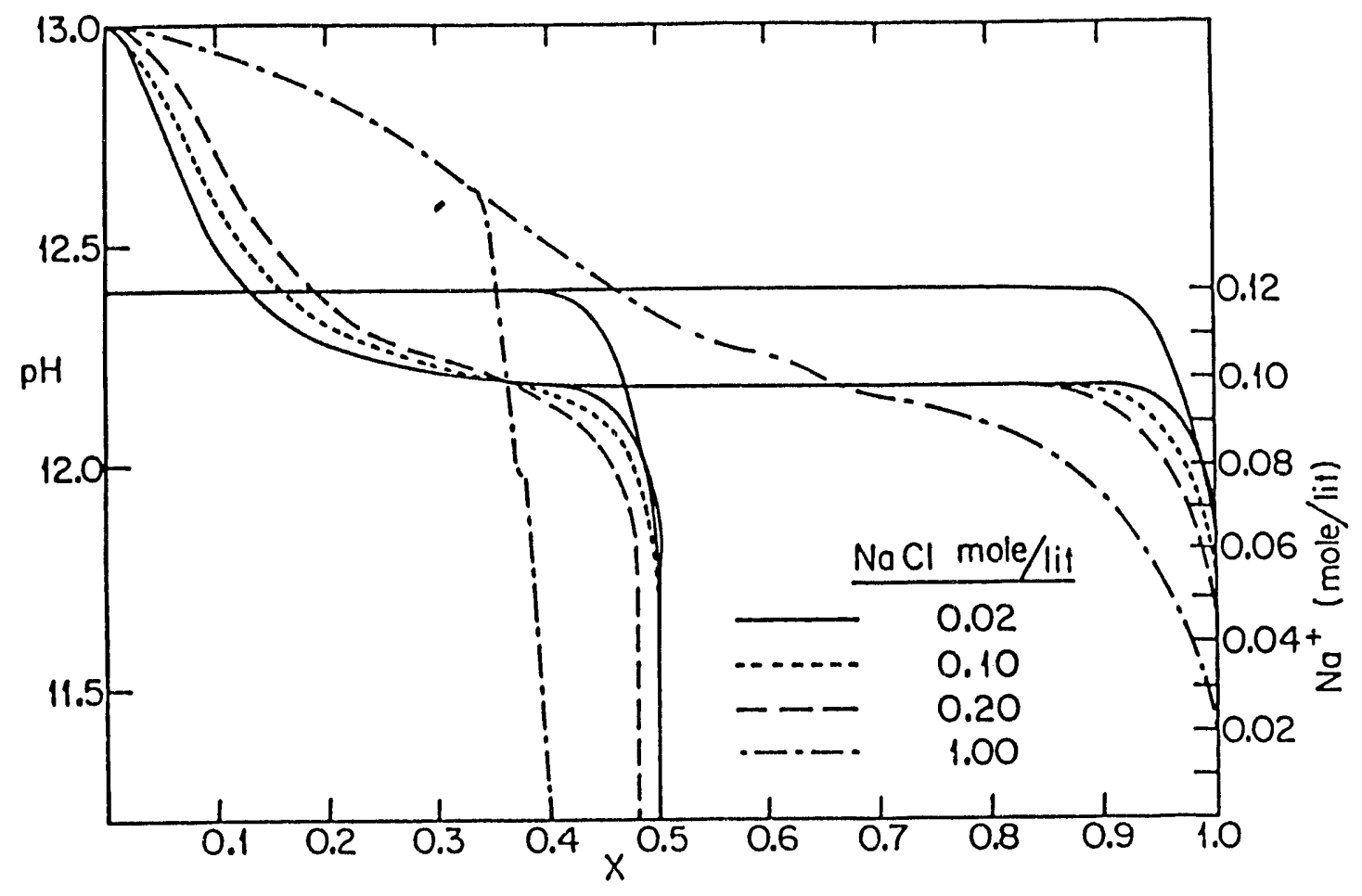

Figure 4.5: Effect of salinity on $\mathrm{pH}$ profile for $.1 \mathrm{~N}$ injected caustic concentration. $(t=0.5$ and 1 pore volume, $L / q=400$ days, $a_{m}=1 \mathrm{~m}^{2} / g r, k_{i} / k_{w}=10^{3}$ ) 
front as recognized by some investigators. ${ }^{137}$ In other words, ion exchange characteristics of the medium determine the speed of hot alkaline flooding which can be obtained from the sodium- hydrogen ion exchange isotherm. Therefore, hot alkaline flooding can be treated as simultaneous injection of hot water and chemical additive. This is the subject of the following chapters. 


\section{Chapter 5}

\section{Displacement of a Viscous Oil by the Combined Injection of Hot Water and Chemical Additive}

In this chapter, the modeling of an adiabatic hot waterflood assisted by the simultaneous injection of a chemical additive is presented. The process considered is one-dimensional, two-phase flow with negligible effects of dispersion, heat conduction, and lateral heat losses. The model allows for the chemical to partition into the aqueous phase and to be adsorbed on the solid rock. The effects of temperature on the viscosity ratio and the adsorption kinetics and of chemical concentration on the fractional flow curves are included. This work was initiated by Karakas and Yortsos, ${ }^{142}$ who conceptualized the mathematical description of the problem.

In order to calculate the process efficiency the model is here extended to simulate the process of combined injection of a finite size chemical slug under tertiary recovery conditions. In addition, a more extensive study of the sensitivity of the process parameters is undertaken. The following is also contained in a published article. ${ }^{143}$ 


\subsection{Introduction}

The displacement of a viscous crude oil by conventional recovery schemes operating at the reservoir temperature is not very effective due to the low mobility of the oleic phase. Taking advantage of the favorable alteration in the viscosity of the fluid phases achieved at high temperatures, various thermal processes have been successfully implemented for the economic recovery of heavy oils. ${ }^{144}$ Steam injection, and, to a lesser degree, in-situ combustion have been already established as commercially viable enhanced mathods for such reservoirs. In an effort to further improve the recovery performance attained in thermal processes, it has been suggested ${ }^{7}$ to aid the displacement mechanisms by the simultaneous injection of chemical additives.

The primary function of chemical additives in enchanced recovery is to alter the mobility characteristics of the fluid phases by reducing the interfacial tension between aqueous and oleic phases, thus increasing the relative permeability of oil to flow. ${ }^{145}$ This effect, if acting in a synergestic way with the increased mobility achieved at higher temperatures, is expected to considerably enhance the recovery efficiency of standard thermal recovery processes. Although factors other than the above may play important roles at higher temperatures, ${ }^{146}$ it is the combined effect of changes in relative permeabilities and viscosity ratios that principally accounts for an enhancement in recovery.

Clearly, the viability of such a combined injection scheme rests on the hypothesis that the injected chemical additive asks its synergestic effect on the heated region of the reservoir, and particularly on the hot liquid region that precedes any advancing condensation fronts (e.g., in the steam injection) (Fig. 5-1a). Therefore, it is important to determine the region of residence of the chemical, with ultimate objective the design of optimal injection schemes that maximize recovery performance. In an attempt to address this complex subject, we study adiabatic hot waterflood assisted by simultaneous injection of a chemical additive. Such a study, besides its own importance for a combined hot water and chemical injection process, will enable us to gain considerable insight on the rates of propagation of chemical and temperature fronts in the liquid zone preceding steam fronts in a combined steam injection process. 

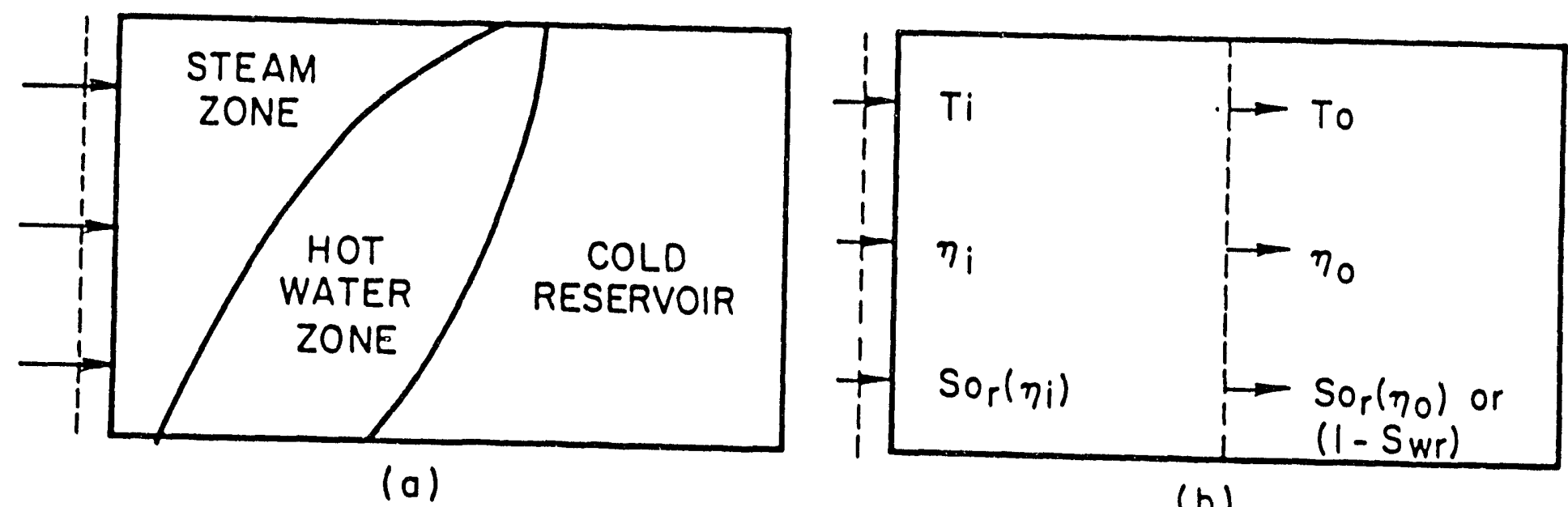

(b)

Figure 5.1: Schematic description of chemical-assisted thermal injection. 
The process to be considered here involves the combined injection of hot water and a chemical additive in one-dimensional reservoir geometries (linear or radial) (Figure 5-1a). For simplicity, the study is restricted to high injection rates such that effects of dispersion, heat conduction, capillarity, and lateral heat losses are negligible. Also, the chemical resides in the aqueous phase only. The mathematical model of the process, cast into a system of hyperbolic equations, is solved by the method of generalized waves ${ }^{147}$ (coherence ${ }^{148}$ ). From the results obtained, a sensitivity analysis of the recovery performance for continuous and slug injection follows with minimum computational requirements.

\subsection{Mathematical Formulation}

The model presented below applies to the design of combined injection of chemical and hot water flood. However, this model is also applicable to the particular case of alkaline flooding. In alkaline flooding it is not the alkali that enhances the oil recovery but rather the hydrolyzed anionic surfactant products. The chemistry of acid hydrolysis has been modeled by several workers ${ }^{15,156}$. The following is the model developed by Dezabala ${ }^{15}$ (Fig. 5-2) It is assumed that the mixture of active acid species in crude oil can be represented as a single component, HA. Upon its exposure to alkali the water soluble anionic surfactant $C_{\bar{A}}^{-}$is generated. According to Dezabala ${ }^{15}$ the overall hydrolysis is represeited as

$$
\mathrm{HA}_{\circ}+\mathrm{NaOH}=\mathrm{NaA}+\mathrm{H}_{2} \mathrm{O}
$$

where the hydrolysis in aqueous phase is

$$
H A_{w}=C_{H}^{+}+C_{A}^{-}
$$

and the acid is distributed between oleic and aqueous phases as

$$
H A_{o}=H A_{w}
$$

the acid dissociation constant can be defined as

$$
\bar{K}_{A}=\left(C_{H}^{+} C_{A}^{-} / H A_{w}\right.
$$




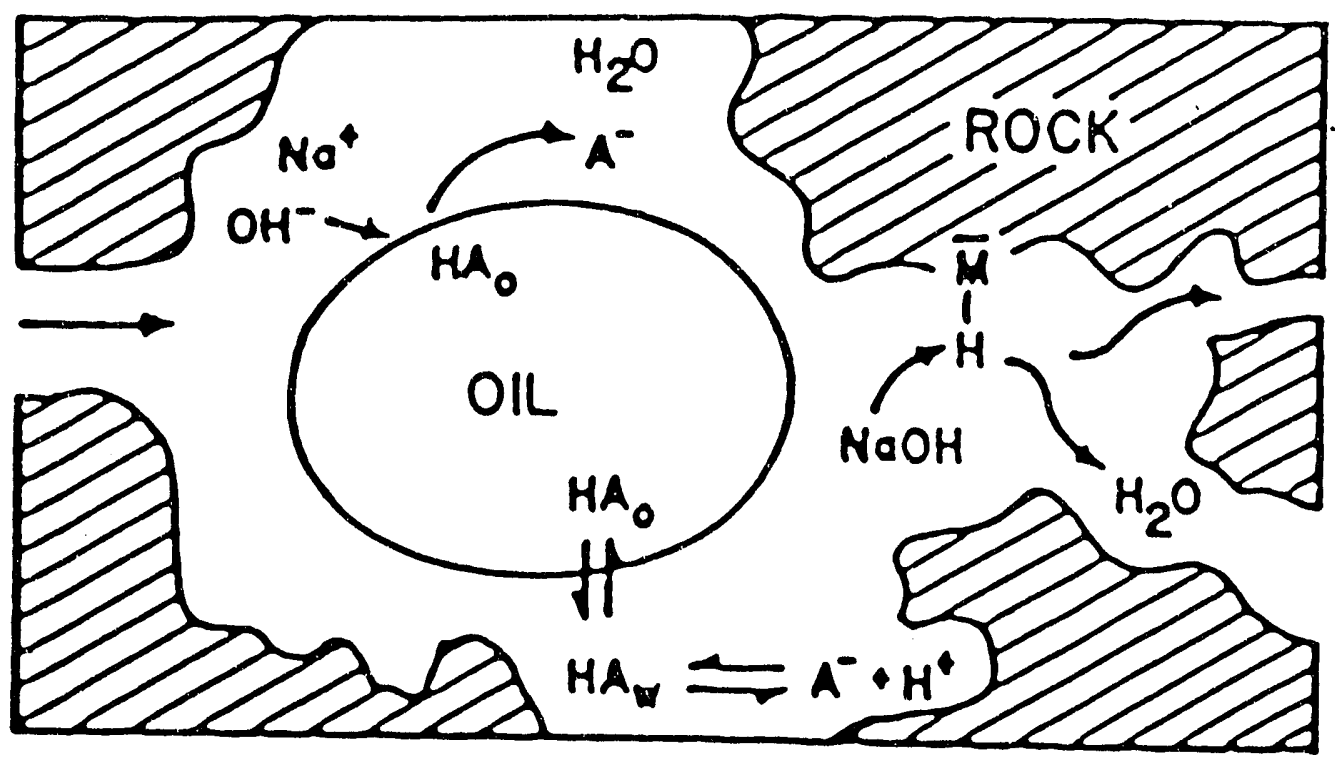

Figure 5.2: Schematic of alkali recovery process (Reference 15). 
and the distribution coefficient of the acid is

$$
K_{D}=H A_{o} / H A_{w}
$$

In the above it is assumed that all reactions are instantenous. Therefore, surfactant and hydroxide are in equilibrium with the oil at its initial acid number. Furthermore, as stated earlier, silica dissolution at high temperature can be treated as an instanteneous reaction. Thus, equilibrium state is established immediately and the electroneutrality balance Equation $(3.26)$ is modified to

$$
C_{N a}^{+}+C_{H}^{+}=C_{O H}^{-}+C_{A}^{-}+C_{a} T P
$$

let us define

$$
K=K_{D} K_{w} / K_{A}
$$

Thus, for a fixed acid concentration in the oil phase and at a known temperature, $C_{N a}^{+}$and $K$ the generated surfactant concentration can be obtained by solving equations (5.1) to (5.6).

In alkaline environments the adsorption of anionic surfactant to the rock surface, due to electrostatic repulsion from negatively charged site, is neglected. Therefore, the sodiumhydrogen ion exchange isotherm, which is Langmuirian in shape, determines the speed of the generated surfactant. The following formulation refers to the combined injection of hot water and chemical additive. However, for direct application to alkaline flooding throughout this chapter, $\eta$ denctes sodium ion concentration except in equations (5.12), (5.13), (5.14) where $\eta$ refers to the surfactant concentration $C_{N a}^{+}$.

The mathematical formulation of the system consists of the partial differential equations describing mass and energy balances inside the reservoir. Two mass balances can be written by defining dimensionless variables by normalizing time with $(\phi A L) / q$, distance with $L$, we obtain at high injection rates

$$
\frac{\partial}{\partial t}\left[S_{w} \eta+g(\eta, T)\right]+\frac{\partial}{\partial x}\left[f_{w} \eta\right]=0
$$

where

$$
g(\eta, T)=\left(\frac{1-\phi}{\phi}\right) \eta^{R}
$$


Here, $\eta$ is the volumetric concentration of the chemical in the aqueous phase, $\eta^{R}$ the adsorbed concentration, $g$ the adsorption isotherm. The latter can have a general dependence, provided that $g(\eta, T)>0, g_{\eta \eta}<0$. Note that for alkaline flooding, where the surfactant is generated in situ, $g$ refers to adsorption of sodium ion and $\eta$ denotes sodium ion concentration.

In the numerical illustration below, we use Langmuir adsorption kinetics of the form ${ }^{149}$

$$
g(\eta, T)=\frac{\eta}{g_{1} \eta+g_{2}}
$$

(b) Water mass balance

$$
\frac{\partial S_{w}}{\partial t}+\frac{\partial f_{w}}{\partial x}=0
$$

(c) Thermal energy balance

$$
\begin{gathered}
\frac{\partial}{\partial t}\left[\left(\rho_{w} C_{p w} S_{w}+\rho_{o} C_{p o} S_{o}+\frac{(1-\phi)}{\phi} \rho_{r} C_{p r}\right)\left(T-T_{o}\right)\right]+ \\
\frac{\partial}{\partial x}\left[\left(f_{w} C_{p w} \rho_{w}+\rho r_{o} C_{p o} f_{o}\right)\left(T-T_{o}\right)\right]=0
\end{gathered}
$$

where $T_{o}$ is the original reservoir temperature. In the above, the fractional flow of water $f_{w}$ is assumed to be a function of $T, \eta, S_{w}$ according to the expression ${ }^{150}$

$$
f_{w}=\frac{1}{1+\frac{\mu_{w}(T)}{\mu_{o}(T)} \frac{k_{r o}^{o}(T, \eta)}{k_{r w}^{o}(T, \eta)} \frac{(1-S)^{n}}{S^{p}}}
$$

where the exponents $n, p$ may be functions of $\eta$, and $S$ is the normalized water saturation

$$
S=\frac{S_{w}-S_{w r}}{1-S_{w r}-S_{o r}(\eta)}
$$

In all of the subsequent numerical illustrations we assume constant $k_{r o}^{\circ}, k_{r w}^{o}, n, p$, while $S_{\text {or }}(\eta)$ was taken to vary according to the relationship ${ }^{15}$

$$
S_{o r}(\eta)=a_{1}+a_{2} \exp \left(-a_{3} \eta\right)
$$

Equations (5.8), (5.11), (5.12) are in the form of a conservative system and they are used later for the derivation of shock conditions. For the developrnent of the solution, the three equations are further rearranged to the following convenient set. Assuming constant heat capacities, we obtain from $(5.11),(5.12)$

$$
\frac{\partial T}{\partial t} \frac{f_{w}+a}{S_{w}+b} \frac{\partial T}{\partial x}=0
$$


where $a$ and $b$ are defined as

$$
a=\frac{\rho_{o} C_{p o}}{\left(\rho_{w} C_{p w}-\rho_{o} C_{p o}\right)}
$$

and

$$
b=\frac{\rho_{o} C_{p o}+\frac{1-\phi}{\phi} \rho_{r} C_{p r}}{\left(\rho_{w} C_{p w}-\rho_{o} C_{p o}\right)}
$$

while a combination of equations $(5.8),(5.11),(5.12)$ yields

$$
\frac{\partial \eta}{\partial t}+\frac{f_{w}}{S_{w}+\frac{\partial g}{\partial \eta}} \frac{\partial \eta}{\partial x}-\frac{\frac{\partial g}{\partial T}\left(f_{w}+a\right)}{\left(S_{w}+\frac{\partial g}{\partial \eta}\right)\left(S_{w}+b\right)} \frac{\partial T}{\partial x}=0
$$

The rearranged equations (5.16), (5.19) along with equation (5.11) are concisely written as the following vector equation

$$
\frac{\partial \underline{U}}{\partial t}+\underline{A} \frac{\partial \underline{U}}{\partial x}=0
$$

Here $\underline{U}$ is the vector of the dependent variables,

$$
\underline{U}=\begin{gathered}
T \\
S_{w}
\end{gathered}
$$

and $\underline{A}$ the $3 \times 3$ coeffieient matrix,

$$
\begin{array}{rll}
\frac{f_{w}+a}{S_{w}+b} & 0 & 0 \\
\underline{A}=-\frac{\frac{\partial g}{\partial T}\left(f_{w}+a\right)}{\left(S_{w}+\frac{\partial g}{\partial \eta}\right)\left(S_{w}+b\right)} & \frac{f_{w}}{S_{w}+\frac{\partial g}{\partial \eta}} & 0 \\
\frac{\partial f_{w}}{\partial T} & \frac{\partial f_{w}}{\partial \eta} & \frac{\partial f_{w}}{\partial S_{w}}
\end{array}
$$

The eigenvalues $\lambda_{i}$ of the lower triangular matrix $\underline{A}$ arereadily obtained

$$
\begin{aligned}
& \lambda_{1}=\frac{f_{w}+a}{S_{w}+b} \\
& \lambda_{2}=\frac{f_{w}}{S_{w}+\frac{\partial g}{\partial \eta}} \\
& \lambda_{3}=\frac{\partial f_{w}}{\partial S_{w}}
\end{aligned}
$$

Since all eigenvalues are real and distinct and the matrix $\underline{A}$ is a function of $\underline{U}$ only, equation (5.20) defines a homogeneous, quasilinear hyperbolic system. 


\subsection{Method of Solution}

The solution to the hyperbolic system (5.20) along with the appropriate initial boundary conditions can be obtained by the method of characteristics. ${ }^{151}$ The family of the characteristic curves $\zeta_{i}$ in the $(x, t)$ plane are solutions of

$$
\frac{d x}{d t}=\lambda_{i}^{(U)}, \quad i=1,2,3
$$

Since $\lambda_{i}$ 's are functions of $\underline{U}$, equation (5.26) generally requires the use of numerical integration. However, for the particular case of continuous injection at a constant state into an initially uniform reservoir of another constant state, of interest here, the solution can be obtained by the theory of coherence. ${ }^{148}$. According to this theory, which is the manifestation in chromatographic processes of the general theory of generalized simple waves, ${ }^{147}$ it suffices to study the characteristic curves $C_{i}$ in the $\left(T, \eta, S_{w}\right)$ space, construct the corresponding paths, and follow the variation of the eigenvalues along the paths. The solution route joins the constant injection and initial states by path segments in order of increasing space velocity $\left(\lambda_{i}\right)$.

\subsubsection{Path Topology}

The characteristic curves in the composition space are determined by the integration of the following system of equations

$$
\frac{d T}{r_{1}^{(i)}}=\frac{d \eta}{r_{2}^{(i)}}=\frac{d S_{w}}{r_{3}^{(i)}}, \quad i=1,2,3
$$

where $r_{1}^{(i)}, r_{2}^{(i)}$ and $r_{3}^{(i)}$ are the components of the right eigenvector $r^{(i)}$ if the matrix $\underline{A}$ corresponding to eigenvalue $\lambda_{i}$. We obtain,

(1) Paths corresponding to $\lambda_{i}$

$$
\frac{d T}{d S_{w}}=\frac{\lambda_{1}-\lambda_{3}}{\frac{\partial f_{w}}{\partial T}+\frac{\lambda_{1}(\partial g / \partial T)\left(\partial f_{w} / \partial \eta\right)}{\left(S_{w}+(\partial g / \partial \eta)\right)\left(\lambda_{2}-\lambda_{1}\right)}}
$$

and

$$
\frac{d \eta}{d S_{w}}=\frac{\left(\lambda_{1}-\lambda_{3}\right) \lambda_{1} \frac{\partial g}{\partial T} /\left[\left(S_{w}+\frac{\partial g}{\partial \eta}\right)\left(\lambda_{2}-\lambda_{1}\right)\right]}{\frac{\partial f_{w}}{\partial T}+\frac{\lambda_{1}(\partial y / \partial T)\left(\partial f_{w} / \partial \eta\right)}{\left(S_{w}+(\partial g / \partial \eta)\right)\left(\lambda_{2}-\lambda_{1}\right)}}
$$


Multiplying (5.28) by $\partial f_{w} / \partial T,(5.29)$ by $\partial f_{w} / \partial \eta$ and taking the sum yields

$$
\frac{d f_{w}}{d S_{u}}=\frac{f_{w}+a}{S_{w}+b}
$$

which can be further integrated to

$$
\lambda_{1}=\text { const } .
$$

Similarly, by a linear combination of (5.28) and (5.29) we obtain

$$
\frac{d g}{d S_{w}}=\frac{\partial g}{\partial \eta} \frac{d \eta}{d S_{w}}+\frac{\partial g}{\partial T} \frac{d T}{d S_{w}}=\left(b-\frac{a}{\lambda_{1}}\right) \frac{d \eta}{d S_{w}}
$$

which can be integrated, in view of (A-4), to

$$
g-\left(b-\frac{a}{\lambda_{1}}\right) \eta=\text { const. }
$$

Thus, the family of paths corresponding to eigenvalue $\lambda_{1}$ are determined as the intersection of the two surfaces described by equations (5.31), (5.33). Note that in the case of negligible temperature effects on adsorption, equation (5.33) predicts that the paths lie on constant concentration planes, thus being identical to the paths of an ordinary hot waterflood.

(2) Paths corresponding to lambda

$$
\frac{d T}{d S_{w}}=0
$$

and

$$
\frac{d \eta}{d S_{w}}=\frac{\lambda_{2}-\lambda_{3}}{\frac{\partial f_{w}}{\partial \eta}}
$$

The family of paths lies on constant temperature planes as in the case of an ordinary dilute chemical flood. The change in the magnitude of $\lambda_{2}$ along the paths can be evaluated from (5.35)

$$
\frac{d \lambda_{2}}{d S_{w}}=-\frac{\lambda_{2} \frac{\partial_{g}^{2}}{\partial \eta^{2}}\left(\lambda_{2}-\lambda_{3}\right)}{\frac{\partial f_{w}}{\partial \eta}\left(S_{w}+\frac{\partial g}{\partial \eta}\right)}
$$

But since

$$
\frac{\partial g}{\partial \eta}>0, \frac{\partial^{2} g}{\partial \eta^{2}}<0, \frac{\partial f_{w}}{\partial \eta}<0
$$


then,

$$
\frac{d \lambda_{2}}{d S_{w}}\left\langle 0, \text { when } \lambda_{2} \hat{\langle} \lambda_{3}\right.
$$

Thus, $\lambda_{2}$ increases with an increase in $S_{w}$ along the paths where $\lambda_{2}$ predominates indicating that a shock will form. Such paths should then be replaced by integral paths satisfying the shock conditions

$$
\Lambda=\frac{f_{w}^{+} \eta^{+}-f_{w}^{-} \eta^{-}}{S_{w}^{+} \eta^{+}+g^{+}-S_{w}^{-} \eta^{-}-g^{-}}=\frac{f_{w}^{+}-f_{w}^{-}}{S_{w}^{+}-S_{w}^{-}}
$$

Note, however, that in the absence of adsorption $(g=0)$, equation (5.35) can be integrated to

$$
\lambda_{2}=\text { const } .
$$

The continuous paths need not be replaced by integral paths, in such a case.

(3) Paths corresponding to $\lambda_{3}$,

$$
\frac{d T}{d S_{w}}=0
$$

and,

$$
\frac{d \eta}{d S_{w}}=0
$$

The family of paths consists of straight lines parallel to the $S_{w}$ axis.

A schematic diagram of the path topology for the case of negligible temperature effects on adsorption is shown in Figure 5-3. The $\left(T, S_{w}\right)$ plane is scanned by straight lines parallel to the $S_{w}$ axis denoting $\lambda_{3}$-paths, and by curved $\lambda_{1}$-paths obtained from (5.31) (Fig. 53a). Three regions are distinguished, one for which $\lambda_{3}>\lambda_{1}$, and two regions to the far right and the far left of the diagram for which $\lambda_{3}<\lambda_{1}$. Notice that $\lambda_{1}$ is constant along $\lambda_{1}$-paths indicating a "contact discontinuity". ${ }^{147}$ All variables along the path travel with constant velocity, thus the corresponding $T, S_{w}$ profiles exhibit a shock-like structure. The path topology in this case is identical to that of an adiabatic hot waterflood, the solution of which has been previously developed by an analogous method ${ }^{152}$. Constant temperature 
planes on the other hand are scanned by straight line $\lambda_{1}$-paths and by curved paths obtained by integration of (5.35). Two regions are distinguished, one for which $\lambda_{3}<\lambda_{2}$, and another for which $\lambda_{3}>\lambda_{2}$ (Fig. 5-3b). The path topology is identical to that of an isothermal dilute chemical flood.

\subsection{Results}

\subsubsection{A. Continuous Injection}

Due to the qualitative difference adsorption introduces in the path topology we examine the two distinct cases separately.

1. No Adsorption

When adsorption is neglected, the solution route follows the path $A B C D O_{1}$ (secondary flooding) or $A B C D O_{2}$ (tertiary flooding) (Fig. 5-4a). Along $A B$ (constant $T, \eta$ ) $\lambda_{3}$ is increasing, hence the solution is continuous. At point $B\left(\lambda_{1}=\lambda_{3}\right)$, the route shifts over to $B C$ along which both $\eta$ and $\lambda_{1}$ are constant. Path $A B C$ is identical to the route followed in an ordinary, hot waterflood while path $C D O_{1}$ (secondary flooding) is identical to the route followed in an ordinary dilute, chemical flood. Shown in Figure 5-4b is also the procedure for the graphical construction of the solution in this case.

A schematic description of the temperature concentration, and saturation profiles obtained for secondary flooding at continuous injection are shown in Figure 5-4c. Note that in this case the chemical front travels ahead of the temperature front. A similar behavior is also followed during the injection of a slug of chemical as shown below. Thus, when adsorption is negligible, the chemical resides ahead of the heated region, and it breaks through the production end ahead of the temperature wave. Three saturation fronts develop, resembling an ordinary waterflood, a dilute chemical flood at the original reservoir temperature, while the third front is due to the reduction of the mobility ratio at the injection temperature and concentration.

2. Effect of Adsurption

When adsorption is included, the solution route differs according to whether 

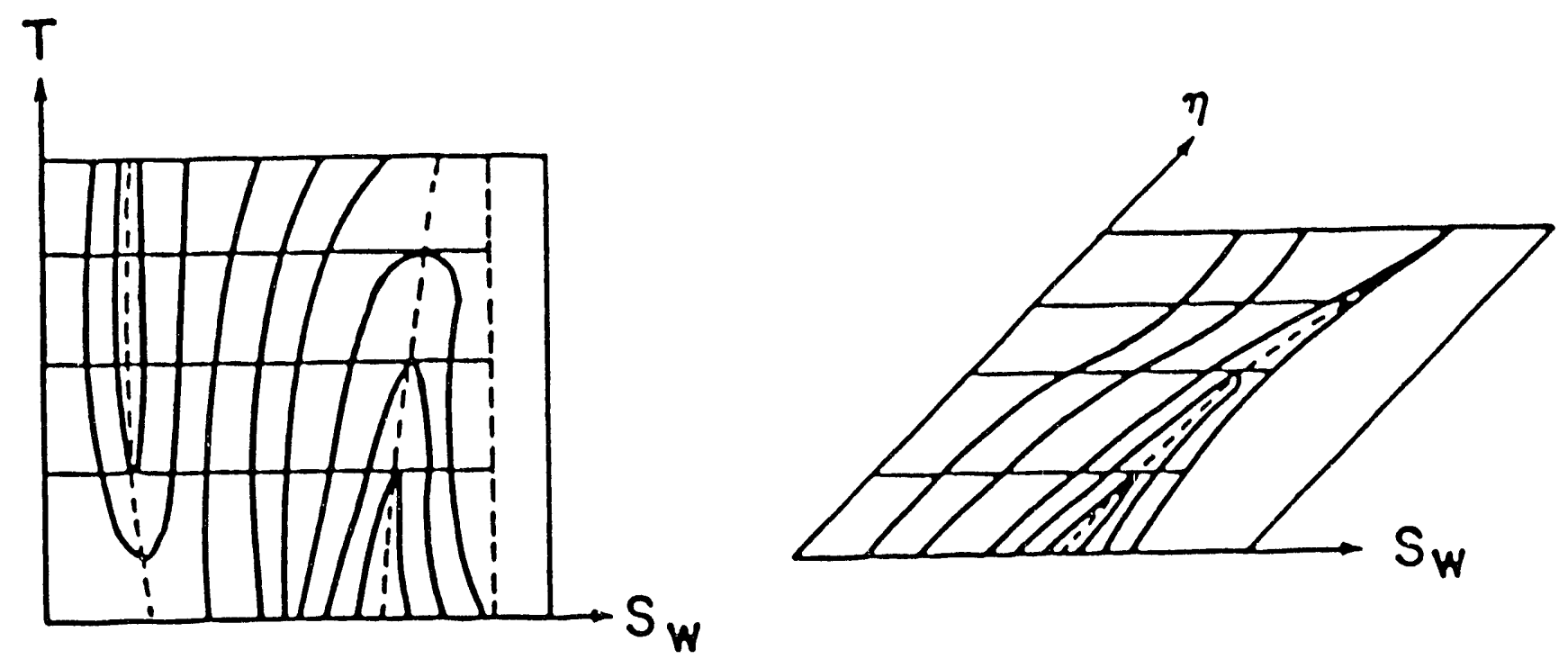

Figure 5.3: Path topology. 


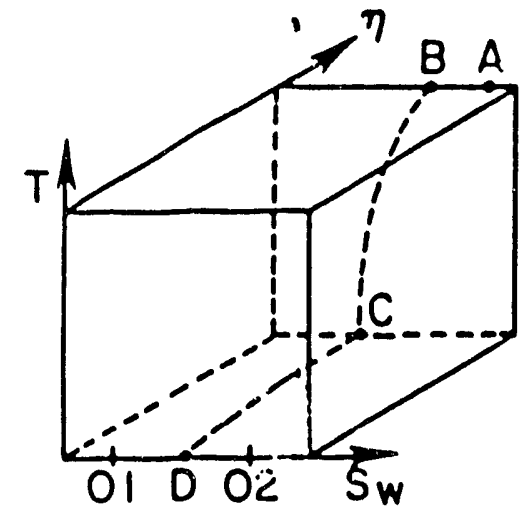

o)

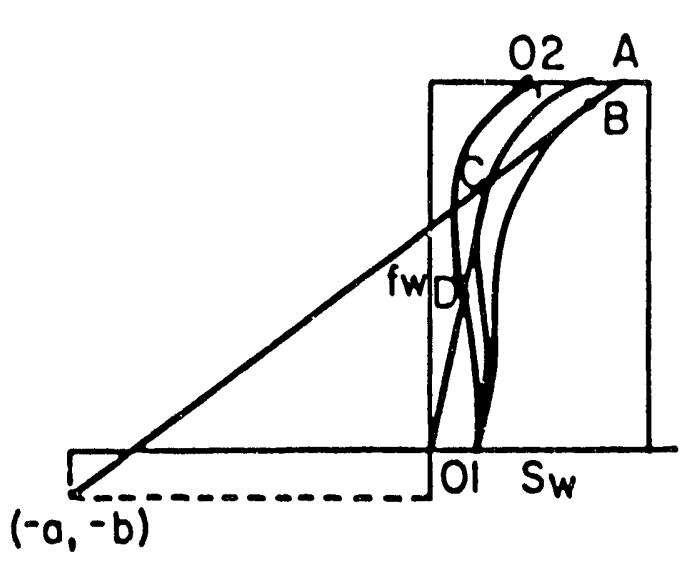

(b)

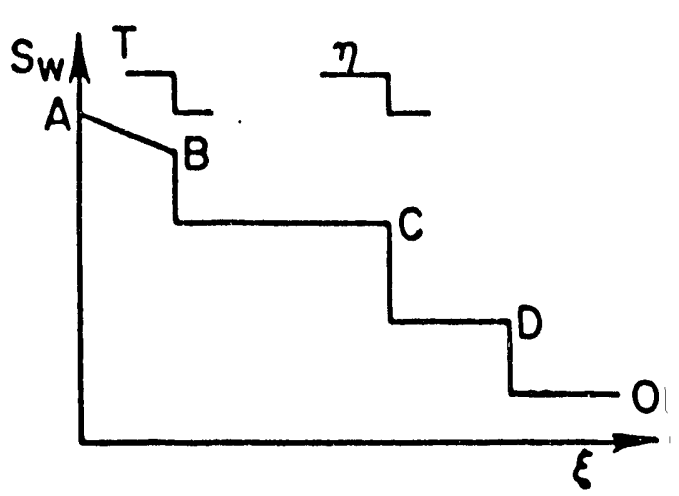

(c)

Figure 5.4: Solution route, graphical constructoin, and profile for continous injection. (no adsorption) 


$$
\eta<\eta_{c r}\left(T_{i}\right) \quad(\text { CaseI })
$$

or

$$
\eta>\eta_{c r}\left(T_{i}\right) \quad(\text { CaseII })
$$

The critical concentration $\eta_{c r}$, a function of the injection temperature, is determined from the solution of the equations.

$$
\lambda_{1}\left(S_{w}, \eta_{c r}, T_{i}\right)=\Lambda_{2}\left(S_{w}, \eta_{c r}, T_{i}\right)=\frac{\partial f_{w}}{\partial S_{w}}\left(S_{w}, \eta_{c r}, T_{i}\right)
$$

Figure 5-5 shows plots of $g_{1} \eta c r$ vs. $g_{1} / a_{3}$ for different values of $T_{i}$ in the case of negligible effects of temperature on adsorption. Note that $g_{1} \eta_{c r}$ is not sensitive to the injection temperature or the rate of approach to the value of the residual saturation $\left(a_{3}\right)$ in the range examined. It was also found that the product $g_{1}$ et $a_{c r}$ is insensitive to the API density of oil for the three values examined $\left(A P I=10^{\circ}, 20^{\circ}, 30^{\circ}\right)$. Thus, an approximate estimate of $\eta_{c r}$ in the case of negligible temperature effects on adsorption is provided by the expression

$$
\eta_{c r} \sim \frac{0.77}{g_{1}}
$$

which further implies that at the critical concentration the adsorption isotherm has reached its plateau value. This result is a consequence of the large differences between the volumetric heat capacity of the rock and the oil and the assumed large $(0(100))$ slope of the adsorption isotherm at the origin. In case of a general isotherm satisfying the above conditions the critical concentration is approximately obtained as the solution of the equation

$$
\frac{\eta_{c r}}{g\left(\eta_{c r}\right)} \sim 0.7
$$

Note, in the case of alkaline flooding $\eta_{c r}$ refers to critical sodium ion concentration in the aqueous phase.

To evaluate the reduction in the residual oil saturation at the critical value we normalize $\eta$ by the rate of reduction $1 / a_{3}$ 


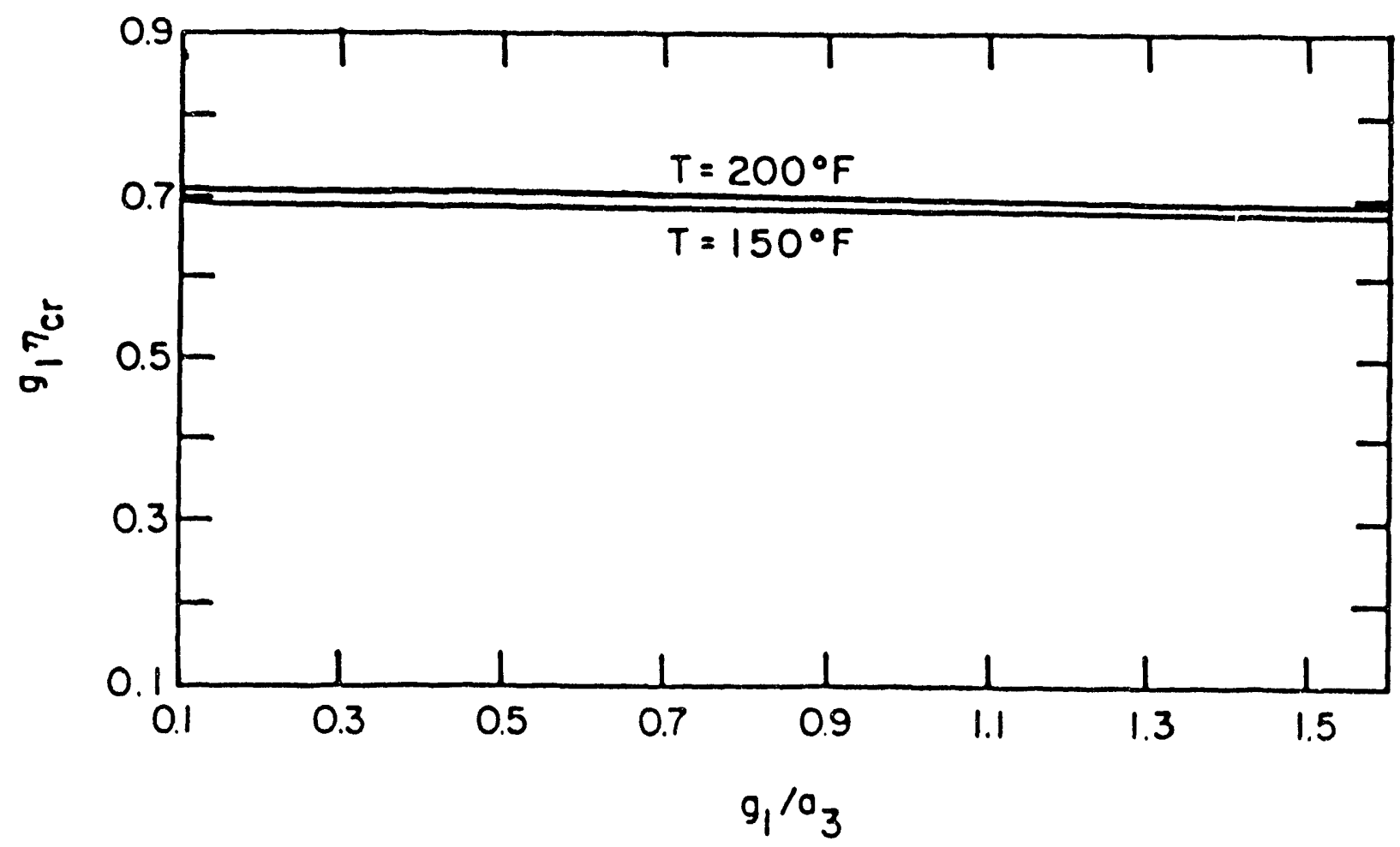

Figure 5.5: Critical concentration for various values of $g_{1} / a_{3}$ and temperature. 


$$
C=\eta a_{3}
$$

Equation (5.47) becomes

$$
C_{c r} \sim \frac{0.7}{g_{1} / a_{3}}
$$

which shows that for low values of the ratio $g_{1} / a_{3}$ (high adsorption plateau values and/or high rates of reduction of the residual oil saturation) the residual oil saturation at the critical concentration has reached its irreducible value $a_{1}$, while for high values of the ratio $g_{1} / a_{3}$ the reduction in the residuil saturation at the critical value is minimal.

Case I, $\eta_{i}<\eta_{c r}$

If at the injection point inequality (5.43) is satisfied, the solution route lines initially on the constant temperature plane $(A B C)$, then switches over to a path on the zero concentration plane $\left(C D O_{1}\right.$ or $\left.C D O_{2}\right)$ (Fig. 5-6a). Due to adsorption, $\lambda_{2}$ is decreasing along $B C$, leading to the formation of shock. The path $B C$ is then obtained from the shock conditions

$$
\Lambda_{2}=\frac{f_{w B}}{S_{w B}+\left.\frac{g}{\eta}\right|_{B}}=\frac{f_{w B}-f_{w C}}{S_{w B}-S_{w C}}
$$

The solution of the latter along with the condition

$$
\lambda_{2}=\lambda_{36}
$$

determines points $B, C$ respectively. The path $C D$ is determined, as before, by the condition $\lambda_{1}=$ const. The remaining portion $D O_{1}$ follows in a straightforward manner. The above lead to a simple graphical construction of the solution outlined in Figure 5-6b.

A schematic description of the temperature, concentration and saturation profiles obtained for secondary flooding are shown in Figure 5-6c. Note that in contrast to the case of no adsorption, the chemical front travels behind the temperature front, while the temperature wave travels faster than in the previous case. In the present case, the chemical resides entirely in the heated region, and it breaks through the production end behind the ternperature wave. This is clearly due to the magnitude of the rate of adsorption at the level of the injected concentration. Despite the fact that the chemical may be present at a concentration 


$$
\eta_{i}<\eta_{C R}
$$

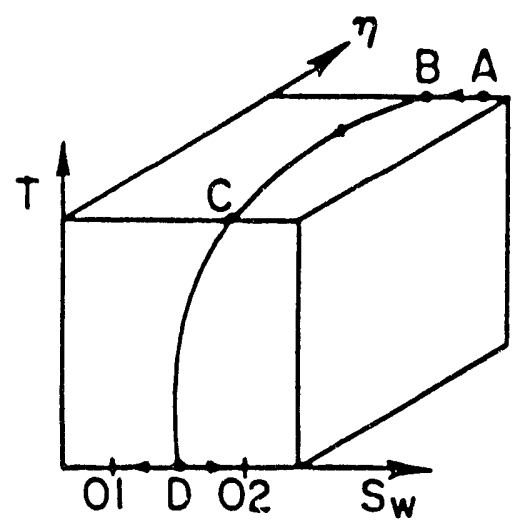

(o)

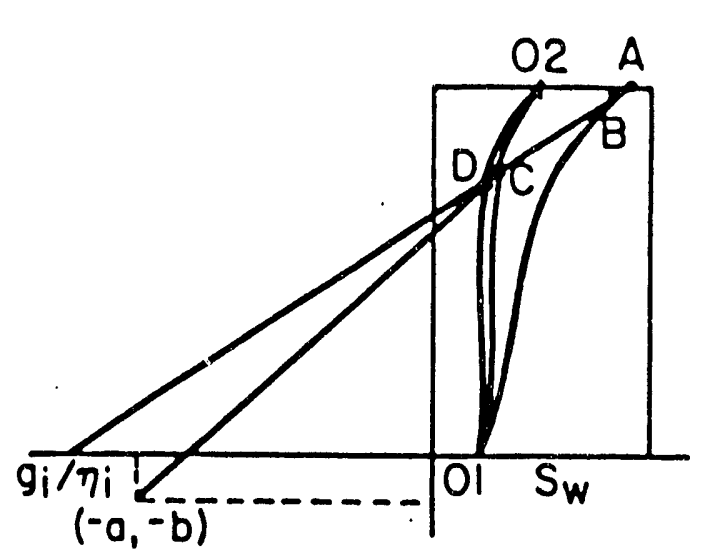

(b)

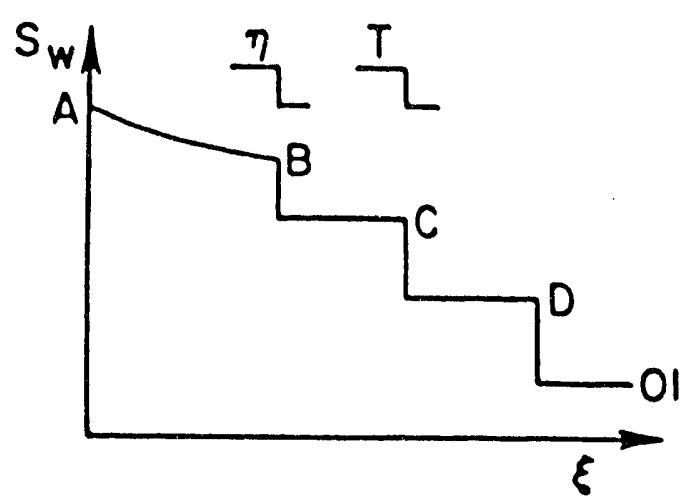

(c)

Figure 5.6: Solution route, graphical constructoin, and profile for continous injection. (case 1). 
sufficient to lower the residual oil saturation significantly, the rate by which the chemical is adsorbed on the rock is considerably high to retard the propagation of the chemical front compared to the temperature front. Three saturation fronts develop, resembling an ordinary waterflood, an ordinary hot waterflood, and a chemical flood at the injection temperature. Case II, $\eta_{I}>\eta_{c r}$

If, on the other hand, inequality (5.44) is satisfied at the injection point, the solution route lies initially on the constant concentration plane $(A B C)$, then switches over to a path on the original temperature plane $\left(C D O_{1}\right.$ or $\left.C D O_{2}\right)$ (Fig. 5-7a). Along $B C, \lambda_{1}$ is constant, while along $C D, \lambda_{2}$ is decreasing, thus leading to the formation of shock. The path $C D$ is then obtained from the shock conditions

$$
\Lambda_{2}=\frac{f_{w C}}{S_{w C}+\frac{g}{\eta} \mid C}=\frac{f_{w C}-f_{w D}}{S_{w C}-S_{w D}}
$$

The solution of the latter determines $D$. The remaining portion $D O$ follows in a straightforward manner (Figure 5-7b).

A schematic description of the temperature, concentration and saturation profiles obtained for secondary flooding are shown in Figure 5-7c. Note that, now, the chemical front travels ahead of the temperature front, although at a velocity lower than in case of zero adsorption, while the temperature wave travels at the same velocity to the case of zero adsorption. The chemical resides ahead of the heated region, and it breaks through the production end ahead of the temperature wave. Thus, although the total amount of chemical adsorbed may be considerably higher than in Case I, the rate of adsorption is not high enough to retard the chemical front behind the temperature wave.

The mathematical model was subsequently used to simulate the recovery performance of a reservoir subjected to combined continuous chemical-hot water injection at typical reservoir conditions. The reservoir was assumed to have initial oil saturation $S_{0}=0.80$ for secondary flooding, $S_{0}=0.40$ for tertiary flooding, and temperature $T_{0}=100^{\circ} \mathrm{F}$. The injection temperature was set equal to $T_{i}=200^{\circ} \mathrm{F}$. Table A-1 lists the values of the reservoir and injection parameters used in the simulations.

The obtained recovery curves for secondary flooding are shown in Figure 5-8 for a $20^{\circ}$ API oil and for $g_{1} / a_{3}=0.1$. Plotted are the cumulative recovery for the combined chemical 


$$
\eta_{i}>\eta_{C R}
$$

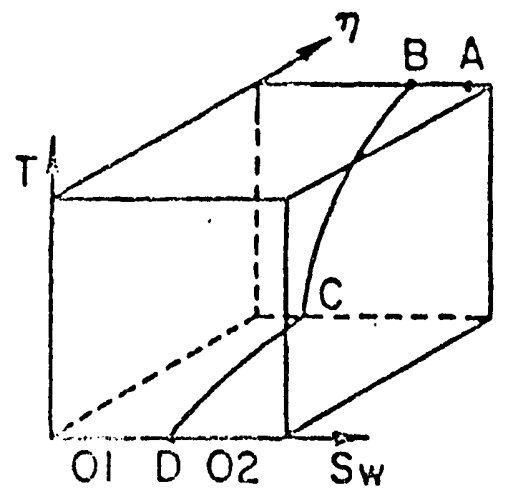

(a)

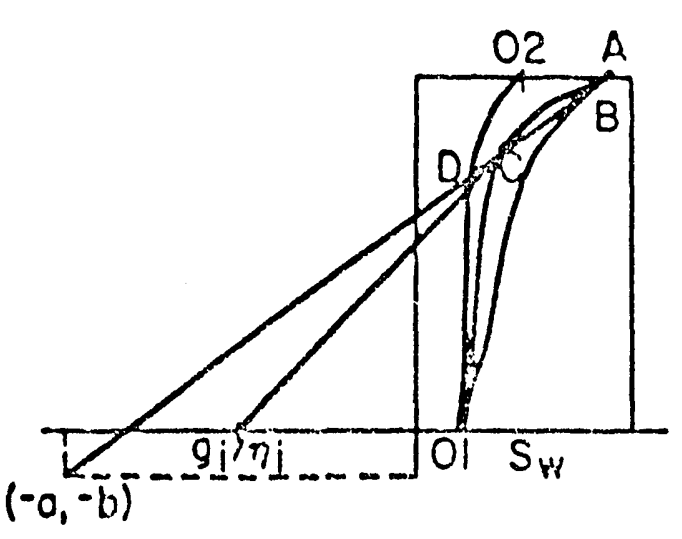

(b)

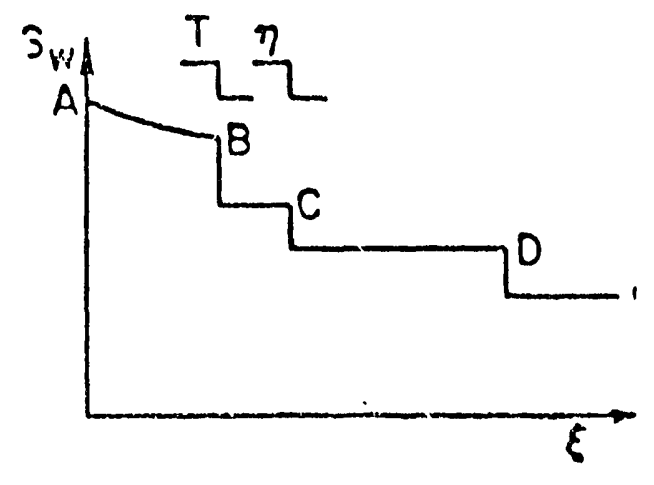

(c)

Figure 5.7: Solution route, graphical constructoin, and profile for continous injection (case 11). 
and hot water injection for various values of the injection concentration $C$, as well as for the unassisted hot water-flood and dilute chemical flood for $C=10$. Substantially higher recovery is shown to result in the combined injection process as compared to cither pure hot waterflood or dilute chemical flood at the original temperature. At the time of temperature breakthrough (- $2 \mathrm{PV})$ the obtained recovery for $C>4$ is almost twofold higher to the recoveries obtained in the unassisted cases. An increase in the injection concentration $C$ leads to higher recoveries. Thus, the recovery curve for injection concentration $C=1$, corresponding to a moderate decrease of the residual oil saturation by a factor of 2.23 , shows significantly superior results in the range shown, in comparison to the recovery curve for the unassisted isothermal chemical flood, where the residual oil saturation is reduced by a factor of 8 to its final value 0.05 . As the critical injection concentration level is approached $\left(C_{c r} \sim\right.$ 7), differences in the recovery curves after both the chemical and temperature fronts break through are marginal. Beyond the time of temperature breakthrough, the combined injection process at high injection concentrations, behaves essentially as an isothermal chemical flood at $200^{\circ} \mathrm{F}$ and also approaches the recovery curve in the case of no adsorption.

The recovery curves for tertiary flooding are plotted in Figure 5-9. Similarly to secondary flooding, the resulting recoveries in the combined injection process are consistently higher than those obtained in the unassisted isothermal chemical flood at $100^{\circ} \mathrm{F}$. As the injection concentration increases, the process performance approaches rapidly the performance of an isothermal chemical flood at $200^{\circ} \mathrm{F}$. Differences in recovery, in the range of the critical concentration, become negligible after both the chemical and temperature fronts arrive at the production end. Similar trends were also observed for oil of different API density and for different values of the adsorption capacity $1 / g_{1}$. As expected, consistently higher recoveries are obtained as the API density and/or $g_{1}$ increases.

\subsubsection{B. Chemical Slug Injection}

The above results show that, in the case of continuous injection, the combined injection process results in recoveries significantly higher than those obtained in unassisted injection processes. In order to calculate the process efficiency and to test the validity of the hypothesis that optimal performance is obtained when the chemical resides in the heated region of 


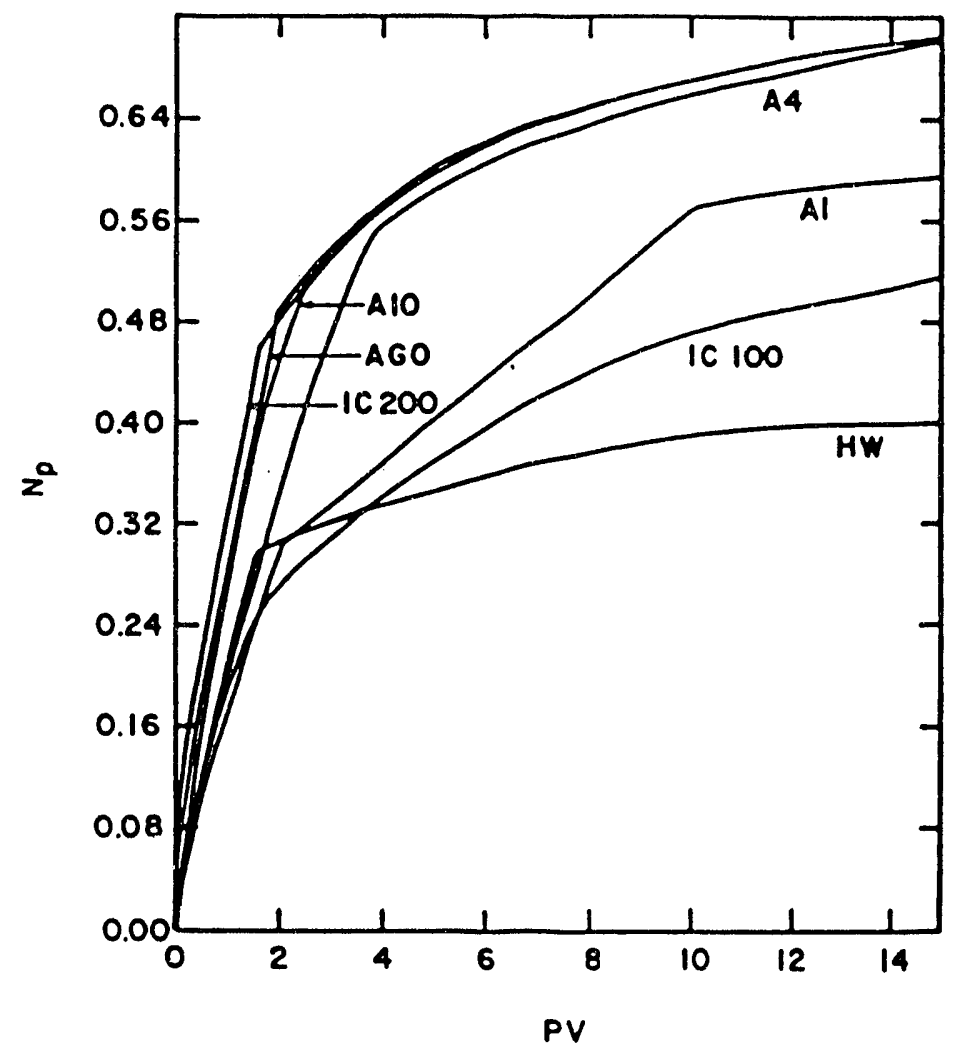

Figure 5.8: Recovery curves for continous injection, secondary flooding $\left(20^{\circ} \mathrm{API}, g_{1} / a_{3}=\right.$ $0.1)$. 


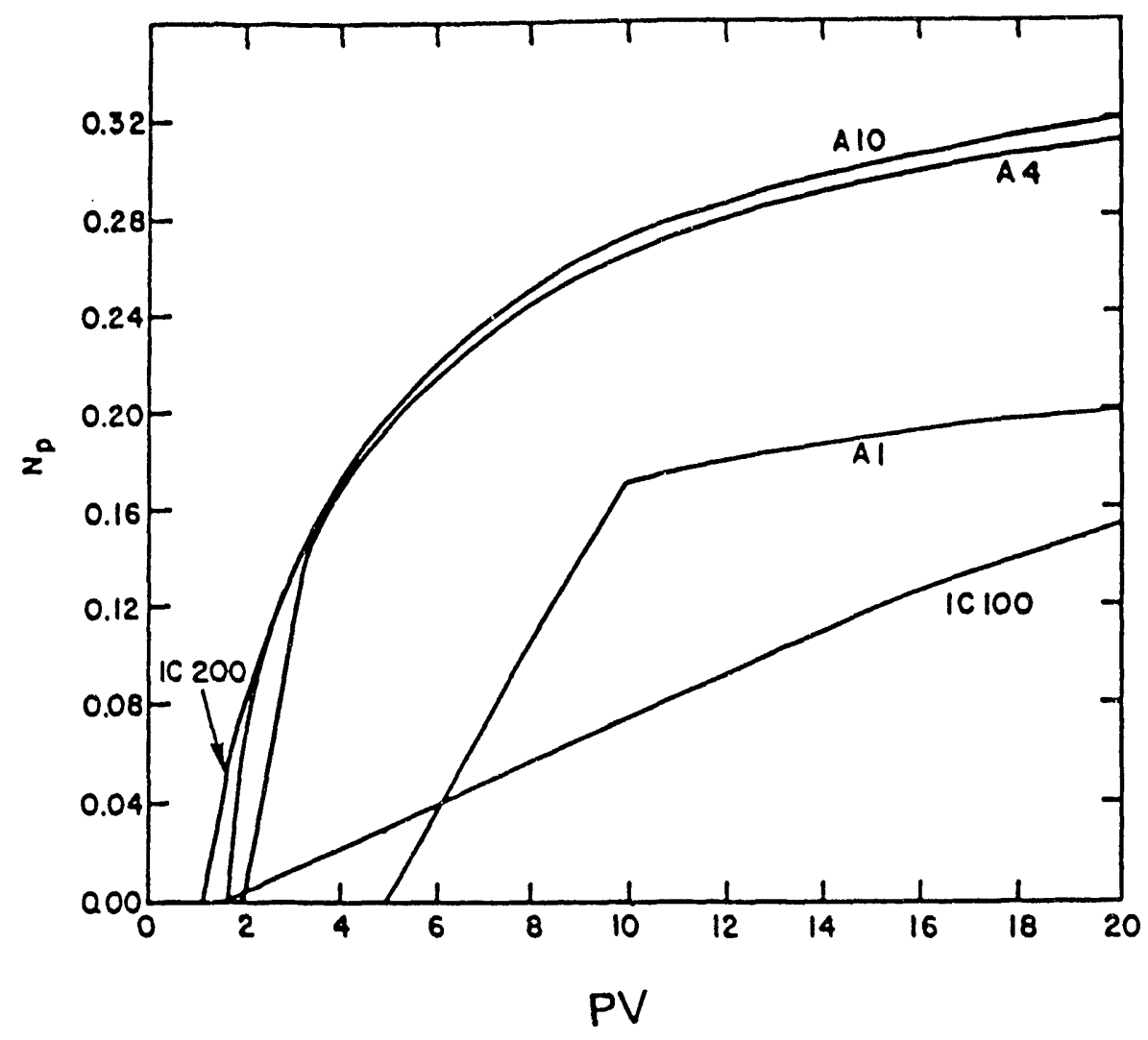

Figure 5.9: Recovery curves for continous injection, tertiary flooding ( $\left.20^{\circ} \mathrm{API}, g_{1} / a_{3}=0.1\right)$. 
the reservoir, we simulated the process of the combined injection of a finite size chemical slug under tertiary recovery conditions. In all simulations, chemical and hot water are simultaneously injected in a reservoir of initial saturation $S_{o}=0.40$. At a particular time corresponding to an optimal slug size, $t_{p}^{o p}\left(\eta_{i}\right)$ injection of chemical is halted while injection of hot water continues. The optimal size was determined by maximizing the ratio of oil recovered to the total amount of chemical injected in the following fashion.

For fixed injection and reservoir conditions in the combined injection process, three saturation fronts $R S_{w B}, S_{w C}, S_{w D}$ develop with breakthrough times $t_{B}, t_{C}, t_{D}$, respectively (Figure 5-6, 5-7). Provided that minimum slug size requirements are met, the cumulative oil recovery $N_{p}$ at any time is determined by the following relationship

$$
\begin{aligned}
& 0 \quad ; t<t_{p} \\
& N_{P}\left(t, \eta_{i}\right)=\left(1-f_{w D}\right) t+S_{w D}+S_{o r}(0)-1 ; t_{D}<t<t_{c} \\
& \left(1-f_{w C}\right) t+S_{w C}+S_{o r}(0)-1 ; t_{C}<t<t_{B} \\
& \left(1-f_{w}\left(S_{w}^{1}\right)\right)+S_{w}^{1}+S_{o r}(0)-1 ; t_{B}<t \\
& \left(\partial f_{w} / \partial S_{w}\right) \mid S_{w}^{1}
\end{aligned}
$$

where $S_{u}^{1}$, the water saturation at the production end $(x=1)$ is a function of time according to the relationship

$$
\left.\frac{\partial f_{w}\left(S_{w}, T_{i}, \eta_{i}\right)}{\partial S_{w}}\right|_{S_{w}^{1}}=\frac{1}{t}, t_{B}<t
$$

At the time $t^{*}$ when the trailing edge of the injected slug breaks through the production end, $S_{w}^{1}$ takes the value $S_{w}^{*}$ given by the expression

$$
t_{p}=\frac{f_{w}\left(S_{w}^{*}, T_{i}, \eta_{i}\right)}{\frac{\partial f_{w}}{\partial S_{w}}\left(S_{w}^{*}, T_{i}, \eta_{i}\right)}-\left(S_{w}^{*}+\left.\frac{d g}{d \eta}\right|_{i}\right)
$$

The ratio of cumulative oil recovery versus total amount of chemical injected up to time $t^{*}$ is

$$
\frac{N_{p}}{\eta_{i} t_{p}}=\frac{1}{\eta_{i}} \frac{1-f_{w}\left(S_{w}^{*}\right)-\left(1-S_{w}^{*}-S_{o r}(0)\right) \frac{\partial f_{w}}{\partial S_{w}^{\prime}}}{f_{w}\left(S_{w}^{*}\right)-\left(S_{w}^{*}+\left.\frac{d g}{d \eta}\right|_{i}\right) \frac{\partial f_{w}}{\partial S_{w}}}
$$


where for simplicity in notation it is implied that $f_{w}, \partial f_{w} / \partial S_{w}$ are evaluated at $T_{i}, \eta_{i}, S_{w}^{*}$. The optimum slug size is obtained by maximizing the ratio in (5.56), assuming that the additional incremental recovery beyond time $t^{*}$ contributes negligibly to the determination of the optimum size. Since

$$
\frac{d}{d S_{w}^{*}} \frac{N_{p}}{t_{p}}=\frac{\frac{\partial^{2} f_{w}}{\partial S_{w}^{2}}\left[S_{w}^{*}+\left.\frac{d g}{d \eta}\right|_{i}-f_{w}\left(1-S_{o r}(0)+\left.\frac{d g}{d \eta}\right|_{i}\right)\right]}{\left[f_{w}-\left(S_{w}^{*}+\left.\frac{d g}{d \eta}\right|_{i}\right) \frac{\partial f_{w}}{\partial S_{w}}\right]^{2}}
$$

The optimum size $t_{p}^{o p}\left(\eta_{i}\right)$ corresponds to a saturation $S_{w}^{o p}$ that makes the RHS of (5.57) equal to zero

$$
\frac{f_{w}\left(S_{w}^{o p}\right)}{S_{w}^{o p}+\left.\frac{d g}{d \eta}\right|_{i}}=\frac{1}{1-S_{o r}(0)+\left.\frac{d g}{d \eta}\right|_{i}}
$$

If equation (5.58) has a root in the interval $\left(S_{w B}, 1-S_{o r}\left(\eta_{i}\right)\right), t^{o p}\left(\eta_{i}\right)$ and max $N_{p} / \eta_{i} t_{p}$ are obtained from (5.55) and (5.56) respectively. The latter becomes

$$
I\left(\eta_{i}\right)=\max \frac{N_{p}}{\eta_{i} t_{p}}=\frac{1}{\eta_{i}}-\frac{1-S_{o r}(0)-S_{w}^{o p}}{S_{w}^{o p}+\left.\frac{d g}{d \eta}\right|_{i}}
$$

If equation (5.58) does not admit a root in the desired interval, the maximum in $N_{p} / t_{p}$ occurs at the time of chemical breakthrough, in Case I $\left(\eta_{i}<\eta_{c r}\right)$, and at the time of temperature breakthrough, in Case II $\left(\eta_{i}>\eta_{c r}\right)$, respectively. The corresponding optimum values are then determined from equation (5.53).

Having obtained an optimum slug size for fixed injection concentration, the maximum recovery index $I\left(\eta_{i}\right)$ in (5.59) is evaluated for different values of $\eta_{i}$. Figures 5-10, 5-11 show plots of $I$ versus $C$ for different values of API density and the ratio $g_{1} / a_{3}$. It is observed that, in the range examined, the curve $I$ vs $C$ exhibits a sharp maximum at a concentration value which is always less than or equal to the critical value given by equation (5.49). For the oil of density $20^{\circ} \mathrm{API}$, the maximum occurs near $C-1$ in the range examined (Figure 5-10). It is noticed that for values $g_{1} / a_{3}$ beyond 0.3 the curve is insensitive to further increases in the parameter values for relatively large values of $C$. On the other hand, for the oil of density $30^{\circ}$ API the value of $C$ at maximum $I$ appears to be proportionally related to the critical concentration (Figure 5-11). In both cases the performance index I and the sharpness of 


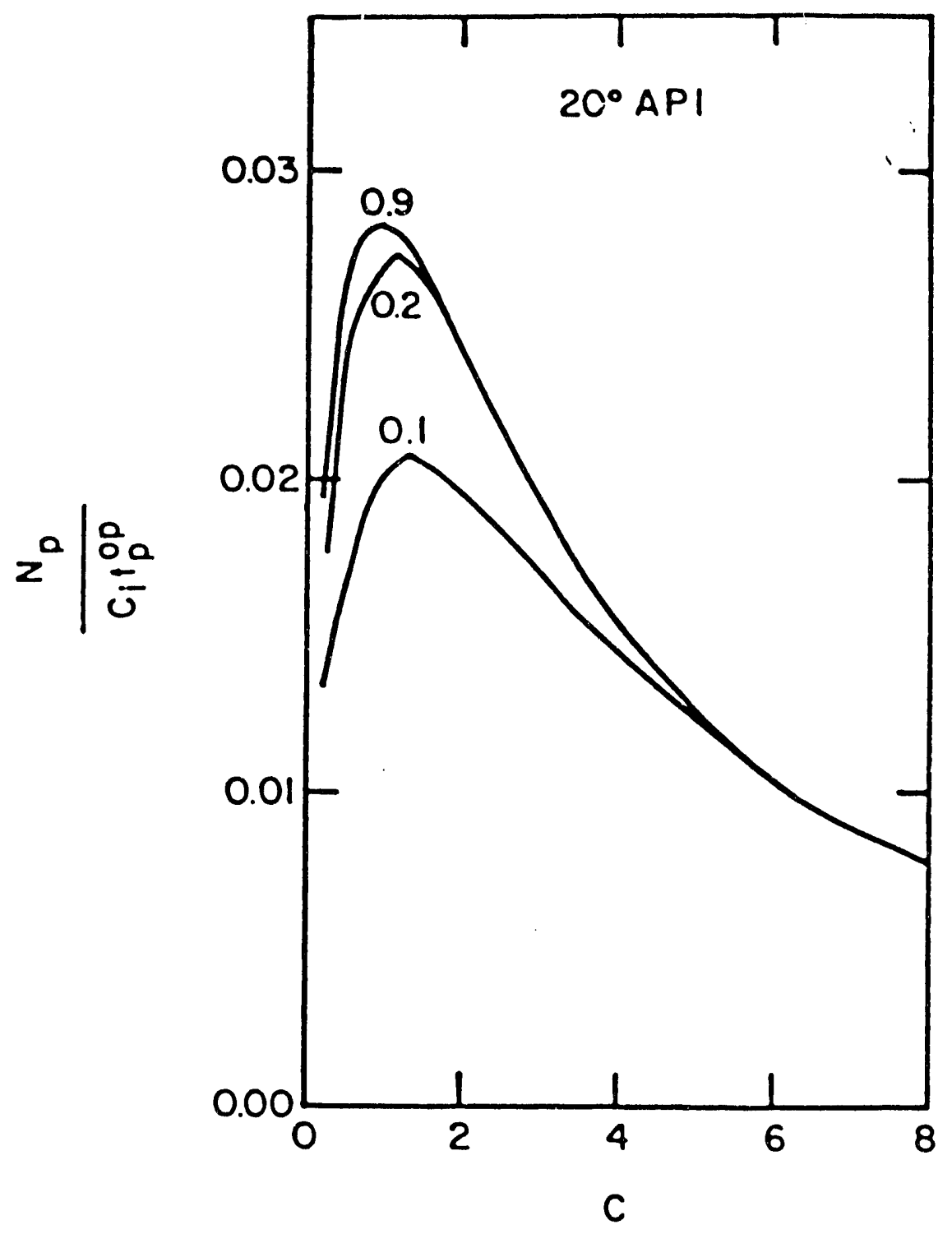

Figure 5.10: Recovery performance index for various values of $g_{1} / a_{3}\left(20^{\circ} \mathrm{API}\right)$. 


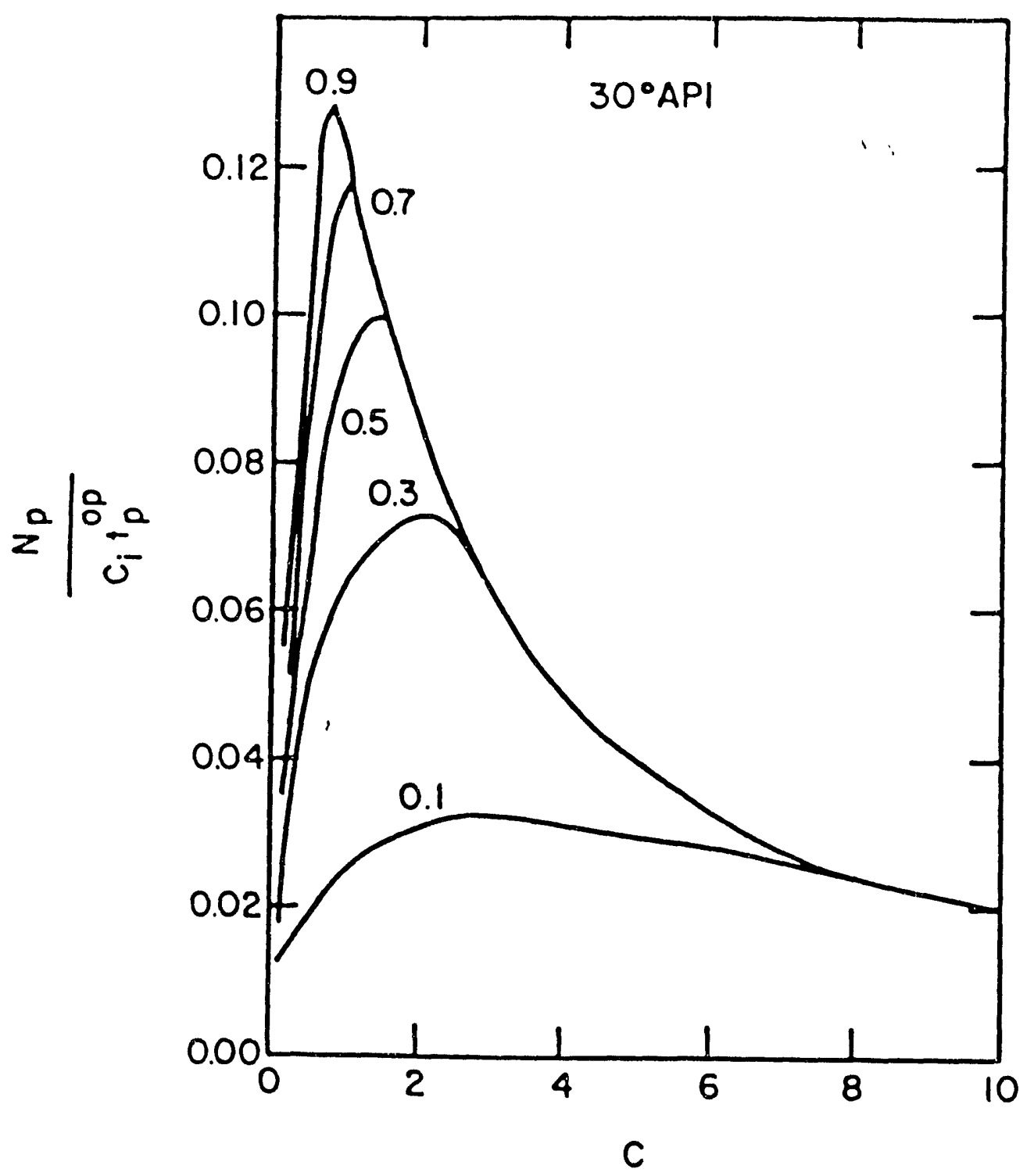

Figure 5.11: Recovery performance index for various vAlues of $g_{1} / a_{3}\left(30^{\circ} \mathrm{API}\right)$. 
the performance curve increase with an increase in $g_{1}$ (decrease in the absorption plateau). Thus, the recovery performance appears to be more sensitive to the injection concentration as the adsorption level decreases. It should be noticed that a root $S_{u}^{o p}$ to equation (5.58) was found for all concentrations, for a $20^{\circ} \mathrm{API}$ oil and values of $g_{1} / a_{3}>0.3$, while no roots were found for all other cases.

The above results lend support to the hypothesis that optimum recovery performances are obtained when the injected chemical slug resides entirely in the heated region of the reservoir. At a fixed value of the parameter ratio $g_{1} / a_{3}$, the injection concentration and chemical slug size that maximize recovery performance in a tertiary recovery process, can be estimated from the analysis indicated above.

\subsection{Conclusions}

In this chapter a simplified mathematical model that describes the combined injection of chemical additive and hot water in a reservoir has been developed. A mathematically tractable solution is obtained under the assumptions of negligible dispersion, heat conduction and lateral heat losses. The first two assumptions can be justified at large flow rates when sharp propagation fronts are expected to develop. By contrast, neglecting lateral heat losses is not as easily justifiable and would lead to optimistic oil recovery rates for an assisted thermal recovery process. Nevertheless, the results obtained here provide considerable insight into the important aspects of any chemical assisted thermal process.

The mathematical analysis indicates that adsorption plays a decisive role in determining the rates of propagation of the chemical additive relative to the temperature front. In the absence of adsorption, or in cases where adsorption is included but the injected concentration lies above a critical value $\eta_{c r}$, the chemical travels ahead of the temperature, thus a significant portion of the injected chemical slug resides in the unheated region of the reservoir. By contrast, when the injected concentration is below $\eta_{c r}$, the chemical resides entirely in the heated region, resulting into more efficient displacement. The dimensionless critical concentration $\eta_{c r}$ varies inversely proportional to the parameter ratio $g_{1} / a_{3}$ and, for injected values of the reservoir parameters, is such that the adsorption isotherm has reached its plateau 
value. However, in the particular case of alkaline flooding this critical concentration refers also to the critical sodium ion concentration in the aqueous phase which corresponds to a critical equilibrium $\mathrm{pH}$ value.

An analysis of the recovery efficiency for typical conditions indicates that the assisted injection is a viable enhanced recovery process. In particular, it is shown that the recovery performance in a tertiary recovery process is maximized when the injected concentration lies below the critical value. 


\section{Chapter 6}

\section{Conclusions and Suggested Future}

\section{Work}

\subsection{Conclusions}

A new model for the kinetics of silica dissolution and hydroxyl ion consumption, which is of significant importance to the optimal design of alkaline flooding, was developed. The model suggests that dissolution occurs via hydrolysis of active sites through the formation of an intermediate complex, in dynamic equilibrium with silicic acid in the solution. The model provides quantitative estimates of caustic consumption during alkaline flooding in terms of reservoir and process variables. Based on the model predictions for a batch process the following can be concluded:

1. The rate of silica dissolution depends on initial silica concentration, as well as temperature, $\mathrm{pH}$, available area, and volume of solution.

2. Total dissolved silica and hydroxyl ion consumption increases with time, original $\mathrm{pH}$ level and the area/volume ratio.

3. The equilibrium concentration of silicic acid is temperature sensitive. However, the time required for equilibrium is very sensitive to the variation of $\mathrm{pH}$, surface area/ volume of solution. 
4. The hydroxyl ion consumption increases with increasing temperature, although the opposite is true for total dissolved silica. This means that hydroxyl ion loss is not necessarily equal to the total amount of dissolved silica.

5. The hydroxyl ion consumption increases with an increase in the ion exchange equilibrium constant. Beyond a certain value of the latter the $\mathrm{pH}$ value remains asymptotically constant.

6. The hydroxyl ion consumption increases with increasing salinity of the solution, while the total dissolved silica decreases with salinity. At low salinity the relative change of $\mathrm{pH}$ is higher for higher value of $\mathrm{pH}$ but the opposite is true for high values of salt concentration.

7. The qualitatively different effect of ion exchange in batch and core flood processes cautions against using final (equilibrium) $\mathrm{pH}$ values of batch experiments in alkaline flood processes.

An analysis of the model prediction for a core flood process reveals the following:

1. Under typical injection and reservoir conditions (moderate flow rate and ion exchange equilibrium constant), the equilibrium $\mathrm{pH}$ in the reservoir is independent of salinity, ion exchange equilibrium constant, surface area/volume ratio.

2. Increasing the ion exchange equilibrium constant results in a sharp and rapid reduction of sodium and $\mathrm{pH}$ concentration profiles. This means that higher effective value of $\mathrm{pH}$ would be able to propagate in the reservoir.

3. Increasing the Damkohler number resulis in a larger decline of $\mathrm{pH}$ level in the region of constant sodium concentration.

4. The overall $\mathrm{pH}$ decline is larger as the available surface area increases, hence a lower effective value of $\mathrm{pH}$ can be propagated through the reservoir.

5. At high salinity a specified $\mathrm{pH}$ level would be able to travel for a longer period of time in the reservoir. 
Hot alkaline flooding can be considered as a simultaneous injection of hot water and chemical additive. Therefore, a simplified mathematical model that describes the combined injection of additive and hot water in a reservoir has been developed. A mathematically tractable solution is obtained under the assumption of negligible dispersion, heat conduction, and lateral heat losses. The obtained results provide considerable insight into the important aspects of many chemical assisted thermal processes. The following main conclusion were drawn:

1. A critical injection concentration for the chemical exists. The chemical resides in the heated region if the injected concentration is below the critical value, otherwise, it travels ahead of the temperature front. The critical concentration depends mainly on the adsorption parameters and the rate of reduction of the residual saturation.

2. The recovery performance is maximized when the slug concentration lies below the critical concentration.

Finally it has been shown that for chemical flooding, in the particular case when all tie lines in the triangular phase diagram originate from a single point on the water-oil axis, the developrnent of the solution, through the application of the theory of coherence can be greatly simplified.

\subsection{Suggested Future Work}

Based on the above results, it appears that there is much more to be learned about dissolution and precipitation of siliceous reservoir rocks. To evaluate the total loss of caustic through reactions with the reservoir rock the following aspects of the problem deserve a closer look.

1. More experimental evidence needs to be accumulated to confirm the validity of the obtained results in this work. A quantitative systematic study of the effect of various parameters, studied in this work, on the rate of silica dissolution is suggested. For example, chemical effluent analysis, especially silica concentration at high temperature, as well as hydroxyl ion measurement, will provide valuable information regarding the alkaline loss mechanism. 
2. The model developed here is only applicable for purely silicic sandstone reservoirs. But a wide variety of highly reactive minerals and clay make up the small non quartz fraction of sandstone, in concentrations that can vary greatly in different sandstones. This might result in precipitation and dissolution of these minerals. In a precipitation and dissolution reaction, species in the fluid phase combine to form a solid phase precipitate. Precipitates also dissolve and return their component's back into the solution. However, the importance of clay mineral reactions with alkali has been noted only recently. ${ }^{54,140}$

Results of experiments by Mohnot ${ }^{54}$ showed that alkalinity loss is the most by kaolinite, less by montmorilinite and illite, and the least by quartz sand. But no studies have been reported on the kinetics of mineral - alkali reaction. Therefore, detailed kinetic information is needed for all other minerals. Once the kinetics of various reactions are quantified one can establish the amount of resulting alkalinity loss, which is extremely important for the successful application of caustic flooding for improving oil recovery.

3. When a reactive fluid such as acid or alkali is injected into the sandstone reservoir, an increase/decrease in permeability is achieved due to dissolution or precipitation of minerals. Whether caustic flooding promotes permeability increase or decrease depends primarily on the sandstone mineralogy and the location of susceptible minerals within the pore structure. The location of clay and large surface area silica minerals within the sandstone pore structure affects the degree of permeability enhancement for a given caustic flood. Dissolution of sandstone up to the point of collapsing the sand grain matrix is nearly synonymous with increasing permeability. On the other hand, in situ precipitation of silicate minerals such as new alumino silicate, which are highly hydrated, tends to be voluminous and interfere with flow. ${ }^{44}$ In other words, depending on sandstone mineralogy and lithology, caustic sandstone interaction causes either permeability increase or decrease. The implication of these phenomena is significant when considering the practical application of alkaline chemicals under reservoir conditions.

4. Some researchers have found that silicate oligomers do exist when silicate concentration is high and the $\mathrm{pH}$ level is low. ${ }^{76,77,161}$ If these conditions are met, rapid polymerization 
occurs and massive precipitation or deposition may follow. It is believed that polymerization proceeds through nucleation and growth stages, influenced principally by supersaturation, $\mathrm{pH}$, and salt concentration. The kinetics of nucleation and growth have been discussed by some researchers. ${ }^{93}$ Considering the practical application of alkaline chemical under reservoir conditions, the implication of this possibility is highly significant. 
Nomenclature For Chapters 1-3

$$
\begin{aligned}
& \text { A }=\text { available area, } L^{2} \\
& a_{m}=\text { specific surface area, } L^{-2} M^{1} \\
& C=\text { total dissolved silica, } M L^{-3} \\
& C_{a}=\text { concentration of } \mathrm{Si}(\mathrm{OH})_{4}, M L^{-3} \\
& C_{a e}=\text { equilibrium value of silicic acid concentration, } M L^{-3} \\
& C_{b}=\text { concentration of } \mathrm{SiO}_{4} H_{3}^{-}, M L^{-3} \\
& C_{c}=\text { concentration of } \mathrm{SiO}_{4} H_{2}^{-2}, M L^{-3} \\
& C_{d}=\text { concentrtion of } \mathrm{SiO}_{4} H^{-3}, M L^{-3} \\
& C_{e}=\text { concentration of } \mathrm{SiO}_{4}^{-4}, M L^{-3} \\
& C_{f}=\text { concentration of } \mathrm{SiO}_{3} H_{2}, M L^{-3} \\
& C_{g}=\text { concentration of } \mathrm{SiO}_{3} H^{-}, M L^{-3} \\
& C_{H}=\text { hydrogen ion concentration, } M L^{-3} \\
& C_{O H}=\text { hydroxyl ion concentration, } M L^{-3} \\
& C_{j}=\text { concentration of } \mathrm{SiO}_{3}^{-2}, M L^{-3} \\
& C_{C l}=\text { chlorine ion concentration, } M L^{-3} \\
& C_{N a}=\text { Sodium ion concentration, } M L^{-3} \\
& k_{1}=\text { kinetic constant of dissolution, } L^{3} T^{-1} M M^{-1} \\
& k_{2}=\text { kinetic constant of dissolution, } T^{-1} \\
& k_{3}=\text { kinetic constant of dissolution, } T^{-1} \\
& k_{4}=\text { kinetic constant of dissolution, } T^{-1} \\
& C^{-1}
\end{aligned}
$$


$K_{1}=k_{1} /\left(k_{2}+k_{3}+k_{4}\right)$, dimensionless

$K_{4}=$ dimensionless kinetic constant of dissolution

$K_{l}=$ ion exchange equilibrium constant, dimensionless

$K_{a}=K_{l}\left(1-K_{4}\right)$, dimensionless

$K_{e 1}=$ equilibrium constant of ionization reaction, $M L^{-3}$

$K_{e 2}=$ equilibrium constant of ionization reaction, $M L^{-3}$

$K_{e 3}=$ equilibrium constant of ionization reaction, $M L^{-3}$

$K_{e 4}=$ equilibrium constant of ionization reaction, $M L^{-3}$

$K_{e 5}=$ equilibrium constant of ionization reaction, $M L^{-3}$

$K_{e 6}^{\prime}=$ equilibrium constant of ionization reaction, $M L^{-3}$

$K_{e 7}=$ equilibrium constant of ionization reaction, $M L^{-3}$

$K_{w}=$ water dissociation constant, $\left(M^{-1} L^{3}\right)^{2}$

$n_{c}=$ adsorbed silicic acid, $M L^{-2}$

$n_{o}=$ original available sites, $M L^{-2}$

$n_{N}=$ adsorbed sodium ion, $M L^{-2}$

$\mathrm{pH}=-\log \left[H^{+}\right]$

$r_{i}=$ rate of ionization reaction, $M L^{-3} T^{-1}$

$T=$ temperature, $t$

$t$ = time, $T$

$V=$ volume of solution, $L^{3}$

Superscripts 
$+=$ cation

$-=$ anion

Subscripts

$e=$ equilibrium condition

$i=$ initial condition 
Nomenclature For Chapter 4

$A=$ silicic acid, dimensionless

$a_{m}=$ specific surface area, $M L^{-2}$

$a_{v}=a_{m} \rho, L^{-}$

$C_{a e}=$ equilibrium value of silicic acid concentration, $M L^{-3}$

$C_{T}=$ total dissolved silica, dimensionless

$C_{T}^{*}=$ total dissolved silica, $M L^{-3}$

$C L=$ chlorine ion concentration, dimensionless

$H=$ hydrogen ion concentration, dimensionless

$H^{*}=$ sodium ion concentration, $M L^{-3}$

$k_{1}=$ kinetic constant of dissolution, $L^{3} T^{-1} M^{-1}$

$k_{2}=$ kinetic constant of dissolution, $T^{-1}$

$k_{3}=$ kinetic constant of dissolution, $T^{-1}$

$k_{4}=$ kinetic constant of dissolution, $T^{-1}$

$K_{1}=k_{1} /\left(k_{2}+k_{3}+k_{4}\right)$, dimensionless

$K_{4}=$ kinetic constant of dissolution, dimensionless

$K_{l}=$ ion exchange equilibrium constant, dimensionless

$K_{a}=K_{l}\left(1-K_{4}\right)$, dimensionless

$K_{w}=$ water dissociation constant, $\left(M^{-2} L^{6}\right)$

$L=$ reservoir length, $L$

$n=$ adsorbed silicic acid, dimensionless 
$n_{0}=$ original available sites, $M L^{-2}$

$n n_{N}=$ adsorbed sodium ion, $M L^{-2}$

$N=$ sodium ion concentration, dimensionless

$N^{*}=$ sodium ion concentration, $M L^{-3}$

$q=$ volumetric flow rate, $L T^{-1}$

$r^{*}=$ rate of silica dissolution, $M L^{-3} T^{-1}$

$t=(\mathrm{qt}) /(\phi L) /$ time, dimensionless

$\mathrm{n} V=$ volume of solution, $L^{3}$

$x=x / L$ axial position, dimensionless

Greek Symbols

$\phi=$ porosity, dimensionless

$\lambda=\rho a_{m} n_{o} x(1-\phi) / \phi$, dimensionless

$\tau=\rho a_{m} n_{0} L k_{2} K_{4} x(1-\phi) / q$, dimensionless

$\rho=$ density $M L^{-3}$

Superscripts

* = dimensional parameter

Subscripts

$e=$ equilibrium condition

$i=$ initial condition

$o=$ injected condition 
Nomenclature For Chapter 5

$a=$ parameter, defined in equation (10), dimensionle

$a_{1}=$ parameter, defined in equation ( 8 ), dimensionless

$a_{2}=$ parameter, defined in equation $(8)$, dimensionless

$a_{3}=$ parameter, defined in equation ( 8$)$, dimensionless

$b=$ parameter, defined in equation (11), dimensionless

$C=$ concentration, defined in equation (32), dimensionless

$C-p=$ heat capacity, $L^{2} T^{-2} t^{-1}$

$C_{\bar{A}}^{-}=$anionic surfactant concentration, $M L^{-3}$

$C_{H}^{+}=$hydrogen ion concentration, $M L^{-3}$

$C_{O H}^{-}=$hydroxyl ion concentration, $M L^{-3}$

$C_{N a}^{+}=$sodium ion concentration, $M L^{-3}$

$f=$ fractional flow, dimensionless

$g, g_{1}, g_{2}=$ adsorption parameters, dimensionless

$K=K_{D} K_{w} / K_{A}$, inverse equilibrium constant of equation $5.1,\left[M L^{-3}\right]$

$K_{A}=$ acid dissociation constant, $M L^{-3}$

$K_{D}=$ distribution coefficient, dimensionless

$k_{r}=$ relative permeability, dimensionless

$L=$ reservoir length, $L$

$N_{p}==$ recovery, dimensionless

$r=$ eigenvector, dimensionless 


$$
\begin{aligned}
& S=\text { saturation, dimensionless } \\
& T=\text { temperature, } t \\
& t=\text { time, dimensionless } \\
& t_{p}=\text { slug size, dimensionless } \\
& x=\text { distance, dimensionless }
\end{aligned}
$$

Greek Symbols

$\eta=$ volumetric concentration, dimensionless

$\Delta=$ shock velocity, dimensionless

$\lambda=$ eigenvalue, dimensionless

$\mu=$ viscosity, $M L^{-1} T^{-1}$

$\rho=$ density, $M L^{-3}$

$\phi=$ porosity, dimensionless

Subscripts

or $=$ denotes critical value

$i=$ injection value

no $=$ oil

$r=$ residual

$w=$ water

\section{Superscripts}

$o p=$ optimum

$1=$ refers to production end $(s=1)$ 


\section{REFERENCES}

1. Prats, M. and Miller, W. C.: "The Role of Technical Publications in the Advancement of Fluid Injection Processes for Oil Recovery," J. Pet. T'cch. (Dec., 1973) 1361-1370.

2. Bear, J.: "Dynamics of Fluids in Porous Media," American Elsevier Publishing Company, Inc., New York (1972).

3. Willman, B. T. and Valeroy, Runberg G. W. "Laboratory Studies of Oil Recovery By Steam Injection," J. Pet. Tech. July 1961 P. 681.

4. Farouq Ali S. M. and Meldau R. F.: "Current Steam Flood Technology," J. Pet. Tech. October 1979 P. 1332-42.

5. Tiab, D., Okoye, C. U. and Osman, M. M.: "Caustic Steam Flooding," J. Pet. Tech. (August, 1982).

6. Okoye, C. U. and Tiab, D.: "Enhanced Recovery of Oil by Alkaline Steam Flooding," SPE Paper 11076, presented at the 1982 SPE Annual Technical Conference and Exhibition, New Orleans, Louisiana, September 26-29, 1983.

7. Copalkakrishnan, P., Boresis, S. A. and Cambarnous, M.: "An Enhanced Oil Recovery Method: Injection of Steam with Surfactant Solutions," Report of Group d'etude IFPIMF sur les Milieux Poreux Toulouse, France (1977)

8. Handy, L. L., Amaefule, J. O., Ziegler, V. M., and Ershaghi, I.: "Thermal Stability of Surfactants for Reservoir Application," SPE 7867, presented at 1979 SPE of AIME International Symposium on Oilfield and Geothermal Chemistry, Houston, TX (Jan. 1979).

9. Robinson, R. J. Bursell, C. G., and Restine, J. L.: "A Caustic Steamflood Pilot - Kern River Field," SPE 6523, presented at California Regional Meeting of SPE of AIME, Bakersfield, CA (April 1977)

10. Squires, F.: "Method of Recovering Oil and Gas," U.S. patent 1,238,355 (Aug. 28, 1917). 
11. Nutting, P. G.: "Chemical Problems in the Water Driving of Petroleum from Oil Sands," Ind. 83 Eng. Chem. 17 , 1035-1036 (1925); also "Soda Process for Petroleum Recovery," Oil and J. (1927) 25 No. 45, 76 and 150: "Principles Underlying Soda Process," ibid (1927) 25 No. 50 , 32 and 106; "Petroleum Recovery by Soda Process," ibid 27 No. 22, 146 and 238, (1928).

12. Atkinson, H.: "Recovery of Petroleum from Oil Bearing Sands," U.S. Patent 1,651, 311 (Nov. 29, 1927).

13. Mayer, E. H. et al:: "Alkaline Flooding -Its theory. Application and Status," Trans., Second European Symposium on Enhanced Oil Recovery, Paris 191-201. (Nov. 810,1982).

14. O'Brien, B. M.: "Enhanced Oil Recovery Chemical Needs," J. American Oil Chem. Soc. Vol. 59, No. 10 839A-852A, (October 1982).

15. De Zabala, E. F., et al.: "A Chemical Theory for Linear Alkaline Flooding," Soc. Pet. Eng. J. (April 1982).

16. Siefert, W. K. and Howells, W. G.: "Interfacially Active Acids in a California Crude Oil: "Isolation of Carboxylic Acids and Phenols," Analytical Chemistry, 41 (4) 554562, (April 1969).

17. Dunning, J., Moore, J. W., and Denekas, M. O.: "Interfacial Activities and Porphyrin Contents of Petroleum Extracts," Ind. Eng. Chem. 45 1759-1765, (August 1953).

18. Dodd, C. G., Moore, J. W., and Denekas, M.: "Metalliferous Substances Adsorbed at Crude Petroleum-Water Interfaces," Ind. Eng. Chem. 44 (11), 2585- 2590 (November 1952).

19. Neumann, H. J.: "Grenzflochensponnung und Entolung Vonlgerstalten," Erdol Kohle, $17346,(1964)$.

20. Pasquarelli, C. H., and Wasan, K. T.: "The Effect of Film-Forming Materials on the Dynamic Interfacial Properties in Crude Oil- Aqueous Systems," presented at the 
Third International Conference on Surface and Colloid Science, Surface Phenomena in Enhanced Oil Recovery Section. Stockholm, Sweden (Aug. 20-25, 1975)

21. Farmanian, P. A. ct al.: "Isolation of Native Petroleum Fractions for Lowering Interfacial Tensions in Aqueous Alkaline System," paper presented at the ACS Div. of Petroleum Chemistry. Anaheim, CA. March 12-17. 1978.

22. Johnson, C. E., Jr.: "Status of Caustic and Emulsion Methods," J. Pet. Tech. 85-92 (Jan. 1976).

23. Mungan, N.: "A Review and Evaluation of Alkaline Flooding," Applications Report AR-4, Petroleum Recovery Institute, Calgary, Alberta, Nov. 1979.

24. Mayer, E. H., Berg, R. L., Carmichael, J. D., and Weinbrandt, R. M.: "Alkaline Injection for Enhanced Oil Recovery -A Status Report," SPE 8848, First Joint SPE/DOE Symp. on EOR, Tulsa, OK, April 1980.

25. Mayer, E. H., Weinbrandt, R. M., Irani, M.R. and Krumrine, P.H.: "Alkaline Waterflooding -Its Theory, Application and Status," 2nd European Symp. on EOR, Paris, France, Nov. 1982.

26. Subkow, P.: "Process for the Removal of Bitumen from Bituminous Deposits," U.S. Patent 2, 288,,857 (July 7, 1942).

27. Jennings, H. Y., Jr., Johnson, C. E., Jr., and McAuliffe, C. D.: "A Caustic Waterflooding Process for Heavy Oils," J. Pet. Tech. 1344-1352, (Dec. 1974).

28. Ehrlich, R. and Wygal, R. J., Jr.: "Interrelation of Crude Oil and Rock Properties with the Recovery of Oil by Caustic Waterfooding," Soc. Pet. Eng. 263 (August, 1977).

29. Cooke, C. E. Jr., Williams, R. E., and Kolodzie, P. A.: "Oil Recovery by Alkaline Waterflooding." J. Pet. Tech. 1365-74, (Dec 1974). 
30. Michaels, A. S. and Timmins, R. S.: "Chromatographic Transport of Reverse-Wetting Agents and Its Effect on Oil Displacement in Porous Media," Trans. AIME 219, 150157 (1960).

31. Kelly, J. G.: Tertiary Displacement of Oleic-Acid Oils with Alkaline Agents," M.S. Thesis, University of California, Berkeley, (December, 1979) .

32. Schecter, R. S., Jones, G. D., Hayes, M. Cayias, J. L. and Wade, E. H.: "Spontaneous Emulsification- A Possible Mechanism for Enhanced Oil Recovery," SPE 5562 presented at the $50^{\text {th }}$ SPE Annual Fall Technical Conference and Exhibition, Dallas, Texas, (September 28 - October 1, 1975).

33. Castor, T. P., Somerton, W. H., and Kelly, J. G.: "Recovery Mechanisms of Alkaline Flooding," presented at the 3rd International Conference on Surface and Colloid Science, Surface Phenomena in Enhanced Oil Recovery Section, Stockholm, Sweden, (Aug. 20-25, 1979).

34. Reisberg, J. and Doscher, T. M.: "Interfacial Phenomena in Crude Oil-Water System," Producers Monthly 43-50, (November 1956).

35. Crawford, J. G.: "Waters of Producing Field, in the Rocky Mountain Region," Trans. AIME, 179, 264-287 (1949).

36. Hill, H. J., Helfferich, F., Lake, L. W., Reisberg, and Pope, G. A.: "Cation Exchange and Chemical Flooding," J. Pet. Tech., 29, 1336, (1972).

37. Smith, F. W.: "Ion Exchange Conditioning of Sandstones for Chemical Flooding," J. Pet. Tech., 30, 959, (1978).

38. Hill, H. J. and Lake, L. W.: "Cation Exchange-Chemical Flooding Experiment," SPE 6770, presented at 52nd Annual Fall Technical Conference, Denver, CO, Oct. 10-12, 1977.

39. Griffith, T. D.: "Application of the Ion Exchange Process to Reservoir Preflushed," SPE 7587, presented at 53rd annual Fall Technical Conference, Houston, TX, Oct. 1-3, 1978. 
40. Lake, L. W. and Helfferich, F. G.: "The Effect of Dispersion, Cation Exchange, and Polymer/Surfactant Adsorption on Chemical Environment," SPE 6769, presented at 52nd Annual Fall Technical Conference, Denver, CO, Oct. 10-12, 1977.

41. Pope, G. A., Lake, L. W. and Helfferich, F. G.: "Cation Exchange in Chemical Flooding-Basic Theory without Dispersion," SPE 6771, presenţed at 52nd Annual Fall Technical Conference, Denver, CO, Oct. 10-12, 1977.

42. Mungan, N.: "A Review and Evaluation of Alkaline Flooding," Petroleum Recovery Institute, Applications Report AR-4 (Jan. 1979)

43. Reed, M. G.: "Gravel Pack and Formation Sandstone Dissolution During Steam Injection," SPE 8424, presented at 54the AnnualFall Technical Conference and Exhibition of SPE of AIME, Las Vegas, Nevada (Sept. 1979).

44. Sydansk, R. D.: "Elevated Temperature Caustic-Sandstone Interaction; Implications for Improving Oil Recovery," Soc. Pet. Eng. J., 453-462 (August 1982).

45. Ehrich, R., Hasiba, H. H. and Raimondi, P.: "Alkaline Waterflooding for Wettability Alteration Evaluating a Potential Field Application," J. Pet. Tech. 1335-1343 (December 1974).

46. Raimondi, P., Gallagher, B. J., Ehrlich, R., Messmer, J. H., and Bennett, G. S.: "Alkaline Water Flooding Design and Implementation of a Field Pilot," J. Pet Tech. 1359-1368 (Oct. 1977).

47. Somerton, W. H. and Radke, C. J.: "Role of Clays in the Enhanced Recovery of Petroleum From Some California Sands," J. Pet. Tech. 643-654 (March 1983).

48. Lieu, V. T., Miller, S. G., and Staphanos, S. J.: "Long Term Consumption of Caustic and Silicate Solutions by Petroleum Reservoirs Sands," presented at the ACS Symposium on Silicate Chemistry, New York city. Aug. 26. 19?1

49. Southwick, J. G.: "Solubility of Silica in Alkaline Solutions: Implications for Alkaline Flooding," SPE 12771, April, 1984 
50. Dehghani, K.: "Caustic Consumption by Reservoir Rock at Elevated Temperature," PhD Thesis, U. of Southern California (August 1983).

51. Krumrine, P. H. and Falcone, J. S., Jr.: "Rock Dissolution and Consumption Phenomena in and Alkaline Recovery System," SPE/DOE 12670 presented in Tulsa, OK, April, 1984.

52. Bunge, A. and Radke, C. J.: "Migration of Alkaline Pulses in Reservoir Sands," SPE 10288, presented at the 56th Annual Fall Technical Conference of Society of Petroleurn Engineers of AIME in San Antonio, Texas, October 5-7, 1981.

53. O'Connor, T. L. and Greenberg, S. A.: "The Kinetics for the Solution of Silica in Aqueous Solutions," J. Phys. Chem., 6, 1995 (1958).

54. Mohnot, S. M., Bae, J. H., and Foley, W. L.: "A Study of Mineral- Alkali Reactions," SPE 13032, presented at the 59th Annual Technical Conference of SPE, Houston, TX, September 16-19, 1984.

55. Thornton, S. D.: "Dissolution and Condensation Kinetics of Crystalline and Amorphous Silica in Alkaline Solutions," M.S. Thesis, University of California, Berkeley (1985).

56. Crocker, M. E., Donaldson, E. C. and Marchin, L . M.: "Comparison and Analysis of Reservoir Rocks and Related Clays," paper SPE 11973 presented at the 58th Annual Technical Conference and Exhibition, San Francisco, CA (October 5-8, 1983).

57. Silicic Science, Ernst A. Hauser, D.Van Nastrand Company (1955)

58. Linsen, B. G.: Physical and Chemical Aspects of Adsorbents and Catalysts. 1970 Academic Press. London, New York.

59. Krauskopf, K. B.: "The Geochemistry of Silica in Sedimentory Environments," Stanford University, Stanford, California.

60. Kennedy, G. C.: "A portion of the System Silica Water," Econ. Cieology 45. p. (i29$653,(1950)$. 
61. Gardner, L. U.,: Mining Technology, 2, A.I.M.E. Techn. Publ. 929.

62. Lenher, V.,: J.Am. Chem Soc.,43, 391 (1921).

63. Paterson, M. S. and Wheatly, K. H.: "Safety in Mines Research Establishment," Research Report Number 124 (Dec. 1955)

64. White, D. E., Brannock, W. W., and Murata, K. J.: "Silica in Hot Spring Waters," Geochim. Cosmochim, Acta, v.10, pp. 27.50 (1956).

65. Gibb, J. P. D. Ritchie and J. W. Sharpe: J. Appl. Chem. (London), 3,182 (1953).

66. Siever, R.: , The Silica Budget in The Sedimentory Cycle: Am. Mineralogist, v. 42, pp $821-841$ (1957).

67. Van Lier, J. A., de Bruyn, P. L., and Overbeek, J. Th. G.: "The Solubility of Quartz," J. Phys. Chem. 64(9), 1675 (1960).

68. Klemm, W.: "FIAT Review of German Science, Part I Inorganic Chemistry," (Washington D.C., 1948), p.265, 1939-1946.

69. Lenher, V. Merrill, H. B.: J. Am. Chem. Soc., 39, 2630-2639 (1917).

70. Scheel, L. D. Fleischer, E. and F.W. Klemperer: Ind. Hyg. and Occupational Med. 8, 564 (1953).

71. Correns, C. W.: 1926, Beitrage zur Petrographie und Genesis der L.ydite (Kieselschiefer): Preuss. Geol. Ladesanstalt, Mitt. d. Abt . f. Gesteins-, Erz- , Kohle-und Salz-Untersuchungen, Heft 1, pp. 18-38

72. Okamoto, F., Okura, T., and Goto, K.: "Properties of Silica in Water," Geochimica et Cosmochimia Acta, 12, pp. 123-132 (1957).

73. Alexander, G. B., Heston, W. M., and Iler, H.K.: "The Solubility of Amorphous Silica in Water," J. Phys. Chem, v.58 453-455 (1954).

74. Iler, R. K.: "The Chemistry of Silica," Wiley-intrscience Publication, John Wiley \& Sons, 1979. 
75. Goto, K.: J. Chem. Soc. Jap. Pure Chem. Sect., 76, 1364 (1955).

76. Ingri, Nils: "Equilibrium Studies of Polyanions: IV. Silicate Ions in NaDl Medium," Acta Chem. Scand., 13 (4), 758 (1959).

77. Lagerstrom, Costa: "Equilibrium Studies of Polyanions: III. Silicate Ions in $\mathrm{NaClO}_{4}$, Medium," Acta Chem. Scand., 13 (4), 722 (15).

78. Stumm, W., and Morgan, J. J.: "Aquasic Chemistry," Wiley -Interscience, New York (1970).

79. Kopeykin, V. A. and Mikhaylov, A. S.: "Solubility and Forms of Occurence of Silica in Normal Dilute Solutions," Doklady Apademii Nauk SSR, 191 (197) 917-920.

80. Kitahara, S.: "The Solubility of Quartz in Aqueous Sodium Choloride Solution at High Temperatures and Pressures." Rev. Phys. Chem. Jpn 30, 115-121 (1960a).

81. Siever, R.: "Silica Solubility, $0-200^{\circ} \mathrm{C}$, and the Diagenesis of Siliceous Sediments," $J$. Geol. 70, 127-150 (1962).

82. Greenberg, S. A. and Price E. W.: "The Solubility Silica in Solutions of Electrolytes," J. Phys. Chem. 61, 1539-1541 (1957).

83. Krauskopf, K. B.: "Dissolution and Precipitation of Silica at Low Temperatures," Geochim. Cosmochim. Acta. 10, 4-26 (1956).

84. Marshall, W. L.: "Amorphous Silica Solubilities I Behavior in Aqueous Salt Solutions at $25^{\circ} \mathrm{C}, "$ Geochim. Cosmochim. Act 44, 907-913 (1980).

85. Holt, P. F., King, D. T.: "The Chemistry of Silica Surfaces," J. Chem. Soc. (London) A, 733 (1955).

86. Bergman, I., and Paterson, M. S.: "Silica Powders of Respirable Size. I. Preliminary Studies of Dissolution Rates in Dilute Sodium Hydroxide," J. Appl. Chem. 11, 369 (1961). 
87. Clelland, D. W., Cumming, W. M. and Rilchie, P. D.: "Physicochemical Studies on Dusts: II . Nature and Regeneration of the High-Solubility Layer on Silicous Dusts," J. Appl. Chem., 2, 42 (1952).

88. Nagel Schmidt, Gorden and Griffin, Nature 169, 5381 (1952).

89. Heavens, Acta Cryst., 6, 571 (1953).

90. Jotten and Pfefferkorn Arch. Hyg. 137, 79 (1953).

91. Wirth, G. S., and Gieskes J. M.: "The Initial Kinetics of the Dissolution at Vitreous Silica in Aqueous Media," Scripps Institution of Oceanography, University of California, San Diego. La Jolla, California 92093.

92. Stober, W.: "Formation of Silicic Acid in Aqueous Solution Suspensions of different Silica Modifications," "Equilibrium Concepts in Natural Water Systems," Adv. Chem. Ser. $(\underline{6} 7), 161$ (1967).

93. Henderson, J. H., Syers, J. K. and Jackson, M. L.: "Quartz Dissolution as Influenced by $\mathrm{pH}$ and the Presence of a Disturtbed Surface Layer," Isr. J. Chem., 8: 357-372 (1970).

94. Rimstidt, J. D. and Barnes H. L.: "The Kinetics of Silica-Water Reactions," Cosmochimica et Cosmochimica Acta Vol 44 pp 1683 to 1699.

95. Kamiya, H. and Shimokata K.: "The Role of The Salts in The Dissolution of Powdered Quartz," Proc. Intl. Symp. Water-Rock Interaction, Czechoslovakia, 1974, 426-429 (1976).

96. Bird, G., Boon J. and Stone T.: "Silica Transport During Steam Injection into Oil Sands 1. Dissolution and Precipitation Kinetics of Quartz; New Results and Review of Existing Data," Chem. Geol. 54, 69-80 (1986).

97. Kevin, G. Knauss and Thomas J. Wolery: "The Dissolution Kinetics of Quartz as a Function of $\mathrm{pH}$ and Time at $70^{\circ} \mathrm{C}$," Geochimica et Cosmochimica Acta vol. 52, pp 43-53 (1987). 
98. Kastner, M., Keene, J. B., and Gieskes, J. M.: Geochim. Cosmochim. Acta 41, 1041 (1977).

99. Aqueous Surface Chemistry of Oxides and Complex Oxide Minerals.

100. Zachariasen. H. J.: Amer Chem. Soc, 54, 3841 (1932).

101. Fehlner, F. P., Mott, N.F.: Oxide of Metals, 2, 59 (1970).

102. Gatos, H. C.: In the Surface Chemistry of Metals and Semiconductors, Wiley, New York, 1960, P. 381.

103. Ahmed, S. M.: "Studies of the Dissolution of Oxide Surface at the Liquid-Solid Interface," Oxide of Metals, 2, 59 (1970).

104. Park, G. A.: "The Isoelectric Points of Solid Oxides, Solid Hydroxides and Aqueous Hydroxo Complex Systems," Chemical Reviews 65, 177-198 (1965).

105. Sterlko, V. V.: "On the Dissolution Mechanizm of Dispersed Silica," Teor. Eksp. Khim., 100, 359 (Engl. Transl. p.277) (1973).

106. Taylor, N. W, Deran, R. F., J. Am. Ceram. Soc. 24, 103 (1941).

107. Langerstrom, G.: "Equilibrium Studies of Ployanions. III. Silicate Ions in $\mathrm{NaCl}$ Medium," Acta chem. Scand. 14 (4) 722-736 (1959).

108. Ingri, N.: "Equilibrium Studies of Ployanions. IV. Silicate Ions in NaCl Medium," Actr Chem. Scand. 13 (4) 758-775 (1959).

109. Anderson, G.M. and Burnham, C.W.: "The Solubility of Quartz in Super-Critical Water," Amer. J. Sci. 263, 494-511 (1965).

110. Hemley, J.J., Montoya J. W., Christ C. L. and Hostetler P.B.: "Mineral Equilibria in the $\mathrm{Mgo}-\mathrm{SiO}_{2}-\mathrm{H}_{2} \mathrm{O}$ and Some General Implications for Alteration/Mineralization Precesses," Econ. Geol. 75, 210-228 (1977). 
111. Marshall, W. L.: "Amorphous Silica Solubilities III. Activity Coefficient Relations and Predictions of Solubility Behavior in Salt Solutions. 0-350C," Geochim Cosmochim. Acta 44, 925-931 (19S0b).

112. Helgeson, H. C.: "Thermodynamics of Hydrothermal Systems at Elevated Temperatures and Pressures," Amer. J. Sci. 267, 728-804 (1969).

113. Walther, J. V. and Helgeson H. C.: "Calculation of the Thermodynamic Properties of Aqueous Silica and the Solubility of Quartz and its Polymorphs at High Pressures and Temperatures," Amer. J. Sci. 277, 1315-1351 (1977).

114. Marshall, W. L.: "Amorphous Silica Solubilities I. Behavior in Aqueous Sodium Nitrate Solutions: 25-300 C, 0-6 molal," Geochim. Cosmochim. Acta 44, 907-913 (1980a).

115. Marshall, W. L. and Warakomski J. M.: "Amorphous Silica Solubilities- II. Effect of Aqueous Salt Solutions at 25²." Geochim. Cosmochim. Acta 44, 915-924 (1980).

116. Founier, R. O. and Potter R. W. II: "An Equation Correlating the Solubility of Quartz in Water from 25 to $900^{\circ} \mathrm{C}$ at Pressure up to 10000 bars," Geochim. Cosmochim. Acta 46, 1969-1973 (1982).

117. Founier, R.O. Rosenbauer R.J. and Bisxhoff J.L.: "The Solubility of Quartz in Aqueous Sodium Chloride Solution at 3500C and 180-500 bars," Geochim. Cosmochim. Acta 46, 1975-1978 (1982).

118. Fatt, I. and Dykstra H.: "Relative Permeability Study," AIMEV 192 P. 249-256 (1951).

119. Burk, J. H.: "Comparison of Sodium Carbonate, Sodium Hydroxide, and Sodium Orthosilicate for EOR," SPE 12039, presented at 58th Annual Technical Conference and Exhibition, SPE-AIME, San Francisco, CA, (October 1983).

120. Healy, T. W. and Fuerstenau D. W.: "The Oxide Water Interface-Interrelation of the Zero Point of Charge and the Heat of Immersion," J. Coll. Sci. 20, 376- 386 (1965).

121. Abendrothe, R. P.: "Behavior of Pyrogenic Silica in Simple Electrolytes," J. Coll. Int. Sci. 34(1) 591 (1970). 
122. Bolt, G. H.: "Determination of the Charge Density of Silica Sols," J. Phys. Chem. 61, $1166(1957)$.

123. Allen, L. H., Matijevic, E., and Meites, L.: "Exchange of $\mathrm{Na}^{+}$for the Silnolic Protons of Silica," J. Inorganic. Nucl. Chem 33, 1293 (1971).

124. Onoda, G. Y., Jr., and De Bruyn, P. L., Surface Sci. 4, 48 (1966).

125. Verwey, E. J. W, Rec. Trav. Chim. 60, 625 (1941).

126. Parks, G. A, and De Bruyn, P. L., J. Phys. Chem. 66, 967 (1962).

127. Biedermann, G., and Chow, J. T., Acta Chem. Scand. 20, 1376 (1966).

128. Davis, J. A., James. R. O. and Leckie, J. O.: "Surface Ionization and Complexation at the Oxide/Water Interface I. Computation of Electrical Double Layer Properties in simple Electrolytes," J. Coll. Interface Sci., 63 (3), 480 (1978).

129. Yates, D. E., Levine S. and Healy T. W.: "Site-binding Model of the Electrical Double Layer at the Oxide/Watr Intrface" Oxide and Aqueous Electrolyte Interface," Faraday I 70, 1807 (1974).

130. Novasad, Z. and Novasad, J.: "Determination of Alkalinity Losses Resulting From Hydrogen Ion Exchange in Alkaline Flooding," Soc, Pet. Eng. 49 (Feb 1984).

131. Bunge, A. L., and Radke, C. J.: "The Origin of Alkali Ion Exchange with Reservoir Rock," SPE 11798, presented at the International Symposium on Oilfield and Geothermal Chemistry, Denver, CO, June 1-3, 1983.

132. Denny, J. J., Robson, W. D., Irwin, D. A.: Can. Med. Ass. J. 40, 213 (1939).

133. Jephcott, C. N., Johnston, J. H.: Arch. Ind. Hyg. Occur. Med. 1, 323 (1939).

134. Lewin, J. C.: Geochim. C'osmochim. Acta 21, 18 (1961).

135. Lieflander, M., Stober, W. Z.: Naturforsc B 15b, 411 (1960). 
136. Iler, R.K.: "Effect of Alumina on the Solubility of Amorphous Silica in Water," J. Coll. Int. Sci. 43(2), 399 (1973).

137. Jensen, J. A. and Radke, C. J.: "Chromatographic Transport of Alkaline Buffers Through Reservoir Rock," SPE 14295, presented at 60th Annual Fall Technical Conference, Las Vegas, Nevada, September 22-25, 1985.

138. Ryzhenko, B. N.: "Determination of Hydrolysis of Sodium Silicate and Calculation of Dissociation Constants of Orhosilicic Acid at Elevated Temperatures," Geokhimiya 2, 161-169 (in Russian) Geochem. Int. 4, 99-107 (English translated).

139. Bryant, S. L., Schechter R. S. and Lake, L. W.: "Interactions of Precipitation Dissolution Waves and Ion Exchange in Flow Through Permeable Media," AIChE Journal, 32, 751-764 (May 1986).

140. Aflaki, R., University of Southern California. (1989)

141. Saneie, S., and Yortsos, Y. C.: "Silica Dissolutoin and Hydroxyl Ion Consumption in Alkaline Flooding," SPE 17410, preseented at the 1988 California Regional Meeting of Soc. of Petr. Engrs. of AIME, Long Beach, California, March 23-25.

142. Karakas, M. and Yortsos, Y. C.: "Chemical Assisted Hot Waterflood: The Adiabatic Case," Proc., U.S. DOE Contractors Meeting, San Francisco (July 1981).

143. Karakas, M. Saneie, S. Yortsos, Y. C.: "Displacement of a Visocus Oil by the Combined Injection of Hot Water and Chemical Additive," SPE 12560, presented at the 1984 California Regional Meeting, Longh Beach, CA, April 11-13. Published in the Soc. Petr. Engrs. Journal.

144. Prats, M.: "A Current Appraisal of Thermal Recovery," SPE 7044, presented at the 5th Symposium on Improved Methods for Oil Recovery, April 16-19, 1978, Tulsa, Oklahoma.

145. Larson, R. G., Davis, H. T. and Scriven, L. E.: "Elementary Mechanisms of Oil Recovery by Chemical Methods," SPE 8840 , presented at the First Joint SPE/DOE Symposium on Enhanced Oil Recovery at Tulsa, OK (April 20-23, 1980). 
146. Ziegler, V. M. and Handy, L. L.: "Effect of Temperature on Surfactant Adsorption in Porous Media," Soc. Pet. Eng. J. 218-228 (April 1981).

147. Jeffrey, A.: Quasilinear Hyperbolic Systems and Waves, Pitman Publishing Limited, London (1976).

148. Helfferich, F.L: "Theory of Multicomponent, Multiphase Displacement in Porous Media," Soc. Pet. Eng. J. 51-62 (Feb. 1981).

149. Adamson, A. W.: "Physical Chemistry of Surfaces," 3rd Ed., Wiley Interscience Publications, New York, (1976).

150. Larson, R. G. and Hirasaki, G. J.: "Analysis of the Physical Mechanisms in Surfactant Flooding," Soc. Pet. Eng. J. 42-58 (Feb. 1978).

151. Aris, R, and Amundson, N. R.: "Mathematical Methods in Chemical Engineering," Prentice-Hall, Inc., Englewood Cliffs, NJ (1973).

152. Fayers, F. J.: "Some Theoretical Results Concerning the Displacement of a Viscous Oil by a Hot Fluid in a Porous Medium," J. Fluid Mech," Volume 13, Part 1, 65-76 (1962).

153. Pope, G. A.: "The Application of Fractional Flow Theory to Enhanced Oil Recovery," Soc. Pet. Eng. J. 191-205 (June 1980).

154. Ramakrishnan, T. S., Wasan, D. T.: "A Model for Interfacial Activity of Acidic Crude Oil/Caustic System for Alkaline Flooding," Soc. Pet. Eng. J. 602-612 (August 1983).

155. Hirasaki, G. J.: "Application of the Theory of Multicomponent, Multiphase Displacement to Three-Component, Two-Phase Surfactant Flooding," Soc. Pet. Eng. J. 191-204 (April 1981).

156. Saneie, S., and Yortsos, Y. C.: "A Note on the Application of the Theory of Coherence to Surfactant Flooding," presented at the 1984 AICHE Annual Meeting, San Francisco, California, November. Published in the Soc. Petr. Engrs. Journal Jan. 1986. 
157. Hand, D. B.: "Dineric Distribution," J. Phys. Chcm. 34, 1961-2000 (1930).

158. Treybal, R.E.: "Liquid Extraction," second edition, McGraw-Hill Book Co. Inc., New York City (1963).

159. Pope, G. A. and Nelson, R. C.: "A Chemical Flooding Compositional Simulator," Soc. Pet. Eng. J. 339-54 (Oct. 197S).

160. Chang, G., Yortsos, Y.C.: "Lamination During Silica Diagenesis-Effect of Clay Content and Ostwald Ripening," Submitted to American Journal of Science, Feb. 1992.

161. Huang, P. Yang, and Qin T.: "A Study of Caustic Consumption by Clays," SPE 14945 presented at the SPE/DOE Fifth Symposium on Enhanced OIl Recovery, Tulsa, Ok. April 20-23, 1986.

162. Diallo, M. S., Jenkins-Smith, and Bunge, A. L.: "Dissolution Rates for Quartz, AluminumBearing Minerals, and Their Mixtures in Sodium and Potassium Hydroxide," SPE 16276, presented at the International Symposium on Oilfield Chemistry, San Antonio, Texas, Feb. 4-6 1987.

163. Fortuin, J. M. H., Okkerse C., and Steggerda J. J.: "Physical and Chemical Aspects of Adsorbents and Catalysts," Academic Press London and New York, 1970. 

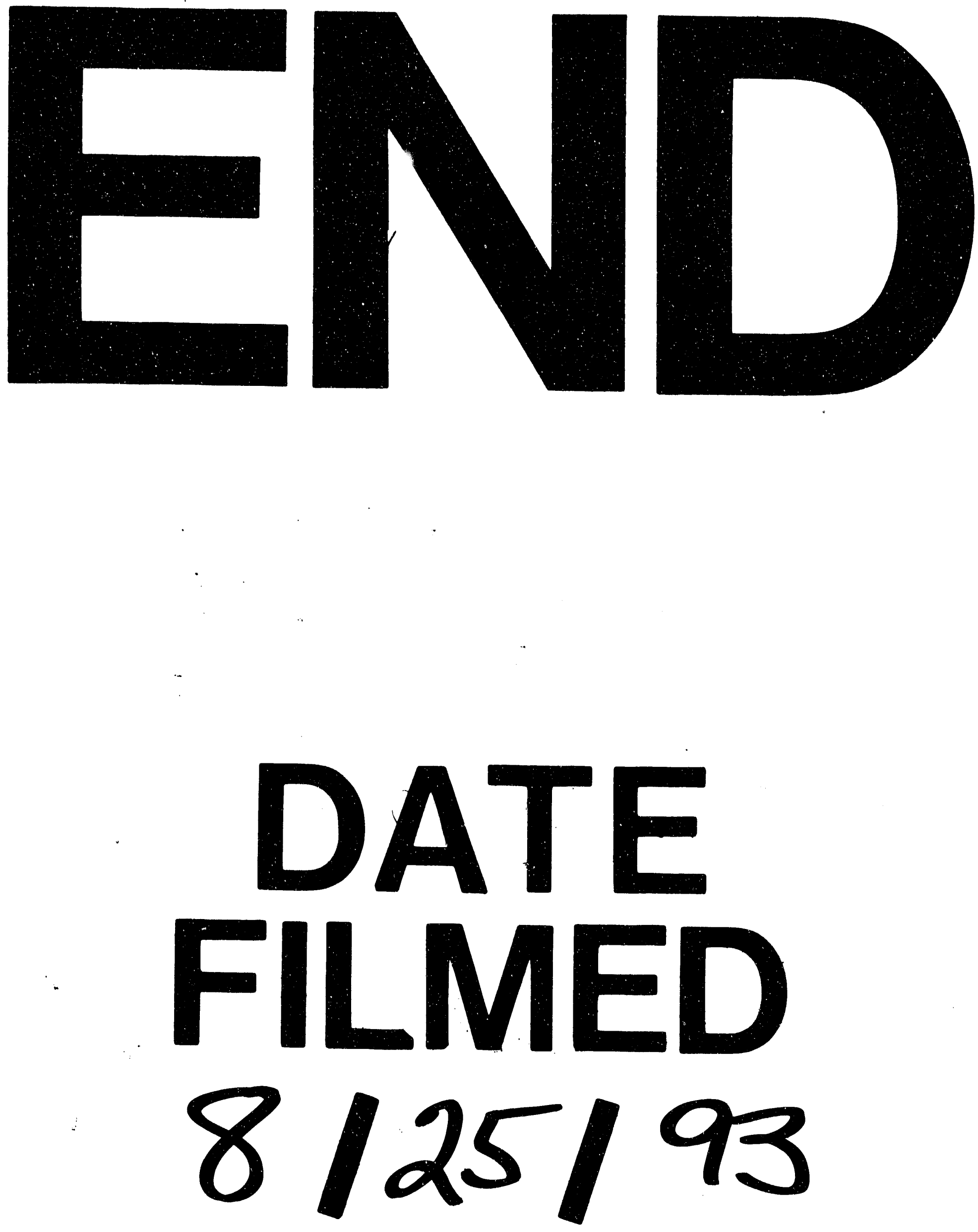
